METHODS FOR HYDROLOGIC MONITORING OF SURFACE MINING

IN THE CENTRAL-WESTERN UNITED STATES

By John T. Turk, Randolph S. Parker, and Robert S. Williams, Jr.

U.S. GEOLOGICAL SURVEY

Open-File Report 84-600

Prepared in cooperation with the

U.S. OFFICE OF SURFACE MINING RECLAMATION AND ENFORCEMENT

Denver, Colorado

1986 


\section{DEPARTMENT OF THE INTERIOR \\ DONALD PAUL HODEL, Secretary \\ U.S. GEOLOGICAL SURVEY}

Da1las L. Peck, Director

For additional information write to:

Colorado District Chief U.S. Geological Survey Water Resources Division Box 25046, Mail Stop 415 Denver Federal Center Denver, CO 80225
Copies of this report can be purchased from:

U.S. Geological Survey Books and Open-File Reports Building 41, Box 25425 Denver Federa1 Center Denver, CO 80225

Telephone: (303) 236-7476 


\section{CONTENTS}

Abstract-1-2-10

Introduction-

Background-1..

Purpose and scope-1.

Surface water-.

Site-selection criteria-1..

Establishing a streamflow-gaging station--

Artificial controls-.-

Weirs

Flumes-1-0.-.

Other types of controls

Stage sensors-1.-

Nonrecording gages-1-

Continuous-stage recorders-1..-

Type of recorder-10

Construction of a streamflow-gaging station--...

Operation of a streamflow-gaging station--

Discharge measurements-

Maintaining the record-

Computation and processing of discharge records-

Precipitation--

Network design--

Site-selection criteria-c-

Types of gages-1.

Operation and maintenance-1.-

Snow-pack measurements--

Ground water-1.-

Ground-water flow systems-10

Recharge areas, discharge areas

Factors that control direction of flow

Flow-system mapping---

Site-selection criteria-

Well drilling-.

Well development and completion-1

Borehole logging-

Geologic logs-.-

Geophysical logs-_.

Water levels in wells

Aquifer tests-.-..-

Representation of water-level data-

Sediment- $\quad$ Network design-

Site-selection criteria-

Sediment-sample collection-1.-

Water quality-

Criteria for selection of constituents-

Sampling considerations-

Site selection-

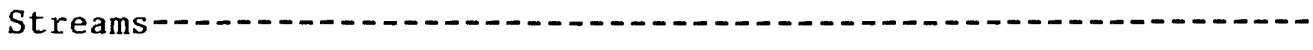


Water quality--Continued

Page

Site selection--Continued

Lakes-10

Ground water-1.

Network evaluation-1.

Onsite measurements-10

Collection and onsite processing

Collection-

Onsite processing--

Filtration--

Filtered samples-1...

Suspended-sediment samples-.-

Unfiltered samples-10

Addition of chemicals to prevent chemical reactions--.-.--

Suppression of biological processes-...

Site-specific examples--

Drainage basin in semiarid region of ridge-valley topography--..--

Precipitation--

Surface water-

Ground water-

Water quality-ar.

Drainage basins in semiarid region of prairie topography-

Precipitation-

Surface water-1.

Ground water-1.

Water quality-10

Drainage basins in arid region of mesa topography

Precipitation-

Surface water-

Ground water-a

Water quality- 92

Summa ry-

Selected references- 93

\section{FIGURES}

Figure 1. Selection guide for measuring runoff using artificial controls-... 7

2. Computation notes of a streamflow measurement by the midsection method-- 22

3. Form used by U.S. Geological Survey as an inspection sheet for surface-water stations with digital recorders-...... 24

4. Diagram of effect of topography on ground-water flow system-- 35

5. Map of idealized geologic section and ground-water observation wells at a surface mine site-1..- 38

6. Standardized form for logging test holes by rotary

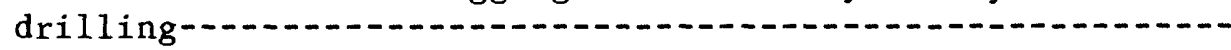

7. Contour map and direction of flow for an idealized groundwater basin3 3 
Figure 8. Diagram of observation wells in a region having two confined aquifers under separate pressures-...

Page

9. Diagram of sample bottle showing desired water levels and essential recorded information-....... 56

10. Graph of thermal stratification effects 61

11. Graphs showing effects of temperature and partial pressure on the solubility of carbon dioxide-12

12. Location map of hypothetical semiarid, ridge-valley basin--.- 76

13. Geologic section of hypothetical ridge-valley mine site-.-.- 79

14. Location map of hypothetical semiarid, prairie basin-..-..- 83

15. Geologic section of hypothetical prairie mine site-......- 85

16. Location map of hypothetical arid, mesa basin-............... 88

17. Geologic section of hypothetical mesa mine site-............. 90

\section{TABLES}

Table 1. Factors affecting choice or use of weirs for measuring flow--- 11

2. Factors affecting choice or use of flumes for measuring flow--- 13

3. Some applications of geophysical logs- 43

4. Some processes and characteristics affecting water-quality site selection along streams- 60

5. Effect of carbon-dioxide partial pressure and temperature on calcite solubility-... 74

6. Well-completion information for hypothetical ridge-valley

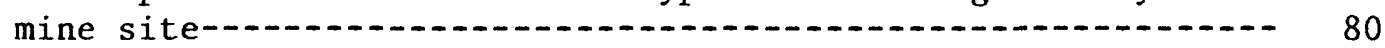

7. Well-completion information for hypothetical prairie mine site- 86

8. Well-completion information for hypothetical mesa mine site---- 91 
Multiply inch-pound units

inch (in.)

inch per year (in/yr)

foot $(f t)$

foot per mile $(\mathrm{ft} / \mathrm{mi})$

mile (mi)

square mile $\left(\mathrm{mi}^{2}\right)$

foot per second $(\mathrm{ft} / \mathrm{s})$

cubic foot per second $\left(\mathrm{ft}^{3} / \mathrm{s}\right)$

pound, avoirdupois (lb)

ton, short
By

$$
\begin{gathered}
25.40 \\
25.40 \\
0.3048 \\
0.3048 \\
1.609 \\
2.590 \\
0.3048 \\
0.02832 \\
453.6 \\
0.9072
\end{gathered}
$$

To obtain SI units

millimeter
millimeter per annum
meter
meter per kilometer
kilometer
square kilometer
meter per second
cubic meter per second
gram
megagram

The water-quality terms listed below also were used in this report:

degree Celsius $\left({ }^{\circ} \mathrm{C}\right)$

gram per liter $(\mathrm{g} / \mathrm{L})$

microgram per liter $(\mu \mathrm{g} / \mathrm{L})$

milligram per liter $(\mathrm{mg} / \mathrm{L})$ 


\title{
METHODS FOR HYDROLOGIC MONITORING OF SURFACE MINING IN THE CENTRAL-WESTERN UNITED STATES
}

By John T. Turk, Randolph S. Parker, and Robert S. Williams, Jr.

\begin{abstract}
Concern over the possible hydrologic impacts of surface mining has resulted in the Surface Mining Control and Reclamation Act of 1977 (Public Law 95-87). This law is administered by the U.S. Office of Surface Mining Reclamation and Enforcement and a designated State agency. The regulations promulgated pursuant to the Surface Mining Control and Reclamation Act require the monitoring of potentially impacted hydrologic systems before, during, and after mining operations. Regional and local differences in hydrologic systems prevent the law from directly addressing the specific requirements regarding how, when, and where to monitor. This report details characteristics and processes that commonly determine the most acceptable approaches to hydrologic monitoring in the arid and semiarid central-western United States. No single approach is best for all hydrologic systems; consideration of basin characteristics, regulatory requirements, and regional patterns in hydrologic systems is necessary in any well-designed monitoring program for hydrologicimpact assessment.
\end{abstract}

This report describes processes and characteristics that control the surface and subsurface hydraulics, as well as the water quality, of typical hydrologic systems being mined in the central-western United States. After a discussion of these processes and characteristics, three examples are presented that describe acceptable, but nonexclusive, approaches to hydrologic monitoring network design.

\section{INTRODUCTION}

\section{Background}

Certain regulations pertaining to the Surface Mining Control and Reclamation Act of 1977 (Public Law 95-87) require needs for hydrologic information to determine baseline conditions and to assess changes resulting from surface mining. Permit applications for proposed mining-development plans include general needs for hydrologic information; however, guidelines for how these needs are to be met are lacking in specific detail. 


\section{Purpose and Scope}

To assist in development of such guidelines, this report is written as a technical manual describing the hydrologic data necessary to determine baseline conditions and to assess change at a given proposed mine site. This manual describes methods for sampling, measurement, and laboratory analysis of the range of hydrologic variables needed for such assessments. Such descriptions will aid in the planning as well as the evaluation of hydrologic-network programs for existing and proposed mine plans. Such programs would have both objectives of areal baseline reconnaissance (for example, determination of current ambient conditions) and detection and assessment of long-term changes (for example, time-series monitoring of development impacts). Principal emphasis is on hydrologic data-collection programs for assessing direct effects of mining rather than the indirect effects of associated economic development (for example, urban growth and services) or the cumulative regional impacts of development for several mining sites.

The orientation of this technical manual is "how to" sample, measure, or analyze various types of hydrologic data. Proper planning and design of a hydrologic-network program must be based on a set of specific objectives influenced by desired information products and limitations of monetary and manpower resources as well as time constraints. Hydrologic networks should be evaluated periodically to insure that specified objectives are being met and that the data are providing the desired information in a timely manner and on a cost-effective basis.

Numerous references describing onsite-measurement and laboratory-analysis techniques are listed under the appropriate topic headings. These methods are compatible with procedures coordinated with and approved by various Federal agencies, including the U.S. Geological Survey and the U.S. Office of Surface Mining Reclamation and Enforcement.

Although evaluation of cumulative hydrologic impacts is not explicitly covered by this manual, numerous procedures described in this manual would be identical with those applied to monitoring site-specific mining impacts. The assessment of cumulative hydrologic impacts may include some form of aggregation of site-specific hydrologic information.

In the last part of the manual, several plans developed from a range of physiographic conditions demonstrate the application of the described hydrologic-monitoring procedures under the varied arid and semiarid conditions prevalent in the central-western United States.

\section{SURFACE WATER}

In developing a streamflow-gaging network, criteria that should be considered are:

(1) Requirements of the Permanent Regulatory Program (U.S. Office of Surface Mining Reclamation and Enforcement, 1983).

(2) Requirements at the discretion of the Regulatory Authority.

(3) Surface-water data needed to fulfill criteria for water quality (see Water Quality section, p. 57). 
(4) Identification of pre-existing water uses that import or consume water (for example, irrigation or municipal water supplies).

(5) If necessary, identification of a hydrologic balance for the area (including number 4 above).

Each criteria should be considered in order to combine purposes for the actual design of the surface-water network.

The criteria stated above stem from Public Law 95-87 that states that the quality and quantity of surface water both on and off the site must be protected and that the rights of present users to the water be protected. The law also states that monitoring may be necessary. The Permanent Regulatory Program (U.S. Office of Surface Mining Reclamation and Enforcement, 1983) amplified the type of surface-water data needed by stating that information on surface-water hydrology shall include minimum, maximum, and average discharges that identify critical low flow and peaks sufficiently to indicate seasonal variations. Guidelines relative to cumulative hydrologic impact assessment (CHIA) and probable hydrologic consequences determination (PHC) (U.S. Office of Surface Mining Reclamation and Enforcement, 1985a, b, c) provide more specific hydrologic analyses needed to estimate seasonal streamflow characteristics. These analyses were to identify peak or flood flows, low flows, and flow duration.

The analyses to derive the types of statistics necessary in the above analyses are beyond the scope of this report. It is important to note that such analyses require long-term data collection and (or) sufficient knowledge of the comparison of gaged and ungaged watersheds so that transfer of information from a gaged site is possible. Therefore, it is important to identify any long-term stations in the area maintained by Federal and State agencies or private concerns. Comparisons between the watershed in the lease area with the gaged watershed should be made with respect to such components as elevation, relief, slope, aspect, vegetation, soil types, geology, type of precipitation, and other factors influencing surface runoff. These comparisons coupled with short-term data collection aid in the transfer of streamflow statistics.

When deciding on the necessary surface-water data to fulfill waterquality criteria, an important problem is whether or not concentrations or loads are needed for particular constituents. If it is necessary to derive loads, continuous discharge data is necessary. If only concentrations of constituents or estimates of loads are needed, surface-water discharge may be needed for only part of the year.

In certain situations, it may be necessary to derive a water balance. But whether it is specifically needed or not, the network design process is helped by considering the water-balance components of input, storage, and output. For the particular watershed or part of a watershed under consideration, identify water input from sources such as ground water, streamflow, and precipitation. Water stored in the area of interest includes ground-water storage, surface-water storage, and soil-moisture storage. Output is from sources such as evapotranspiration, ground water, and streamflow. Pre-existing water uses that import or consume water should be considered in each of the water-balance components, including interactions among components. 
If a water balance is to be derived, it will probably be necessary to gage precipitation. If some model is used to compute the water balance, additional climatic parameters may be necessary as input to particular models. Use of a model is desirable because the hydrologist must consider each hydrologic component.

\section{Site-Selection Criteria}

The basic unit for hydrologic analysis is the watershed. The area under investigation for surface-water hydrology is, therefore, normally larger than the area identified for coal mining.

In developing a streamflow-gaging network, the overland-flow segments or valley segments that contribute to particular stream segments and their location should be considered in relation to the potential mine areas. The valley sidewall segments with very similar hydrologic responses are described as hydrologic-response units (HRU's) that are delineated by different soil types, infiltration rates, elevation, slope, and aspect. These factors can index differing amounts of soil-moisture storage.

Identification of these HRU's helps to identify the variety of hydrologic problems of the area and to focus on particular areas where more information is needed. For example, a small basin may be divided into two response units; one, a "clinker" area with high infiltration rates, and the other, a shale bedrock with low infiltration rates that contributes most of the water to the channel. In terms of the natural hydrology, it is important to know the hydrologic response of both HRU's. However, the changes in response of a basin because of mining depend directly on which of these areas is mined.

A common approach in initiating a streamflow-gaging network is to establish gaging stations upstream and downstream from the mine area and to attribute differences detected between the two gaging stations relating to the mining operation. Such a comparison is not always realistic. Difficulties might result because little was known about the premining hydrology of the area between the gaging stations. Also, expected changes may not be large enough to be differentiated from error in the gage records.

\section{Establishing a Streamflow-Gaging Station}

The overall criteria for network design will identify certain reaches of a stream to be monitored. In a particular reach of the stream, there may be several individual sites where hydrologic information can be obtained (Rantz and others, 1982a, p. 5). An important factor in determining a specific site is accessibility. A site that could yield important hydrologic information is of little value if the site cannot be reached during a storm event or during snowmelt. 
At any streamflow-gaging station a relation must be developed between stage and discharge. This is important to remember when deciding on a specific station location on the stream. This relation is controlled by the physical features of the channel downstream from the gaging station and is referred to as the station control (Carter and Davidian, 1968, p. 10). A controlling feature in a short length of channel is described as a section control; it can be natural or constructed. For example, an outcrop of bedrock immediately downstream from the gaging station can act as a section control for the stage-discharge relation. If a stage-discharge relation is governed by the slope, size, and roughness of the channel over a considerable distance, the station is under channel control. At most streamflow-gaging stations, there is no one single control that is effective at all stages, but rather, a combination of both section control and channel control at different discharges (Linsley and others, 1975, p. 116).

At times it is necessary to obtain information at a site where natural controls do not exist or where more precise information is needed than a natural control would provide; in such cases, an artificial control can be constructed. In many instances, artificial controls are established to provide a more sensitive stage-discharge relation for one part of the rating. For example, a particular artificial control may give excellent results during low water but may be completely drowned out during high water when the channel is the effective control. Carter and Davidian (1968, p. 3) suggest general design criteria to follow when establishing an artificial control.

One problem to avoid is backwater caused by dams, channel constrictions, or inflow from tributary streams directly downstream from a gage but in the influencing reach of the station control. Such backwater effects may make it difficult to establish a stage-discharge rating.

The network design criteria should be maintained in establishing a particular gaging station, but if a particular site is totally unsuited for the operation of a streamflow-gaging station, little is gained enhancing the overall network design. If a site cannot provide useful hydrologic information, the time and money spent in establishing the station are wasted.

The type of data needed at a particular site dictates the type of station that should be established. A station should be a continuous-record site if data are to be collected throughout the hydrologic year. The site should be a partial-record station if data are to be collected during only part of the year, and the site should be a miscellaneous site if a discharge measurement is to be obtained with no plans to return to the site on any routine basis. Examples of partial-record stations are stations that record only storm runoff but do not record low flows, crest-stage gages that record only the peaks, or stations where discharge is obtained only when a monthly water-quality sample is taken. Each of these three types of stations requires a certain amount of manpower and money to operate. Therefore, decisions about which type of gage to be installed at a given site are based primarily on the design criteria of the overall network. 


\section{Artificial Controls}

Three factors to be considered in the establishment of an artificial control are:

(1) Will sediment or debris depositing or hanging up in the vicinity of the control be a problem, or can it become a problem with the advent of mining? For many types of artificial controls, sediment proves troublesome in maintaining a rating. Scouring of the bed and banks downstream from the control also can be a problem.

(2) What will be the measured range of discharge? This question usually decides the size of control that will be needed.

(3) Is it important to monitor specific flow ranges? For example, if low flows must be measured accurately, a weir may be an appropriate control.

Using these three general categories, the Science and Education Administration of the U.S. Department of Agriculture (Brakensiek and others, 1979, p. 79) has established a flow chart to aid the hydrologist in determining what type of artificial control is needed (fig. 1).

There are two basic types of artificial controls--weirs and flumes. In general, a weir requires pondage of water behind it with a subsequent loss of practically all momentum and, therefore, allows sediment to deposit. Weirs also require some drop in head in the channel because a weir measures the total potential energy behind an overfall. A flume, on the other hand, does not depend on the loss of kinetic energy but, rather, depends on the constancy of the water surface relative to a critical control section. Measurement is typically obtained upstream from a critical control section. This type of artificial control generally provides an increased velocity that allows sediment to move through the measured section. In addition, a flume does not need the drop in head required by weirs. In a flume, critical flow is forced either by wall contraction or by floor superelevation. Flow is generally returned to subcritical velocity before exiting the flume structure.

Even though artificial controls provide theoretical ratings, these ratings need to be checked by discharge measurements. Problems with construction and installation can effect changes in the theoretical ratings. In addition, measurements need to be continued to ensure the ratings are maintained.

\section{Weirs}

A weir may be defined as an overflow structure built across an open channel--usually to measure the rate of flow of water. For free flow the discharge is a function of the water level in a pool upstream from the weir crest relative to the crest elevation and the size and shape of the weir. The U.S. Bureau of Reclamation (1967) provides recommendations for the installation and maintenance of weirs and the channels in the vicinity of these weirs. It must be emphasized that failure to follow the recommended installation and maintenance procedures can introduce large errors in 


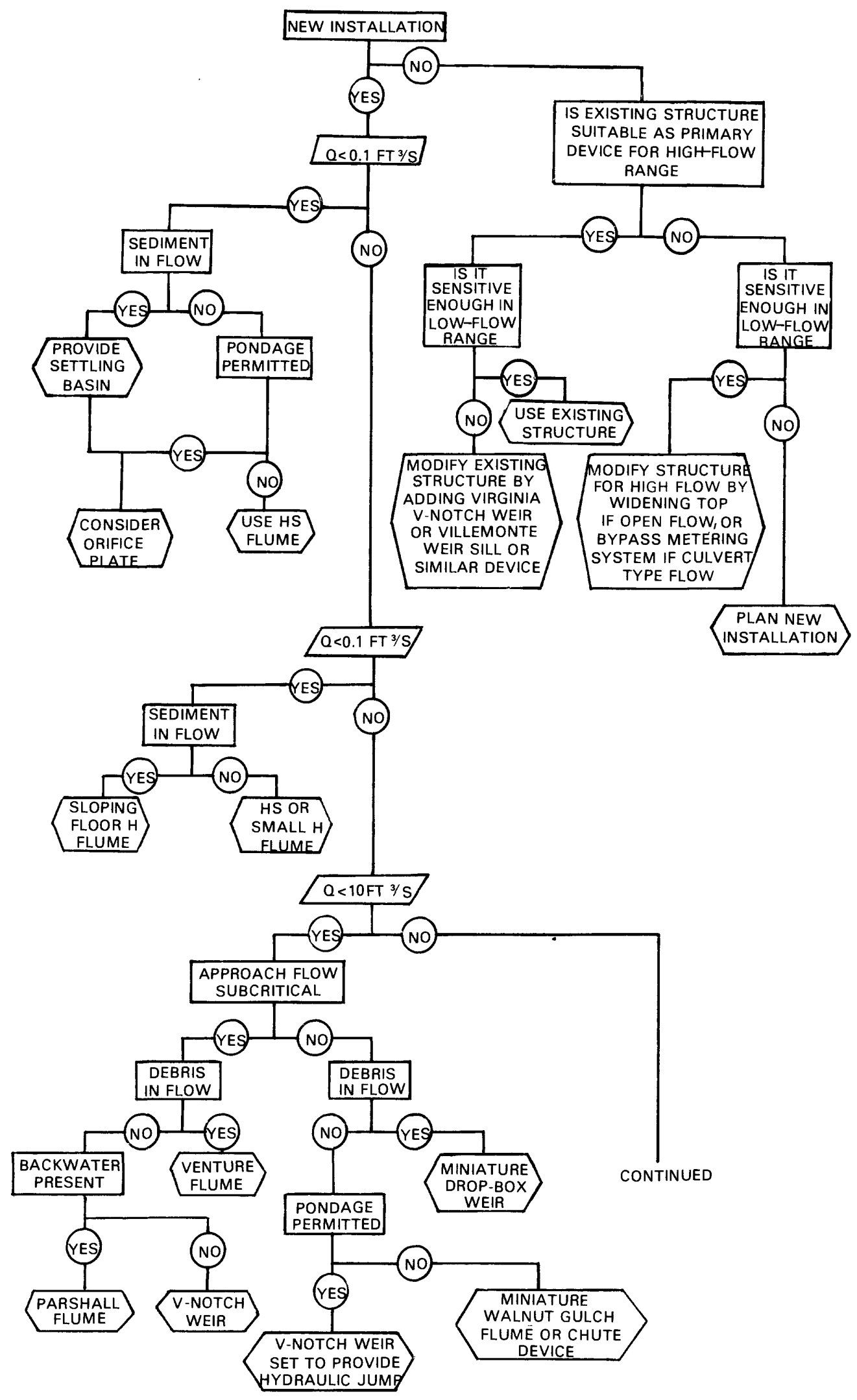

Figure 1.--Selection guide for measuring runoff using artificial controls (Brakensiek and others, 1979, p. 79). 


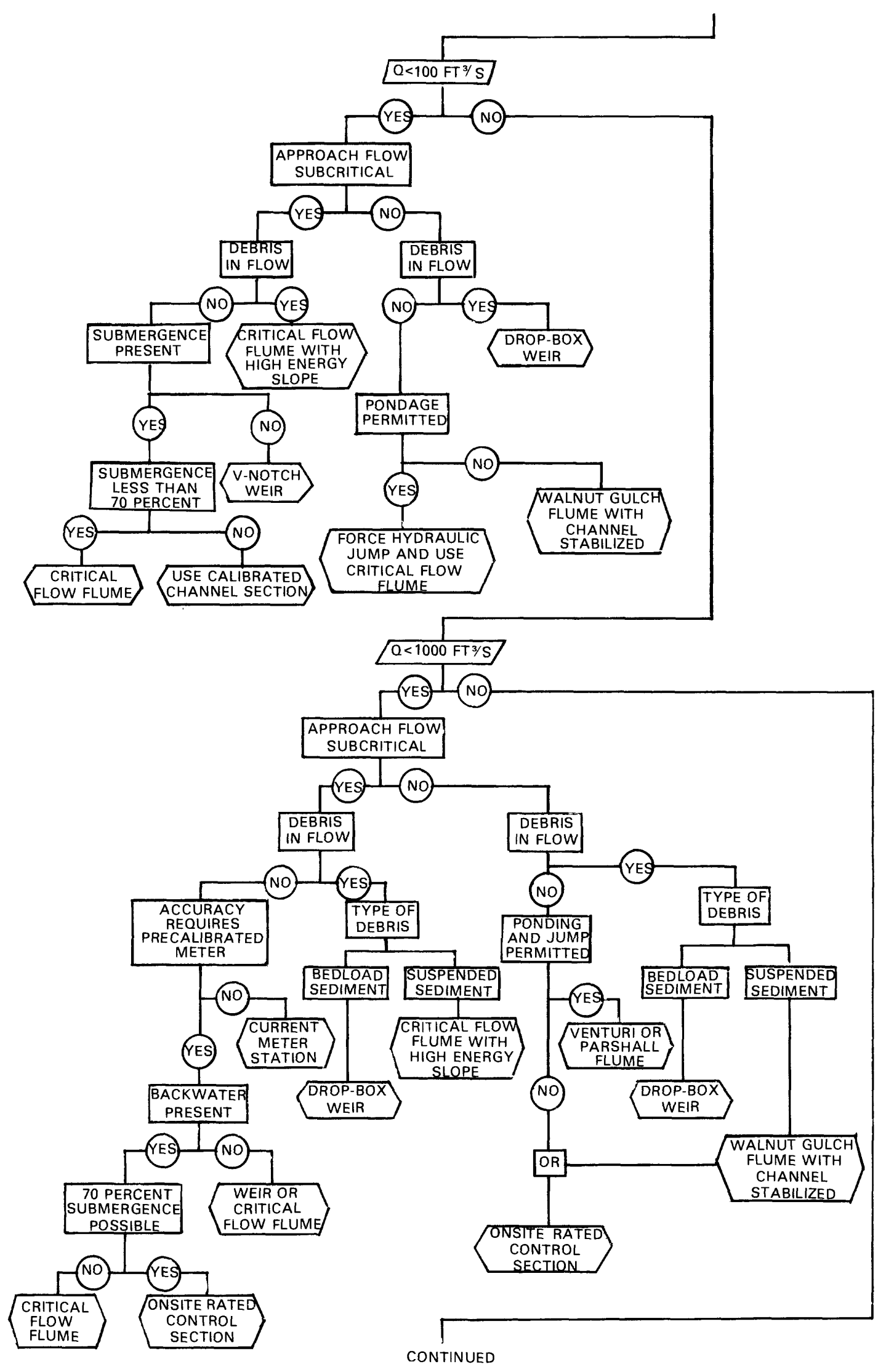

Figure 1.--Selection guide for measuring runoff using artificial controls (Brakensiek and others, 1979, p. 79).--Continued 


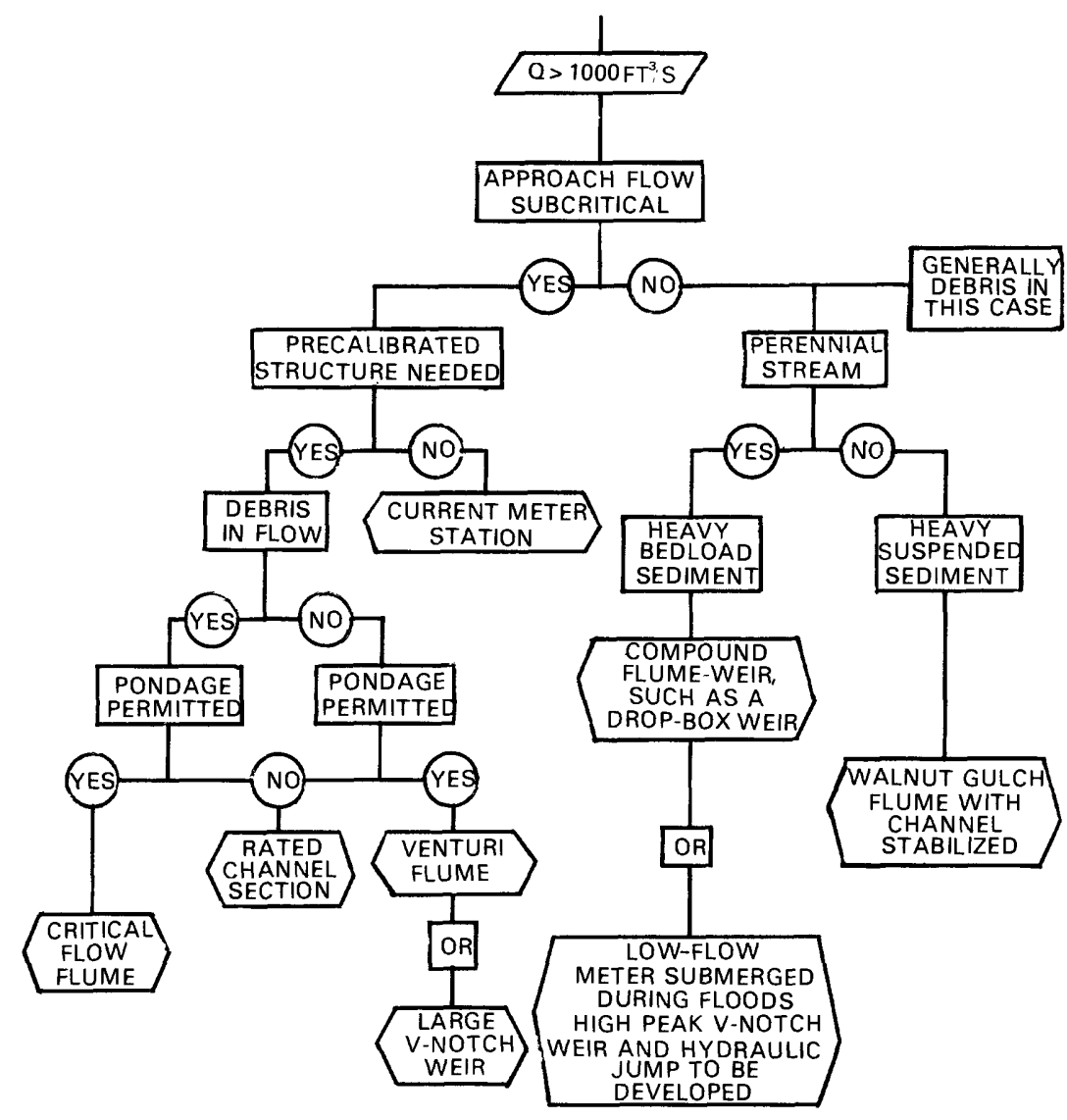

Figure 1.--Selection guide for measuring runoff using artificial controls (Brakensiek and others, 1979, p. 79).--Continued 
weir-flow measurements. Large amounts of sediment transported and deposited in the weir pond cause the theoretical rating of the weir to be useless. As this pond fills with sediment, velocity can increase across or near the measuring section of the weir. Depending on the objectives of a particular streamflow-gaging station, such a weir pond may be acceptable if the weir pond can be periodically cleaned.

It is cautioned that if the nappe (the sheet of water leaving the weir crest) is not well vented, the relation between the water level and discharge may change because of the low pressure beneath the water overfall. When the downstream water level rises above the crest elevation of the weir, the flow is considered to be submerged. If submerged, there can be some effect on the rating of the weir depending on the degree of submergence. Free flow is usually desirable.

Weirs are categorized into two general types. A contracted weir is one in which contractions occur on the sides and bottom of the channel. The second type is a suppressed weir, which extends across the entire channel. Suppressed weirs generally have a vented nappe in order to fulfill the proper conditions for use of the weir equations. Equations and methods of determining the coefficients used in the equations for both types of weirs are given in U.S. Bureau of Reclamation (1967) and Kulin and Compton (1975). Weirs also may be designated by the shape of their openings, such as rectangular, triangular $\left(90^{\circ} \mathrm{V}\right.$-notch), or trapezoidal (Cipolletti). Examples of such weirs are given in table 1 along with factors to consider on selecting a particular weir.

The Cipolletti weir is a contracted weir that is trapezoidal in shape. Its crest and sides are thin plates, set such that full contraction occurs. The sides of the weir are sloped outward at a slope of one horizontal unit to four vertical units (U.S. Bureau of Reclamation, 1967).

Another type of contracted weir is the V-notch weir. It is particularly suited for measurements of low flow. Different designs and equations for these types of V-notch weirs are given by the U.S. Bureau of Reclamation (1967) and Brakensiek and others (1979).

The flow of water often is measured through gates and sluices in many stream channels. Most gates or sluices must be individually calibrated, which requires making current-meter measurements.

\section{Flumes}

A variety of flumes is available. Before deciding on a particular type, consideration should be given to:

(1) The amount and size distribution of sediment necessary to be passed.

(2) The rate of change of stage expected. 


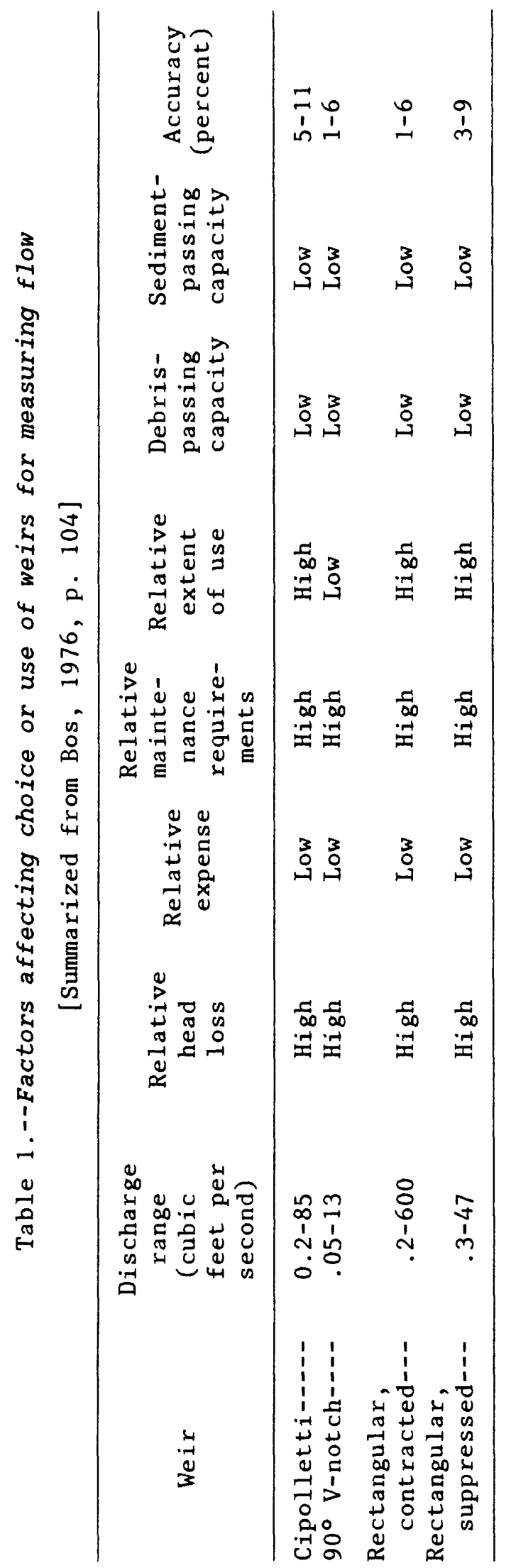


(3) Discharge-frequency relation and the shape of the stream cross section compared to the flume.

(4) Construction costs.

(5) The accuracy needed for flow ranges of interest.

A summary of these various factors is shown in table 2. Several specific types of flumes will be identified in order to explain some advantages and disadvantages.

One of the most common flumes in use is the Parshall flume. Its principal advantages are the relatively low headloss in the channel and the fact that, for moderate sediment loads, it will pass most sediment that enters. The shape and design of the Parshall flume can be obtained from U.S. Bureau of Reclamation (1967, p. 46-47) and from Kulin and Compton (1975, p. 4-7). In a free-flow situation, the discharge depends solely on the size of the throat and the depth of the water. The discharge rating curve for a Parshall flume is affected by submergence; at a submergence of 95 percent, the flume is no longer considered to be an effective flow-measuring device.

For submergence less than 95 percent, correction tables are available (U.S. Bureau of Reclamation, 1967). In order to accurately measure low flows, the smallest size flume that will handle the expected flows should be used, but thought must be given to the channel size in which the flume is to be installed. The flume size should be about one-third to one-half the width of the channel in which it is installed. The flume is designed for use in a channel in which the flow across the cross section is reasonably tranquil and uniformly distributed. If submergence occurs, a rating will have to be developed by using a standard current meter or some other type of stagedischarge measurement.

A portable modified Parshall flume has been used by the U.S. Geological Survey (Kilpatrick and Schneider, 1983, p. 13; Buchanan and Somers, 1969) for measuring discharges where the depths are shallow and the velocities are low. The U.S. Bureau of Reclamation (1967) also describes a number of modified Parshall flumes.

The term "Venturi flume" describes a variety of flumes that depend on the contraction of the flow through a critical depth. The flow is contracted either by tapering the sidewalls or by changing the elevation of the flume floor, or both. The U.S. Bureau of Reclamation (1967) has provided fabrication instructions and rating details for one such flume. Replogle (1971) has described several sizes and shapes of Venturi flumes and provides discharge ratings for each of these designs.

H-flumes are a type of critical-depth flume that can be used in areas of small to moderate amounts of sediment. These flumes use a free fall like a weir but allow for some velocity head at the measuring section. They are built to close tolerances, are usually metal, and the dimensions used in building the flume specify a predetermined rating. H-flumes come in a variety of sizes with the small flumes designated as HS, the medium size as $\mathrm{H}$, and the larger sizes as HL. The dimensions for building these flumes and their appropriate ratings are given in Brakensiek and others (1979). 


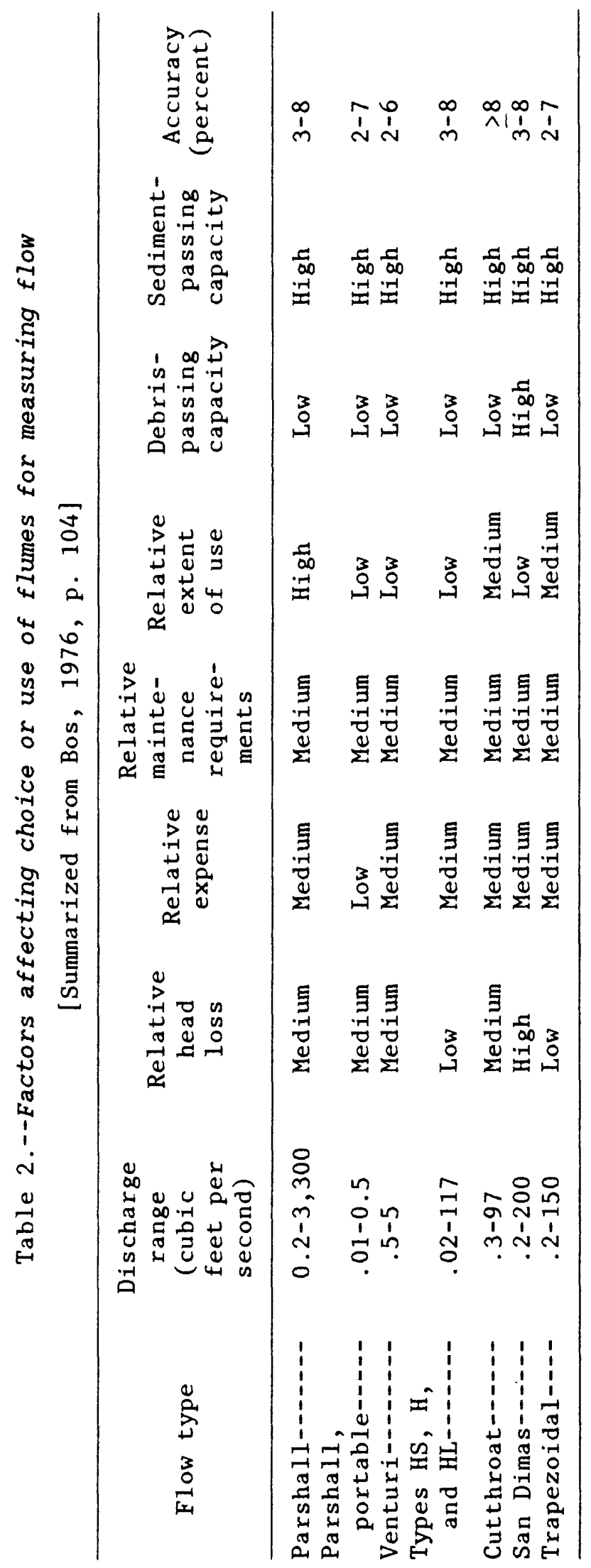


The cutthroat flume is a flat-bottomed flume, the main advantage of which is the extreme simplicity of design and construction. It has a horizontally contracting entrance and flared exit section, but it has no parallel wall throat section--hence its name. Kulin and Compton (1975) provide the general dimensions and the rating coefficients for a variety of cutthroat flumes. They also provide the discharge equations and coefficients for submerged flows.

A class of flumes that should be considered if large amounts of sediment are a problem at a site is called supercritical depth flumes. In general, these flumes accelerate the flow past a critical section by providing a throat geometry in which supercritical flow occurs. A measuring depth in the throat is provided as flow accelerates. When installing such a flume, consideration should be given to some sort of energy dissipation at the flume exit. The measuring section should be located at a distance at least as far upstream from the exit as the maximum flow depth.

Included in this category of supercritical flumes is the San Dimas flume. The floor of this flume is set on a $3^{\circ} \mathrm{slope}$, and the flow is funneled into the flume, producing supercritical flow. The flume has a rectangular cross section and, except for the rounded entrance, contraction is of equal width throughout its length. The San Dimas flume is not sensitive and is inaccurate for low flows. Further description of this flume and its rating is given by Kulin and Compton (1975).

Another supercritical flume is the trapezoidal flume, which can provide more stage sensitivity in the lower flow ranges than the San Dimas flume. It has sloping sidewalls, and the bottom is sloping to produce the supercritical flow. The measurement of stage is made in the supercritical section of the flume. Kulin and Compton (1975) provide dimensions and rating curves for several sizes of this type of flume. Chamberlain (1957) and Robinson (1961) provide some discussion on the early development and the rating of these particular types of flumes. The Walnut Gulch flume improved on the basic idea of the trapezoidal flume (Gwinn, 1970); this design was later improved and called the Santa Rita flume. Descriptions and calibrations for several sizes are reported by Smith and others (1982). Another design is described and dimension given for construction by Kilpatrick and Schneider (1983, p. 19).

\section{Other Types of Controls}

When measuring discharge at a reservoir or pond, several factors need to be considered. If the capacity, gain-or-loss in storage, and the inflow to the reservoir are known, the outflow from the reservoir can be computed (U.S. Bureau of Reclamation, 1967, p. 176). The inflow can be computed if all other factors are known.

This process is simplified if the reservoir has no outflow. For example, the inflow of a sediment pond in which most flows do not exceed the storage capacity can be gaged by knowing the capacity of the reservoir for each incremental change in depth (depth-area-volume curve). This can be obtained by surveying the reservoir. A stilling well and recorder can be placed on the 
reservoir to record the stage hydrograph. To derive the discharge hydrograph of the incoming water, the volume should be subtracted at incremental time steps. In gaging at a reservoir, losses from evapotranspiration, bank storage, or leakage to ground water need to be considered. If sediment yield to the pond is large, the reservoir capacity may decrease so rapidly that this method is inappropriate.

\section{Stage Sensors}

Stage (gage height) in an open-channel situation is the height of the water surface above an established datum. The primary importance of the measurement of stage is to relate the water-surface elevation to the discharge in order to develop a stage-discharge rating curve. Because stage is so important, it is necessary that the datum selected remains constant for the life of the gaging station (Rantz and others, 1982a, p. 23; Buchanan and Somers, 1968). All gages should be checked periodically by running levels to the fixed datum. This datum may be referenced to a recognized datum, such as sea level, or an arbitrary datum selected for expediency and convenience.

\section{Nonrecording Gages}

Nonrecording gages are of two general types: staff gages that are read directly and wire-weight gages that are read by measurement to the water surface from some fixed point. Staff gages generally are porcelain-enameled metal plates graduated every $0.02 \mathrm{ft}$. They are installed in the stream either in the vertical or in the inclined position. Type A wire-weight gages consist of a drum wound with a single layer of cable with a weight attached to the end of the cable. A counter and a check bar of known elevation all are housed within a small lockable box and generally mounted to a rigid structure such as a bridge or a trestle directly above the water surface where gage-height readings are required (Buchanan and Somers, 1968, p. 22).

A crest-stage gage was developed to measure the maximum instantaneous stage or flood crest (Buchanan and Somers, 1968, p. 27). The most satisfactory version is a vertical piece of 2 -in. galvanized pipe containing a graduated aluminum or wood staff held in a fixed position relative to a datum. Specific placement of intake holes in the bottom of the pipe is needed to minimize hydrostatic drawdown or superelevation within the pipe. Granulated cork is placed in the bottom of the pipe, and as the flood wave passes, the water rises in the pipe and the cork floats on the water surface. As the flood crest passes, the water starts to recede and the cork adheres to the staff inside the pipe, retaining the crest stage of the flood. The gage height of the flood peak is determined by measuring the elevation of the flood mark relative to the established reference-point elevation on the pipe. Crest-stage gages are sometimes used as auxiliary gages at recording stations in order to record the stage of a particular flood even if the recording instruments are not working. A series of these gages may sometimes be placed at sites where indirect methods are used to compute discharge. The data from a set of crest-stage gages can provide the water-surface profile that is necessary for these techniques. The crest-stage gage is typically used in ephemeral streams. 


\section{Continuous-Stage Recorders}

For continuously recording stage gages, there are basically two types of sensors available (Carter and Davidian, 1968). First, there is a pressure-type gage in which pressure exerted by the height of the water in the stream can be sensed and transmitted through a tube to a recorder inside the

gaging station (Craig, 1983). Gas is bubbled freely into the stream through a tube connected to an orifice located at a fixed elevation in the stream (Buchanan and Somers, 1968, p. 4). The pressure in the connecting tube is equal to the head on the bubble orifice at any gage height. The proper placement of the orifice is essential for accurate stage readings. The orifice should be placed where the height of the water represents the stage in the open channel as determined by the control of the gaging station. The orifice must be located where it will not be buried by mud and sand, although small amounts of sediment covering the orifice may not detract from its reliability. Areas of highly turbulent flow should be avoided when installing an orifice because it may be swept away or knocked loose from its mounting. Areas of high turbulence also may cause a drawdown situation to occur over the orifice. This type of gage is generally easy to install in the channel, but the equipment is expensive and requires onsite personnel experienced in the operation and maintenance of the system.

The second type of sensor is the float gage, which consists of a float attached to a counterweight by means of a steel tape that passes over a suitable pulley assembly on the recording device. This type of float gage requires some type of stilling well in which to operate (Buchanan and Somers, 1968 , p. 14). Thus, the installation may be time-consuming. In sedimentladen streams, stilling wells have a tendency to fill with sediment; during low flow, the float can rest on the deposited sediment, thus destroying the stage record. Continued maintenance of the stilling well is required to keep sediment flushed from the system.

\section{Type of Recorder}

The two types of stage sensors discussed previously will be used with some type of recorder at a continuous gaging station. The recorder can be either an anaiog (graphic) recorder or a digital recorder. An analog recorder provides a visual record of stage (Buchanan and Somers, 1968, p. 5). Most analog recorders obtain an unlimited range in stage by using a reversing device or by unlimited rotation of the drum. These recorders can usually run for at least a month or longer without servicing. The advantage of the analog recorder is that it provides a visual record, continuous in time, of the water levels. The graphic record is extremely valuable at stations where water-quality data are collected for particular stages; they also are necessary at those stations where sediment data are to be obtained. Sediment-concentration values can be written directly on the analog chart, and both the sediment-concentration curve and the water-stage curve already recorded provide a way of maintaining, storing, and reducing the sediment record. In addition, the analog recorder has the advantages of simplicity and low cost. For small or isolated stations the analog recorder is recommended. 
The digital recorder records the information in a digital form at preselected uniform time intervals, but the instantaneous stage also can be read directly from the recorder. Most digital recorders use a 16-channel paper-tape punch to record four decimal digits (00.01 to 99.99) (Buchanan and Somers, 1968). Because of the form of the recorded data, this recorder is useful if data are to be read directly into a digital computer for processing and storage. Therefore, when a number of gaging stations are to be operated, the digital recorder provides an easy way to process the discharge record.

Digital recorders document the gage height only at preselected time intervals of $5,15,30$, and 60 minutes. One must decide which is the best time interval to use. For example, a recorder punching on a 60-minute time interval may completely miss a storm peak in a small watershed. On the other hand, the 5-minute time interval may produce too much information to be economically processed. The drainage area of the watershed and how rapidly the stream may rise are the major factors in selecting the appropriate time interval.

Because the data for stage are coded in a digital form, identifying previous fluctuations in stage onsite is more difficult. Decoding this information is possible, but if decisions on sampling water quality or sediment concentrations depend on changes in stage, it requires more time to analyze the necessary information from the digital recorder.

Buchanan and Somers (1968) describe a telemeter system that can be used when current information is needed at frequent intervals at a particular gaging station. An example of this type of telemeter is the Tele-Mark ${ }^{1}$ system $^{2}$ in which a telephone provides direct access to gage height at the site.

The choice of whether to use an analog recorder or a digital recorder depends directly on how the data are to be reduced and stored. Some thought should be given to these problems before any streamflow-gaging network is put into operation. As has been shown, the analog recorder can be important in reducing auxiliary data collected at a particular site. The analog record usually is hand-computed before entering the data into a computer file. This may require more time than a digital system. If the network of gaging stations will be fairly large, the digital system may well be needed in order to reduce the amount of time required for data reduction to enter and store the data into the computer.

\section{Construction of a Streamflow-Gaging Station}

A gaging station consists of equipment to sense stage, a shelter, and a control--either natural or artificial. If an artificial control is to be established, cost and manpower must be considered. It is important to remember when building an artificial control to try to disturb as little of the natural channel as possible.

${ }^{1}$ Use of trade names in this report is for identification purposes only and does not constitute endorsement by the U.S. Geological Survey. 
Instrument shelters come in various sizes and are built of almost any type of building material. It is usually advisable to build the shelter large enough that the attending personnel can stand inside the building. Therefore, the inside dimensions of the shelter optimumly should be at least about 4 by $4 \mathrm{ft}$ and about $7 \mathrm{ft}$ tall (Buchanan and Somers, 1968). There are, however, examples of shelters that house only the recorder and are mounted directly on the stilling well.

If additional equipment for collecting other hydrologic data is needed, such as a sediment data pumping sampler or a water-quality monitor, the building may have to be somewhat larger. Many buildings that house PS-69 sediment-pumping samplers are 8 by $10 \mathrm{ft}$ or larger (Buchanan and Somers, 1968, p. 15). Small outbuildings sold by a variety of commercial companies can be used effectively for shelters.

Two types of stage sensors are the pressure-type gage and the float gage. The pressure-type gage does not require a stilling well. The orifice should be placed at least $0.5 \mathrm{ft}$ below the lowest expected stage in the stream. The plastic tube connecting the orifice and the instrument can be encased in a metal pipe or other conduit and buried in the streambank to protect against the elements, animals, and vandalism (Buchanan and Somers, 1968, p. 16).

A float system for operating the recorder requires a stilling well that protects the float and dampens the fluctuations in the stream caused by wind and turbulence or surge. Stilling wells can be made of concrete, reinforced concrete block, concrete pipe, steel pipe, or occasionally wood. These wells are usually placed in the bank of the stream, but they can be attached directly to bridge piers, abutments, or placed directly in the stream. The stilling well should be deep enough so it is at least a foot below the minimum stage anticipated and high enough to be above the stage of a 50-year flood (Buchanan and Somers, 1968, p. 7). Normally, a pipe approximately $4 \mathrm{ft}$ in diameter will be satisfactory in size, although other sizes can be used. A 4-ft diameter provides access to the stilling-well floor for cleaning and maintenance.

When the stilling well is placed in the bank of the stream, the bottom should be sealed so that ground water cannot seep into it and stream water cannot leak out. Water from the stream enters and leaves the stilling well through an intake pipe so the water in the well is at the same elevation as the water in the stream. Intake pipes and stilling wells should be of sufficient size or have some mechanism to flush the system of sediment to prevent clogging. An example is shown by Buchanan and Somers (1968, p. 14). Intakes, commonly of 2-in. pipe, should be anchored well into the stream and should be placed at right angles to the direction of flow. Care should be taken so that the velocity of water past the intake does not draw down or pile up water in the stilling well, which could cause a difference in the water level between the stream and the stilling well. If the station is to be operated during the winter months, some means should be provided for preventing ice from forming in the stilling well. Typical methods of preventing ice formation are the addition of subfloors, heaters, and oil. Further descriptions are given in Buchanan and Somers (1968, p. 15). 
Additional equipment may be necessary to collect other data. For example, water-quality monitors or pumping samplers for collecting sediment data may be required at the site. It is desirable to have only one clock operate all the necessary equipment. If more than one clock is used, the timing can be different between various parameters. If it is necessary to use additional clocks, an event recorder should be used to mark the time sampling occurs directly on the trace for stage. Therefore, even if the clocks are recording different times, the time of the sampling event will be known with respect to the stage hydrograph.

If sediment data are collected or more sophisticated electronic equipment is used in a gaging station, requirements for heating the shelter will have to be considered. As the sophistication of the equipment increases, heating and reliable power become more important. In such situations, it may be desirable to locate the station near a power line in order to obtain the necessary electricity.

\section{Operation of a Streamflow-Gaging Station}

Buchanan and Somers (1968) give a general list of several important points to emphasize in operating a station. First, the datum of the gage should be maintained to $0.01 \mathrm{ft}$ by running levels to the reference marks at least once every 2 to 3 years. If conditions are unstable, these levels should be run more frequently.

Second, during each visit, the recorded gage heights should be checked against the water level in the stream and in the stilling well to make sure the intakes are open and that there is no malfunction of the equipment. To insure the proper water level, it is important to check the following during each visit:

(1) The staff gage or wire-weight gage in the stream noted as the outside gage.

(2) An appropriate staff gage or wire-weight gage stage reading in the stilling well, if a float type, to determine the water level in the stilling well itself--recorded as the inside gage.

(3) The water-level stage being recorded on the water-stage recorder.

All differences in recorded values should be noted and, if possible, adjustments made so that all agree with a stable outside gage.

The time should be accurately noted. Three values of time are generally recorded: (1) The actual watch time; (2) the tape time or analog-recorder time, depending on the type of recorder; and (3) the time of clock driving the recorder.

At a majority of gaging stations, discharge ratings consist of a simple relation between stage and discharge. However, these stage-discharge relations are rarely permanent for natural controls because of changes in the stream channel resulting from aquatic growth, ice, movement of the streambed, beaverdams, and other factors. Therefore, frequent discharge measurements are usually necessary to define or monitor the stage-discharge relation at any time. At a station that has been operating for some time, a series of stage-discharge relations will be developed. 
Some discussion of station controls has already been given. In developing the stage-discharge relation, it is important to know the stage at which various controls are in effect. These observations help to identify how often and at what stages discharge measurements need to be made. Also, one should determine the gage height of zero flow (PZF) or the gage height at which discharge becomes zero. This is an important point on the stagedischarge relation, although it can be identified graphically, or mathematically from two low winter measurements. Onsite measured PZF's are helpful in identifying this point.

The term "shifting control" refers to that condition where the stage-discharge relation does not remain permanent but varies in time either gradually or abruptly due to changes in the control for the station. Even in fairly stable channels, shifts in the rating will occur. Some of these shifts are seasonal and become consistent through time. Thus, an orderly progression of discharge measurements can be made. It is important to note that in channels with heavy sediment loads, the control can shift quite dramatically. In sand-bed channels, the rating can change throughout the rise and fall of a hydrograph due to changes in bed forms in the channel.

During monthly maintenance visits, a discharge measurement and the recording of stage can be made to help develop this stage-discharge relation. If a strict monthly schedule is maintained, it would be possible that measurements covering the entire range of flow at the station would not be obtained. It is important that special efforts are made to obtain more measurements during runoff events and to measure as close to the yearly peak as possible. It is equally important to measure extreme low flows also, because the high and low ends of most rating curves are usually the problem areas.

It is doubtful, particularly in small watersheds, that the higher flow events can be measured directly because of the short duration of the hydrograph. Therefore, indirect methods of obtaining a discharge measurement may have to be made to fully develop the stage-discharge relation.

A series of publications by the U.S. Geological Survey entitled, "Techniques of Water-Resources Investigations" provides procedures and techniques for making indirect discharge measurements under a variety of conditions (Benson and Dalrymple, 1967; Dalrymple and Benson, 1967; Bodhaine, 1968; Matthai, 1967; and Hulsing, 1967). Defining the energy gradient is important in all these techniques. Therefore, selecting a suitable reach of the stream is one of the most important elements in developing a useful, indirect measurement of discharge. Obtaining good high-water marks is basic to a reliable computation. The reach should be chosen in which the small trash line produced at the flow peak can be identified and mapped. Changes in the energy gradient are affected by roughness and change in shape of the channel; therefore, a uniform channel section is desirable.

In some watersheds, high-water marks are not easily identified along the bank. At these gaging stations, it may be necessary to establish several crest-stage gages along the channel profile in order to obtain high-water marks. If such a sequence of crest-stage gages is used, the publications listed above should be consulted for proper placement in order to obtain the necessary information on the water profile. 


\section{Discharge Measurements}

A current-meter discharge measurement is the summation of the stream cross-sectional area multiplied by the respective average velocity in the partial area. An excellent discussion of stream-discharge measurements and the necessary equipment is given by Buchanan and Somers (1969). The calibration and maintenance of vertical axis current meters, commonly used in discharge measurements, is given by Smoot and Novak (1968).

In selecting a location for making the discharge measurement, the location of the control must be considered with respect to the location of the gage and accessibility. Channel storage, incoming tributary water, or diversions can change the discharge sufficiently from what is being recorded at the station. During high water, access to the measuring site may be a problem, and discharge measurements may have to be taken from bridges. If a suitable bridge is not available, a cableway may have to be constructed. If high-water measurements are made from a bridge some distance from the gaging station, an adjustment for travel time may be necessary.

It is important to adopt a standard note-taking system so that a complete set of notes can be maintained. Note paper, such as that shown in figure 2 (Buchanan and Somers, 1969, p. 3), provides an example of such a note-keeping method. In addition to keeping the notes on the velocity and dimensions of each partial area for computing the discharge, information should be recorded concerning the location of the site, the condition of the channel and control, weather conditions, the type of equipment, and checks performed on the equipment. This information is necessary to develop a stage-discharge relation.

To adequately represent the vertical velocity profile within each partial area, measurements of velocity at specific depths are used. The U.S. Geological Survey generally uses two velocity methods for measurement of mean velocity. The first method is referred to as the 0.6 -depth method in which one observation of velocity is made in the vertical 0.6 of the depth below the surface. This single velocity measurement is considered to be the mean velocity in the vertical.

The second method is the two-point method. Velocity measurements are made at two points in the vertical, and the values are averaged. The two points used for observation of velocity are 0.2 and 0.8 of the depth below the surface of the water. 

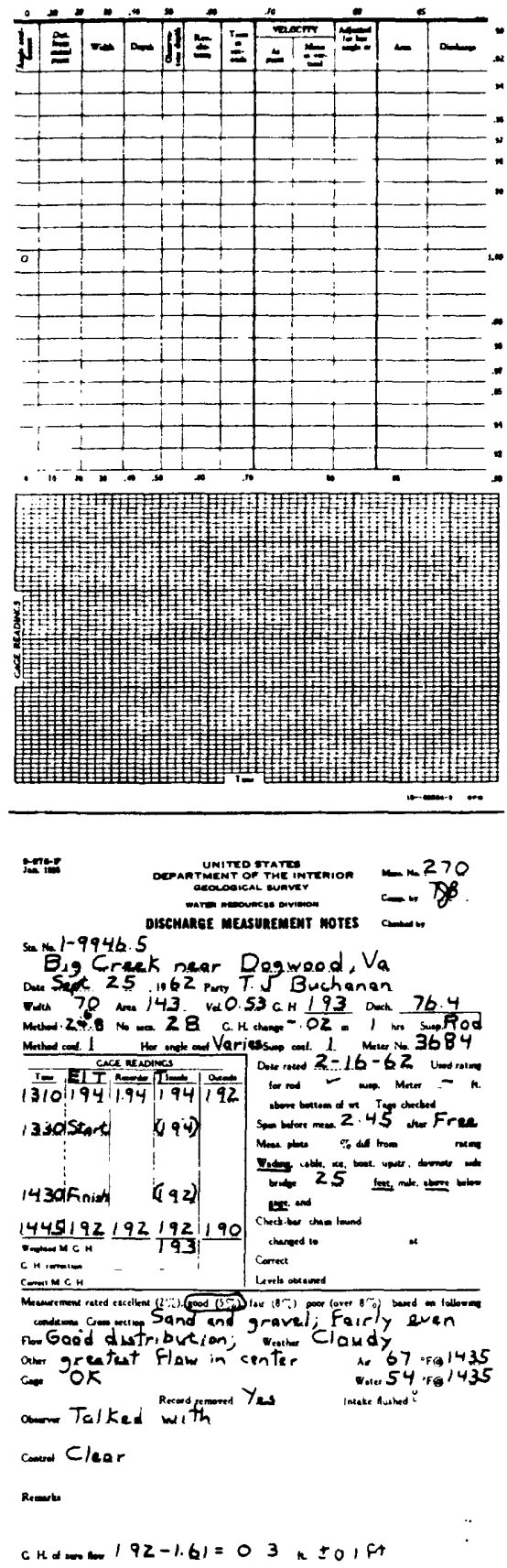

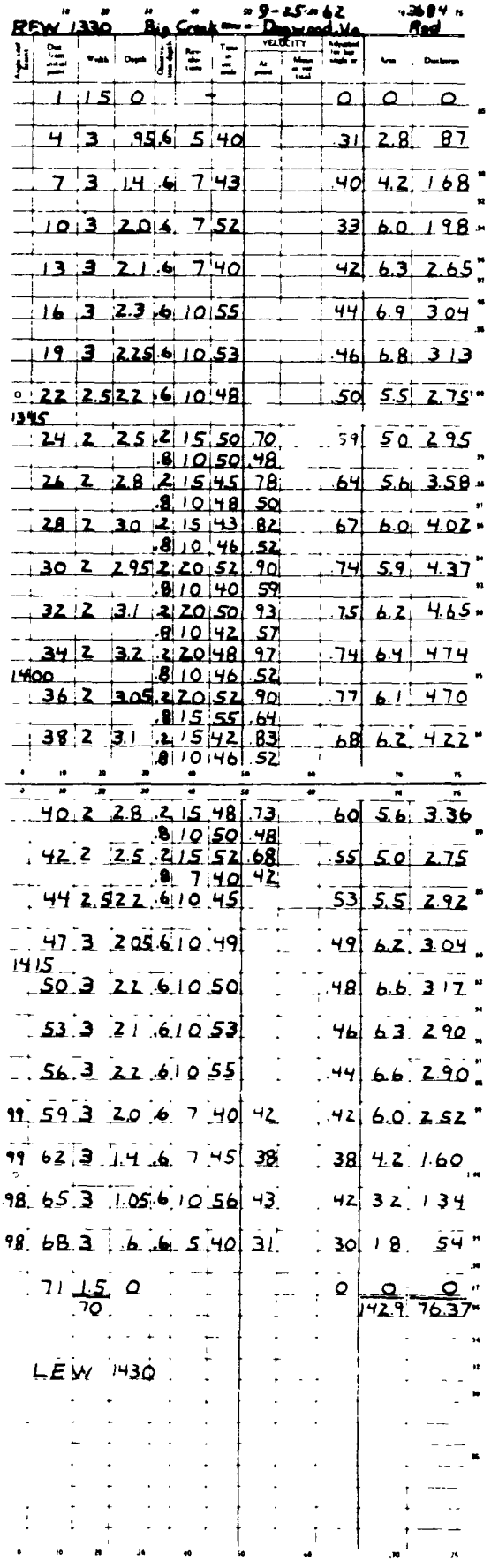

Figure 2.--Computation notes of a streamflow measurement by the midsection method (from Buchanan and Somers, 1969, p. 3.). 
The type of current meter to use and the velocity method used in a measurement are dependent on the depth of water. The following system is used by the U.S. Geological Survey:

\begin{tabular}{|c|c|c|}
\hline $\begin{array}{l}\text { Water depth } \\
\text { (feet) }\end{array}$ & Meter & $\begin{array}{l}\text { Velocity } \\
\text { method }\end{array}$ \\
\hline $\begin{array}{r}2.5 \text { and deeper- } \\
1.5 \text { to } 2.5- \\
.3 \text { to } 1.5-\end{array}$ & $\begin{array}{l}\text { Type } A^{1}, A^{1} \\
\text { Type } A^{1}, A^{1} \\
\text { Pygmy }{ }^{1} 2\end{array}$ & 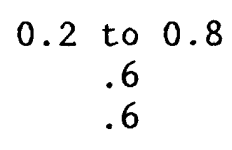 \\
\hline .0 to $.3-\cdots$ & $\begin{array}{l}\text { Surface float, } \\
\text { volumetric, weir, } \\
\text { flume, dye }\end{array}$ & \\
\hline
\end{tabular}
second.

${ }^{1}$ Meter not recommended for velocities less than 0.2 cubic foot per

${ }^{2}$ Meter not recommended when velocities exceed 2.5 cubic feet per second.

\section{Maintaining the Record}

Information concerning the equipment and stage condition of a streamflowgaging station determined during routine visits is most important. The form used by the U.S. Geological Survey as an inspection sheet for stations with digital recorders is shown in figure 3 . Although it is not necessary to use this form, it is important to note the type of information that is included. First, there is information about the gaging station, including the name and location. Second, there is information on the time and date that the recorder was started. Third, there is information on the time and date (both actual time and recorder time) the tape was removed. Fourth, there is a place to record time and stage for visits when the tape is not removed but an inspection is made. This type of information is necessary for the data to be put in its proper sequence and to document any shifts in either stage or time. If the station has an analog recorder, most of this information is written on the strip chart. For example, an inspection visit should include the stage of both the outside and inside gages and the watch time when the readings were made.

\section{Computation and Processing of Discharge Records}

Data reduction and processing already should have been considered in designing the gaging-station network. If, for example, developing a water balance or calculating loads for water-quality constituents is important, the calculation of daily mean flows may be an important part of the data reduction. On the other hand, if the peak-discharge data from storms are required, unit data as small as 5-minute intervals may be needed for analysis. 

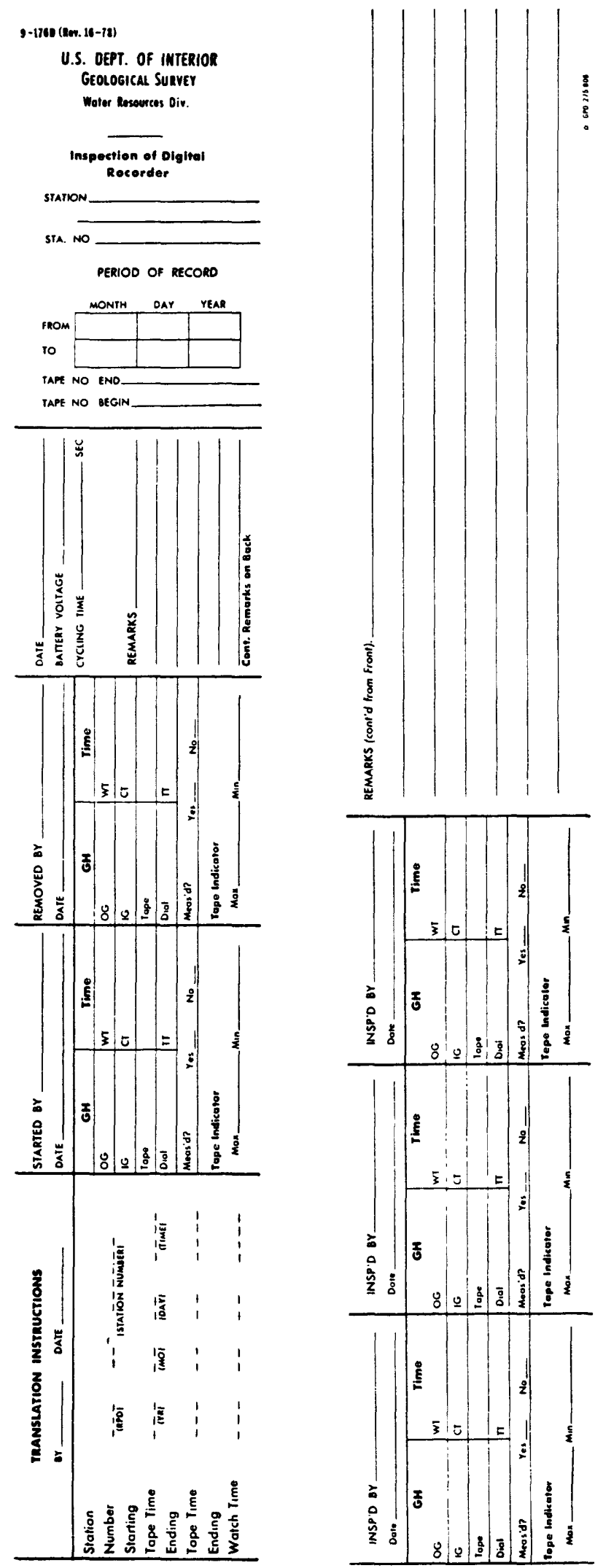

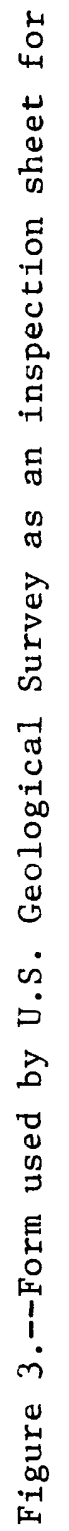


A station analysis that includes a discussion of the following items should be prepared for each of the stations (Kennedy, 1983, p. 45; Carter and Davidian, 1968, p. 12):

(1) Onsite survey of gage datum and any datum corrections to be applied to the gage readings taken during the year.

(2) A review of the discharge-measurement notes.

(3) An analysis of the stage-discharge rating and the determination of the rating or shifts applicable during each period of the year.

(4) The preparation of the stage-discharge rating.

The station analysis is prepared for each station each year in order to provide a record of the methods of record computation.

The method of computing daily mean discharge from the stage record depends somewhat on the type of instrument used to record stage. The sequence of manual computation of discharge from a strip chart recorder is given by Carter and Davidian (1968, p. 12). This sequence of computation identifies the important steps in maintaining any discharge record. The computation sequence is:

(1) Determination and application of gage height and time correction to the gage-height chart.

(2) Computation of the mean gage height for each day or for shorter periods if the range in discharge is large during the day.

(3) Computation of discharge for each period from mean values of stage and the stage-discharge rating, including any shift corrections.

(4) Computation of peak values of gage height and discharge.

(5) Listing of the values of mean daily gage heights, peak discharge, and instantaneous peaks.

(6) Computation of mean flow for each month and the year.

(7) Review and comparison of the record of discharge with that of nearby streams (if available).

\section{PRECIPITATION}

It is not always necessary to collect precipitation data when collecting surface runoff. At times, measuring the surface water and deriving the flood frequencies or low-flow characteristics from that data is sufficient.

For purposes of modeling or general computation of a water balance, the amount of precipitation must be known. Precipitation provides the total input to a water balance from which all losses, storage, and output must be subtracted.

\section{Network Design}

Precipitation is highly variable in space; therefore, it would be desirable to have the network of precipitation gages as dense as possible. However, in order to gage the spatial variability of precipitation, the network would become so dense that it would be economically unfeasible and require intensive manpower commitments for operation and maintenance. Thus, some compromises have to be made. 
The general criteria for network design revolves around two major points. The first criterion is the type of precipitation events expected in the particular area, and the second is the types of data needed for the analysis of an area.

The types of events in an area can be frontal (or cyclonic), convective, and orographic, or a combination of these three types. Frontal-type storms usually occur over broad areas with more consistency in the amounts of precipitation delivered to the surface. On the other hand, convective-type storms are usually isolated cells that can deliver large quantities of rainfall in short periods of time to small areas of the land surface. In most of the western areas, the frontal-type and convective-type storms change in relative importance by the season. For example, the winter months characteristically have frontal-type storms, and the convective-type storms are more dominant in the summer season. Depending on the relief in the watershed, the orographic effect can be quite substantial.

If the frontal-type storm is dominant, the precipitation network can be less dense with the knowledge that precipitation is more uniform over the area. If convective-type storms are dominant, the network should be extremely dense because a small area might receive large quantities of precipitation. If the orographic effect has a large influence in the area of concern, network considerations will focus on elevation in order to effectively identify the change in amounts of precipitation with changes in elevation. In determining orographic effects, it is extremely important to record both lower and higher elevation precipitation in the watershed. If a combination of these storm types is expected, one must consider them in the network design.

The type of precipitation data needed also must be considered, as well as data requirements for future analysis. If it is necessary to know only yearly, monthly, or daily totals of precipitation amounts, the equipment used for data collection is fairly simple, and the network may contain few sites. If, on the other hand, it is necessary to know the intensity of precipitation (the depth of water per unit of time), the data-collection system will become more sophisticated, and the network will contain more gages. It may be necessary to know not only the intensity of the precipitation but the timing of the rainfall, which may need to be correlated directly to the runoff event. The spatial variability of precipitation intens'ity becomes important, making the network more dense.

Some compromise in the network design is inevitable. However, it is possible to augment the network with a series of low-cost storage-type gages and have only a few recording-type gages in the basin. The recording gages probably will give sufficient information on the timing of precipitation delivered to the surface, and the storage gages will help to identify the spatial variability. In determining the type of gage necessary at a particular location, it is important to know if snow or rain is the dominant form of precipitation. 


\section{Site-Selection Criteria}

In a perfect exposure, the catch of the gage should accurately represent the precipitation falling on the surrounding area. This ideal, however, is very difficult to attain in practice, primarily because of the effects of wind. The effects of wind can be considered from two aspects: (1) The effects on the instrument itself, and (2) the effects of the site on the air trajectories. The result of the first aspect generally reduces the amount of water collected. The general result of the second aspect--and frequently more important--is either an excess or a deficiency in the precipitation recorded. The effects of wind motion are reduced but not entirely overcome by choosing the site so that the wind speed at the gage mouth is as small as possible without actually cutting off any of the precipitation.

It may be possible to modify the surroundings immediately around the gage so that the air flow across the mouth is horizontal. One way of modifying the immediate surroundings of the gage is to fit a suitably shaped windshield around the instrument. Criteria for an ideal windshield are given by Brakensiek and others (1979, p. 6). Primarily, the shield should ensure the parallel flow of air over the mouth of the gage without introducing local wind currents that can dramatically increase or decrease gage catch efficiency. In areas with significant snowfall, the shield can influence "capping" of the gage by snow. The Alter shield is less susceptible to "capping" and is effective in improving gage catch efficiency in these high snowfall areas.

The most important requirements of a gage are (World Meteorological Organization, 1965, p. II.3):

(1) The rim of the collector should have a sharp edge, fall away vertically inside, and be steeply beveled outside.

(2) The area of the mouth should be known to the nearest 0.5 percent and the construction should be such that the area remains constant.

(3) The collector should be designed to prevent rain from splashing in and out, which can be done by having the vertical wall sufficiently deep and the slope of the funnel sufficiently steep (at least $45^{\circ}$ ).

(4) The receiver should have a narrow neck and should be sufficiently protected from radiation to minimize loss of water by evaporation. This requirement may have to be ignored when collecting precipitation in the form of snow.

The growth of vegetation or manmade alterations to the surrounding area should be avoided. The angle from the gage orifice to the top of any nearby object should not exceed $30^{\circ}$. Under no circumstances should an obstruction be nearer the gage than its own height. Additional site-selection considerations are given by Brakensiek and others (1979, p. 4).

The size of the orifice generally should be 8 in. in diameter, which is the standard set by the National Weather Service (Brakensiek and others, 1979). Smaller diameter orifices can be used for rainfall (Huff, 1955). However, if snow is the predominant form of precipitation, a gage orifice larger than 8 in. may be desired. 


\section{Types of Gages}

Nonrecording rain gages usually consist of a collector and a funnel leading into a receiver used for storage. These gages have been standardized to one type in the United States; this type is the National Weather Service's standard 8-in. gage. In this gage, the top part of the funnel has an 8-in. inside diameter and a funnel-shaped bottom that conducts any liquid caught in the receiver into a cylindrical measuring tube. To measure rainfall depth to hundredths of an inch, the measuring tube has a cross-sectional area that is one-tenth the cross section of the orifice. Additional rainfall will overflow into an outer can.

Specialized types of nonrecording gages usually are used in remote areas, such as in isolated mountain areas where inspections are infrequent, to measure the winter snowfall. Their size depends on the expected precipitation. The Sacramento-Totalizer is a popular nonrecording storage gage that has a truncated right circular cone mounted on a tower above the maximum expected depth of snow, surrounded by a windshield to reduce the effects of wind on the catch (Brakensiek and others, 1979, p. 13). This gage with an 8-in. orifice may become capped by snow if the snow is frequently wet and sticky. In such locations, these gages have been fitted with a 12-in. orifice to prevent such capping.

Other nonrecording gages have been used as secondary gages to fill in gaps in the network of standard or recording-type gages. These gages usually have a support that can be mounted on a metal or a wooden post, come in all shapes and dimensions, and are made of plastic or metal. Gages with small orifices are less accurate--primarily because they are read directly and do not have the magnified scale of the larger gages. In a network, all gages should be installed with the orifice level at the same height above the ground.

Three types of recording gages are in general use: the weighing bucket, the tipping bucket, and the float type. It should be emphasized that the only satisfactory instrument for measuring both rainfall and snowfall is the weighing-bucket type gage. The tipping-bucket and float-type gages are used as rainfall-intensity recorders and are more complex to operate than the weighing bucket. A satisfactory record of rainfall intensity can be determined from the weighing-bucket type recorder, provided there is a proper time scale.

The universal weighing-bucket gage commonly used consists of a collecting bucket resting on a weighing platform and frame, which are suspended from a spring system. Precipitation collected in the bucket increases the load on the spring, which lowers the platform frame. This deflection is proportional to the amount of precipitation collected. The movement of the frame is transmitted through a system of links and levers to a pen that marks a graduated chart revolving in time. Falling precipitation is directed into a bucket through an 8-in. collecting ring and funnel. This universal weighingtype gage has been designed to prevent excessive evaporation losses. 
Difficulties due to movement of the balance and pen in strong winds can be reduced by a damping mechanism. Most universal weighing-type gages are a dual-traverse type with a 12-in. precipitation capacity, although singletraverse gages are available with a 6-in. capacity. The main usefulness of such a gage is a direct recording of both rain and snow. Snow does not need to be melted before it is recorded.

The time scale for the revolving drum must be selected in advance and can range between one revolution in 6 hours to one revolution in 30 days. With a short revolution period, intensities can be obtained from the chart. However, if a 30-day revolution is used for the drum, the time increments are so small that intensities cannot be obtained.

A digital precipitation gage is a weighing-bucket type gage that records the weight of the accumulated precipitation (rain or snow) on a 16-channel paper tape at selected time intervals. This digital recorder is much the same as that used in gathering streamflow information. The overall mechanism is very similar to the weighing-bucket type gage previously described.

Unfortunately, the punched value of precipitation can be recorded only to the nearest $0.1 \mathrm{in.}$, whereas data can be interpreted to the nearest 0.01 in. on the weighing-bucket gage with a graphical record.

The tipping-bucket gage consists of a collector orifice that funnels rainfall to a small outlet directly over a tipping-bucket mechanism. The tipping bucket is divided into two equal compartments--each holding exactly 0.01 in. of rainfall. When one compartment fills, the bucket will tip and empty into an overflow reservoir, and the opposite compartment is positioned to receive the incoming rainfall. The electrical impulses from the bucket tip are transmitted to a recorder. Each impulse, therefore, indicates 0.01 in. of rainfall. The recorder identifies the time of each tip. All the water is funneled to a bucket so that the total rainfall recorded is stored. The main advantage of the tipping-bucket gage is that the intensity of the rainfall can be identified and that no record is obtained during periods of no rainfall.

The disadvantages of such a gage are:

(1) The bucket takes a small but finite time to tip; during the first half of this motion, the incoming rain leads into a compartment already containing the calculated amount of rainfall. Therefore, during an intense storm, some water may not be measured.

(2) Because the water surface exposed in a tipping bucket is relatively large, evaporation can occur. If the area is fairly hot, the evaporation losses can be large.

(3) Due to the discontinuous nature of the record, the gage is unsatisfactory during light drizzle or rain because the times of the beginning and the ending of such precipitation events cannot be accurately determined.

(4) Due to the small diameter opening that drains the collector funnel, the funnel often becomes clogged with debris. Water frequently builds up in the collector, resulting in the loss of record.

(5) Because of the nature of the gage, it cannot accurately record snowfall. 
In the float-type gage, rain passes into a chamber containing a light float. Vertical movement of the float as the level of the water rises then is transmitted by a suitable mechanism into a movement of a pen on a chart. By adjusting the dimensions of the receiving funnel, float, and float chamber, any desired scale value can be obtained.

This type of gage has been outfitted to a standard digital recorder used in surface-water data collection. Thus, the amount of water collected is stored on a 16-channel paper tape in any suitable time scale. This gage can be used for intensity information if the time scale is reduced to 5-minute punch intervals. The disadvantage of this type of gage is that it records continuously. In many arid areas, there can be a considerable amount of time given to translation and reduction of data with no recorded precipitation. Another problem with this gage is its susceptibility to freezing--in colder climates, it cannot be used during the winter months. Also, this type of gage is not useful for recording snowfall.

\section{Operation and Maintenance}

In the operation of a storage gage, the storage area should be charged with an oil-antifreeze solution, which will melt the snow and prevent the solution from freezing. In addition, the solution can help to preserve the catch by retarding evaporation. An automotive antifreeze can be used. To suppress evaporation, oil that allows easy passage of the precipitation, and at the same time completely covers the solution, can be used.

Observers for nonrecording gages should have onsite books to record the date, the time of observation, the depth of the water, and any remarks about the site or day. Before measuring precipitation in the 8 -in. nonrecording gage, the observer should remove the receiver. The depth of precipitation can be read to the nearest $0.01 \mathrm{in}$. The observer should empty the measuring tube, allow it to drain, and replace it. The water equivalent of samples of frozen precipitation is determined by melting each sample and measuring the liquid content or by weighing the frozen sample. Weighing the sample is the fastest and most accurate method of determining the amount of precipitation. A full discussion of servicing nonrecording gages is found in Brakensiek and others (1979).

In order to understand the maintenance of the weighing-bucket type gage, the manual that comes with the gage should be used, although an excellent discussion is given by Brakensiek and others (1979). It is important to point out that the gage dash pot should be filled with fluid. In most areas in the west, there is sufficient wind that the lack of damping action by this dash pot can cause severe vibration of the pen arm, destroying the precipitation record. Calibration should be done at least once a year, or more frequently. The pen should be checked so that a free-flowing ink is supplied to the chart. 
Charts should be changed on a recording gage in accordance with the timing mechanism. Before the chart is placed on the cylinder, it should show the proper station designation, the chart number, date and time of placement, and the name or initials of the observer. When removing a chart, the date and time also should be noted. If the recording gages are equipped with batteryoperated clocks, the battery voltage should be inspected.

It is important to process the charts as soon as they are received in the office. Visual editing of the charts and onsite notes helps to determine any periods of missing record or problems with the gage. Charts should be compared with charts from adjacent gages, and any discrepancies in either time or the amount of precipitation should be noted. Make annotations by transferring onsite notes directly onto the charts and by adding notes to aid in data tabulation. The charts become the primary level of data storage; sufficient information should be placed directly on these charts to aid in their interpretation.

The comments given for operation and maintenance of the weighing-bucket gages also can be made for any of the tipping-bucket and float-type gages. However, it is important that the time and date of the start of a period of data collection and the removal of that record be recorded. If the gage is run in conjunction with a runoff recorder, any discrepancies in time between the two gages should be noted.

\section{Snow-Pack Measurements}

Snow depths and water content represent a summation process through the accumulation period of winter. Therefore, several measurements made through this period may be related to other snow courses that have been operated for longer periods of time in adjacent areas. Snow courses operated by the U.S. Soil Conservation Service can provide data that can be related to an individual snow course fairly easily.

In establishing a network of snow courses, remember that the course is only an index with which to describe the amount of snow throughout the watershed. If there is a large change in elevation, the snow-course network must take that into consideration. If there is a variety of vegetation types, these types also need to be taken into consideration for the snow courses.

If a recording weighing-bucket gage is placed at a site, it may be desirable to place a snow course near the gage in order to estimate its catch efficiency. This comparison may serve as only a rough guide because the amount of water recorded in the snow pack may have losses due to sublimation, evaporation, and melting.

Snow courses should be inspected in the summer months with no snow on the ground so that the area can be cleared of fallen trees and limbs that would interfere with the snow measurements. Two pins of sufficient height, so that they are not buried in the snow, should be set at opposite ends of the course. The sequence for a measurement is to take a series of readings of depth of snow and water content along the course. 
The snow course is an index to the water content of the snow in the watershed. It may be desirable, during the peak of snow accumulation, to grid the watershed and take a series of measurements at each of the grid points. Such a sampling method helps to identify the variability of the snow pack throughout the watershed as related to the established snow courses.

Snow-course data provide information on depth, density, and water equivalent of the snow pack. Notes also should provide information on the condition of the ground, the type of snow, and the stream conditions that occur during the sampling, as used in the notebooks used by the Snow Survey Unit of the U.S. Soil Conservation Service.

Before going to the snow course, the scales should be tested, and the snow tube should be checked to be sure that the cutter is sharp and firmly attached. A light coating of paraffin on and in the tube helps to prevent the snow from sticking. Recommended sampling procedure is to cut a core with the snow tube and force the sampler downward until it reaches the ground. If conditions permit, the core should be taken with a steady downward thrust with some clockwise turning through its layers. The cutter should normally penetrate the ground; a trace of ground litter or a small amount of soil in the end of the core indicates that a complete core has been obtained.

There is a place in the measurement notes to indicate whether this soil core is dry, moist, or frozen. When the tube has penetrated below the ground, the outside of the tube can be read for snow depth. When pulling the tube from the snow, the slots in the side allow observation to see if the core is one continuous piece. The soil plug can be removed with a knife and the core weighed to determine the water content. A series of measurements taken along the course are usually averaged to obtain one reading for the amount of water in the pack for that particular course. The density of each sample should be observed and compared with the other samples along the course. Large variations in density for individual samples may indicate a poor sample. An additional check on each sample should include an inspection of the core in the tube that should be about the same length as the measured snow depth.

There are several recording snow gages available. One, the snow pillow, is a large flat rubber pillow, generally $12 \mathrm{ft}$ in diameter and 9 in. thick, or thin sheets of steel welded together. The snow pillow, filled with a mixture of methyl alcohol and water, is attached to an instrument that records the pressure changes that occur when snow accumulates on the surface.

Another recording gage uses the gamma-ray method for measuring snow density. The measurement of snow density with radioactive isotopes depends on the attenuation of gamma rays traversing a medium. The attenuation is a function of the energy from the source and the density and thickness of the substance traversed. Because a high source of gamma radiation is required, cobalt/60 and cesium/137 are frequently used.

The water quality of the snow can be obtained in a manner similar to making snow measurements with a snow tube. The major concern is to use a tube that will not contaminate the sample being collected. Also, care must be exercised not to include vegetation or soil in the sample. A sufficient amount of snow must be collected that, when melted, will yield enough water for analysis in the laboratory. 


\section{GROUND WATER}

The depositional environments of coal areas in the central-western United States frequently contain ground water. Generally, the stratigraphy in the coal areas is made up of an interbedded sequence, such as sandstones, shales, and coal. These units may exhibit a multitude of lithologic variations that affect the hydrogeologic properties of the rocks. In addition, specific units may become thicker or thinner, may split, or may pinch out.

Each of the above-mentioned geologic units has the potential to contain water. Shales often will act as confining or semiconfining layers. Depending on the degree of cementation and other factors, sandstones may contain and transmit a large amount of water. In many areas, fractured coal may be the best aquifer.

Mine operators are required to evaluate the hydrogeologic regime at their mine sites. The U.S. Office of the Federal Register (1985) defines the minimum ground-water requirements as follows:

"The location and ownership for the permit and adjacent areas of existing wells, springs, and other ground-water resources, seasonal quality and quantity of ground water, and usage. Water quality descriptions shall include, at a minimum, total dissolved solids or specific conductance corrected to $25^{\circ} \mathrm{C}, \mathrm{pH}$, total iron, and total manganese. Ground-water quantity descriptions shall include, at a minimum, approximate rates of discharge or usage and depth to the water in the coal seam, and each water-bearing stratum above and potentially impacted stratum below the coal seam."

The following discussion is intended to acquaint mine operators with a variety of accepted procedures for assessing the hydrogeologic characteristics of a mine site. The methodology discussed is meant to act as a guideline. Equally acceptable approaches and new methodology should not be ignored. In addition, innovative approaches to unique problems may be necessary.

\section{Ground-Water Flow Systems}

Recharge Areas, Discharge Areas

The general nature of ground-water flow systems must be understood prior to any assessment of the ground water at a potential mine site. The groundwater flow system is a subcycle of the hydrologic cycle. Recharge areas are the zones where water enters the ground-water system, and discharge areas are the zones where water leaves the ground-water system.

The following discussion relies heavily on material taken from Freeze and Cherry (1979). For a more comprehensive discussion of the material, their text is highly recommended. 
Freeze and Cherry (1979) state that "A recharge area can be defined as that portion of the drainage basin in which the net saturated flow of ground water is directed away from the water table." Direct precipitation and surface runoff are the major sources of recharge in many areas.

Freeze and Cherry (1979) state that "A discharge area can be defined as that portion of the drainage basin in which the net saturated flow of ground water is directed toward the water table." Springs, streams, seeps, and lakes can all be points of discharge.

\section{Factors That Control Direction of Flow}

The direction of flow, simply stated, is from the area of recharge to the area of discharge. The direction of flow may be affected by factors such as topography, transmissivity, and structure.

A relatively flat topography, such as in a plain, will tend to produce a regional ground-water flow system. A more varied topography, such as mountainous terrain, will result in more localized flow systems. Between the extremes of an all-localized flow system and a regional flow system will be many gradations of intermediate flow systems. A representation of these systems is shown in figure 4. The flow lines are not graphically or mathematically exact, but they do represent the general direction of flow.

Transmissivity is a measure of the ease with which water moves through an aquifer. The higher the transmissivity, the more easily water will move through the ground-water system. A zone of low transmissivity, such as a clay layer, will tend to inhibit ground-water flow in an area. A zone of higher transmissivity, such as a sand layer, will facilitate flow from an area. In a homogeneous, isotropic geologic system, the topography can have a marked influence on the flow system, and ground water will tend to flow from areas of high topography toward areas of low topography. However, if a vertical variation in transmissivity is introduced into the system, the flow characteristics can change. For instance, if an area of large transmissivity underlies an area of small transmissivity, then regional ground-water flow can develop in spite of the topographic controls or influences.

Structure is "wis the sum total of the structural features of an area *-*:" (American Geological Institute, 1976). Structural features are "ist: features produced in the rock by movements after deposition, and commonly after consolidation, of the rock W-'s" (American Geological Institute, 1976).

The direction of ground-water flow through an aquifer may be abruptly halted by the presence of a fault. The resulting surficial display of the flow interruption may be a spring or seep. Anticlines, synclines, and folds are types of structural features that can influence the direction of groundwater flow and, hence, the areas of recharge and discharge. 


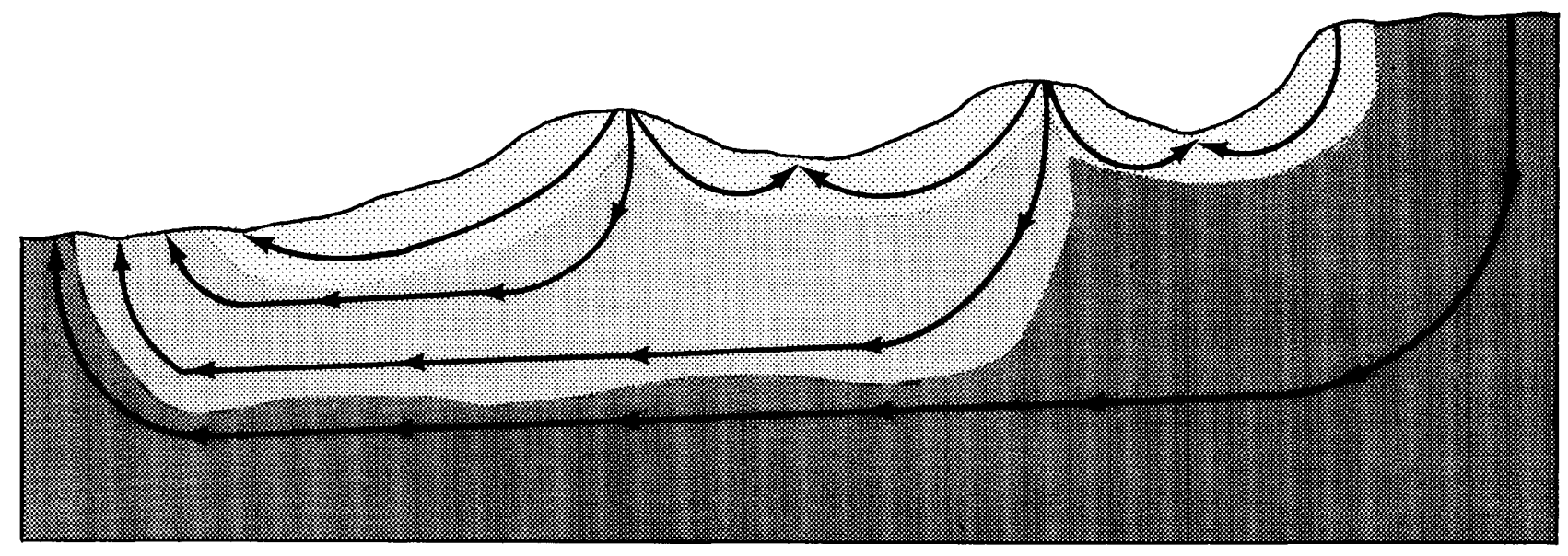

EXPLANATION

SYSTEM OF GROUND-WATER FLOW

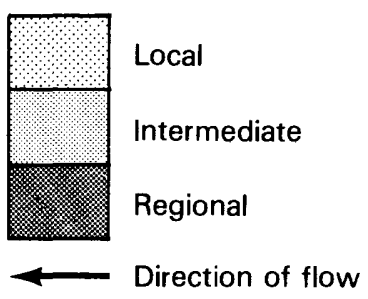

Figure 4.--Effect of topography on ground-water flow system. 
A knowledge of the factors that control ground-water flow can be supplemented with additional information to define the flow system in the area of interest. Recharge and discharge areas can be mapped with five indicators: (1) Topography, (2) piezometric pattern, (3) hydrochemical trends, (4) environmental isotopes, and (5) soil and land surface features (Meyboom, 1966; Tóth, 1966).

The influence of topography has previously been discussed. Basically, upland areas are areas of recharge, and lowland areas are areas of discharge.

Piezometric patterns show that downward flow gradients are representative of areas of recharge, while upward flow gradients are representative of areas of discharge.

Dissolved solids is an example of a hydrochemical trend. The area of recharge will have a lower dissolved-solids concentration than the area of discharge.

Environmental isotopes, such as tritium $\left({ }^{3} \mathrm{H}\right)$ and carbon-14 $\left({ }^{14} \mathrm{C}\right)$, can be used to identify the direction of ground-water flow and the age of the ground water. These isotopes also can be used to gain information on the velocity of flow.

Observation of soil and land surface features can often be a quick and inexpensive way to identify discharge areas. Hydrochemical trends indicate that areas of discharge may have saline water. Therefore, saline soils and phreatophytes can be indicators of discharge areas.

\section{Site-Selection Criteria}

The first vital step in ground-water investigations is to obtain existing publications and maps that relate to the area of interest. These will help in selecting drilling locations where the most information will be obtained for the least cost. Numerous geologic, topographic, hydrologic maps, and water-supply reports published by the U.S. Geological Survey and State, local and private sources give information about specific areas. These reports and maps list professional papers, bulletins, water-supply papers, maps, miscellaneous investigations, and other information. These publications also generally list numerous references that provide supplementary material.

The observation-well drilling program should be planned to obtain optimum hydrologic information. The observation-well site selection will be determined by many factors, such as use of the well, number of wells to be drilled, variation in geologic structure, variations in topography, variation in hydrogeologic properties, variations in hydrologic setting, and location of existing wells. The wells need to be established for all significant aquifers so that aquifer tests and water-level monitoring can be done. Additionally, groups of piezometers need to be installed in recharge and discharge areas to define vertical and horizontal components of flow. 
An idealized mine site is depicted in figure 5. We1ls are located around and within the area to be mined and are completed in different zones. This allows monitoring of inflow to the mine site and outflow from the mine site for each aquifer that potentially will be influenced by mining. The cross section along the edge of figure 5 shows the mine-site stratigraphy. The information obtained from the wells can be used in a number of ways to aid in the interpretation of the hydrogeologic system. For instance, geologic sections and fence diagrams or three-dimensional depictions of an area can be drawn. The well information also facilitates the determination of the dip and slope of stratigraphic units.

Once water levels have been measured in the wells, the slope of the potentiometric surface can be defined. By comparing a water level with the position of strata in the geologic cross section, it may be determined if the aquifer is confined. For instance, if the well is completed in a coal seam $100 \mathrm{ft}$ below the land surface, and the water level is $75 \mathrm{ft}$ below the land surface, then water in the coal may be confined.

\section{Well Drilling}

Numerous books are available that offer in-depth discussions of equipment available for drilling wells. These books include "Ground Water and Wells" (Universal Oil Products, Inc., Johnson Div., 1975), "Ground Water Manual" (U.S. Bureau of Reclamation, 1977), and "Hydrogeology" (Davis and DeWiest, 1966).

The direct-circulation rotary method of drilling wells is very popular. A drill bit at the end of the drill stem breaks up the material being drilled. Air, mud, or some other agent capable of lifting the fragments is forced down through the center of the drill stem and up through the borehole annulus. Drilling mud or other agents help to seal the borehole wall during drilling in order to maintain circulation and reduce the loss of drilling fluid to fractures or permeable zones. The drilling fluid must be cleaned from the well and the walls of the well when drilling is completed; otherwise hydrologic and chemical properties of aquifers can be affected. The main drawbacks to direct-circulation rotary drilling are that it is expensive and it can require considerable amounts of water. The major advantages of the method are that it is fast, deep holes can be drilled, and it does not require that the hole be cased during drilling.

Another method of drilling is the cable tool method. A tool that is suspended on a cable is raised and dropped to the bottom of the drill hole. This action breaks up the material so that it can be removed from the borehole by a bailer. The main drawbacks to this type of drilling are that it is slow and may be limited to depths of $2,000 \mathrm{ft}$ or less. This depth limitation should not be a problem near surface mines. It also may be necessary to use casing when drilling under certain conditions. The advantages to the method are that it is less expensive and it uses less water than rotary drilling. The cable tool rig also is capable of successfully drilling holes under a wide range of conditions. 


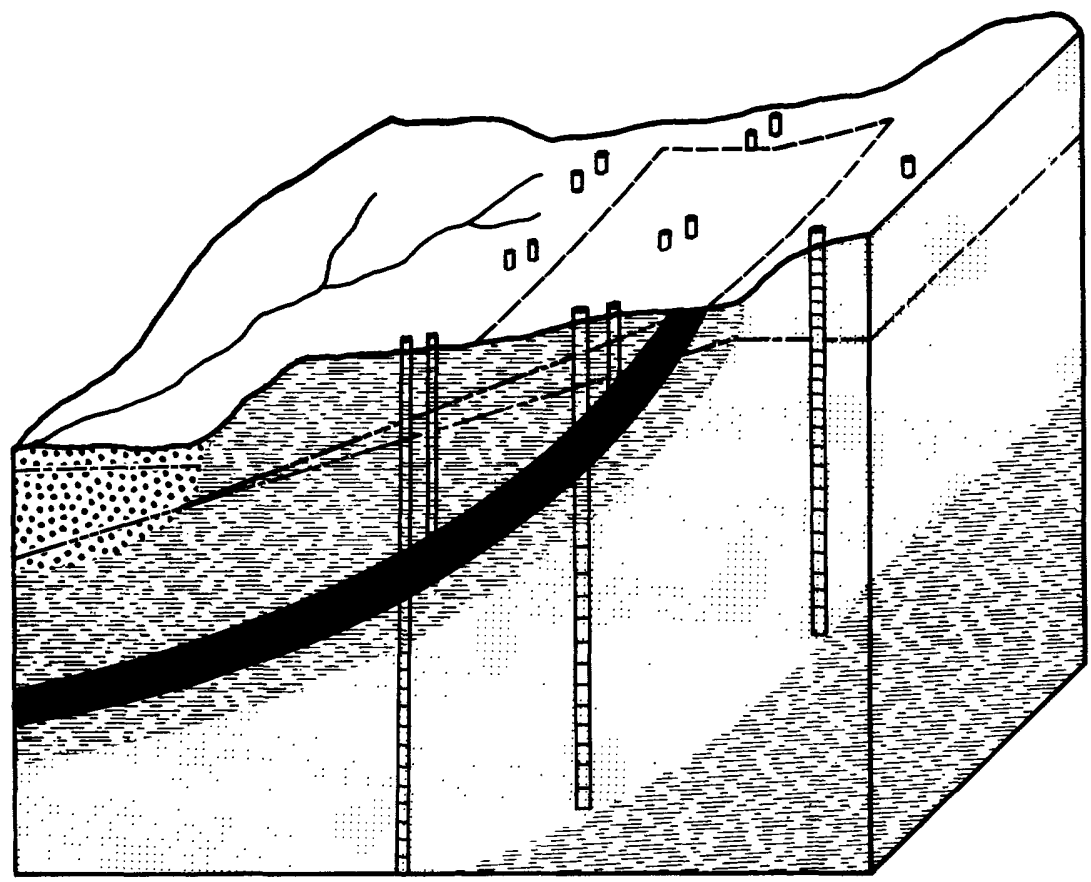

EXPLANATION

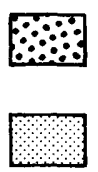

ALLUVIUM

SANDSTONE

SHALE

COAL

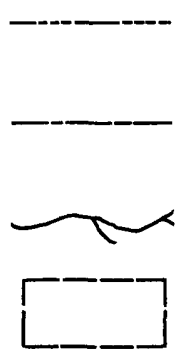

PIEZOMETRIC SURFACES

WATER TABLES

STREAM CHANNEL

MINE AREA
WELL COMPLETION

IN GEOLOGIC SECTION

ZONE OF COMPLETION

WELLS AT

- $\square$ LAND SURFACE

Figure 5.--Idealized geologic section and ground-water observation wells at a surface mine site. 
Augering is a third method of drilling wells. Auger rigs may range in size from a large rig with a hollow-stem auger to a small truck-mounted rig. The auger tip breaks up or loosens the formation material, which then is moved up the fins of the auger to the surface. The drawback to augers is that they are limited in the depth they can drill. If coring is not used, identifying the point of stratigraphic change may be less accurate than by other drilling methods. Also, in permeable, saturated alluvium, there often are no cuttings brought to the surface from below the top of the water table. The auger rigs are inexpensive, use little to no water, and are easy to transport. These rigs can be quite useful for drilling shallow holes in alluvium or other loosely consolidated materials.

There are many other types of drilling methods. Often these methods are similar to the techniques just described. There are tradeoffs in expense, time, site accessibility, manpower, and accuracy of hydrogeologic interpretation for each drilling technique. Also, the type of material to be drilled, the presence of aquifers, and the maximum depth of drilling will influence the selection of drilling equipment. The needs of each drilling project must be determined before a drilling method is chosen.

\section{We11 Development and Completion}

Proper development of the well can have a significant influence on the quality of hydrogeologic information obtained. The purpose of well

development is to minimize any detrimental effects drilling and casing a well may have had on the aquifer. Generally, well development consists of pumping and surging air or water in the well. Chemical additives are used at times. Both the "Ground-Water Manual" (U.S. Bureau of Reclamation, 1977) and "Ground Water and Wells" (Universal Oil Products, Inc., Johnson Div., 1975) have chapters that discuss the need for, and problems concerning, well development.

One of the most important steps in evaluating the hydrogeology of an area is the proper completion of a well. If the well is not completed properly, the hydrologic data gathered may be so seriously in error that the data have little practical meaning.

All significant aquifers in the vicinity of the mine should be identified and their hydrogeologic properties determined. Recharge, discharge, and direction of flow should be determined for all aquifers.

To obtain information concerning individual aquifers, it is necessary to place casing with openings only in these zones. Then the open section of pipe and the aquifer of interest should be isolated from other geologic units and aquifers. Various types of packers are available that will serve this purpose.

This isolation of individual aquifers is extremely important if any useful information about the aquifers is to be obtained. With an open-hole completion or one where the water from all aquifers is free to intermix, interpretation of hydrogeologic properties becomes very difficult, if not impossible; head differences cannot be determined, aquifer test results are questionable, and water chemistry is uncertain. 
The type of openings in a well casing should be carefully chosen, depending on the use to be made of the well. If the well is going to be used only to monitor water levels, then expensive well screen or extensive slotting or perforating usually is not necessary. The openings need only be numerous and large enough to allow response to the expected ground-water fluctuations. The well need only be large enough to allow a measuring device to be lowered unobstructed into the well. For a well fitted with a recorder, the well diameter will influence the type of recording system. Generally, a 4-in. diameter well will be adequate for most recorders.

If the wells are going to be used to evaluate hydrologic and chemical properties of the aquifer, then casing is needed that will allow water to pass rapidly through the openings. Well screen often is better suited than slots or perforations for obtaining accurate data.

It also is necessary to use a casing large enough in diameter to provide adequate clearance between the walls of the casing and a pump. Submersible pumps are often 3 in. or greater in diameter. If the pump is too close to the walls of the casing, the flow into the pump can be restricted. Therefore, the inside diameter of the well casing should be at least 1 in. greater than the outside diameter of the pump being used in a pump test.

The type of geologic material surrounding the well openings also will influence the size of the opening. A smaller opening will be necessary for fine materials, while a larger opening may be acceptable for coarser materials.

If casing strength is a consideration, then steel casing should be the first choice, followed by fiberglass and plastic. However, steel casing can add metals to the water and thus contaminate the water sample. Therefore, fiberglass casing or plastic casing should be used if water samples are to be obtained for inorganic chemical analysis.

\section{Borehole Logging}

\section{Geologic Logs}

Aquisition of a good geologic $\log$ is a highly important step toward proper interpretation of the hydrogeologic system. The more descriptive the log the more useful it will be for mineral-resource and hydrogeologic evaluation. Logging the drill hole from cuttings is less expensive than coring the hole. However, the information obtained is usually less precise. Siegel (1980) notes the following points as major problems:

(1) There is too little time to record all the data. This is especially true under adverse weather conditions, when writing is difficult.

(2) Identification of materials drilled is uncertain. This is especially true when drilling through fine sediments that disaggregate and cannot be distinguished from the drilling mud.

(3) Different workers record items in different sequence. This makes the search for specific information in old logs tedious and difficult. 
To assist the logger in overcoming these problems, Siegel has proposed a standardized form and guidelines for its use (fig. 6). To get the most use from the cuttings, they should be collected over 3- to 5-ft intervals or at stratigraphic changes, whichever comes first. This will facilitate stratigraphic definition by reducing mixing of the cuttings. The drill-rig operator often can help the logger locate stratigraphic change by telling him when there is a change in the rate of drilling.

Cored samples can be very helpful in interpreting the hydrogeologic properties of rocks if care is taken in obtaining the samples. Once the sample is obtained, the degree of expertise of the onsite geologist will influence the quality of the information gained from the onsite log. Additional evaluations of the core $\log$ can be made in the laboratory if the cored samples are properly prepared onsite.

Although written primarily for the petroleum industry, both "Coring and Core Analysis Handbook" (Anderson, 1975) and "Subsurface Geology" (Leroy and Leroy, 1977) are useful guides for obtaining maximum information from geologic logs. The "Manual of Field Geology" (Compton, 1962) also is a very helpful onsite reference.

\section{Geophysical Logs}

Geophysical logs add valuable information to the understanding of the hydrogeology of an area. Data from geophysical logs readily supplement information gained from geologic logs. Furthermore, geophysical logs can provide information that may have been omitted from the driller's log or can supply data that are not available from geologic logs.

A wide variety of geophysical $\operatorname{logs}$ is available. Logs that are commonly run are natural-gamma, gamma-gamma, neutron, resistivity, spontaneous potential, caliper, and temperature. These logs are made by lowering the probe down a cased or an open drill hole. The response then is recorded on a chart or other recorder as the probe is raised from the bottom of the drill hole to the surface. Some of the hydrogeologic properties that can be identified with geophysical logs are listed in table 3 . Geophysical logs are discussed in many books and articles (Keys and MacCary, 1976; Fetter, 1980; Davis and DeWiest, 1966).

Surface geophysics may prove to be a valuable tool for selecting a well location. Once a first well is drilled, the geologic log and subsurface geophysical logs should be used to calibrate the surface geophysical information. Surface geophysics then can be used with increased confidence to pick additional well sites nearby where geologic conditions are similar. The feasibility of using surface geophysics depends on distinct variations in earth properties and noncomplex spatial distribution of the geologic units. Davis and DeWiest (1966) discuss these ideas as well as methods of measurement. Zohdy and others (1974) also discuss surface geophysical methods at length and provide a bibliography on specific topics. 


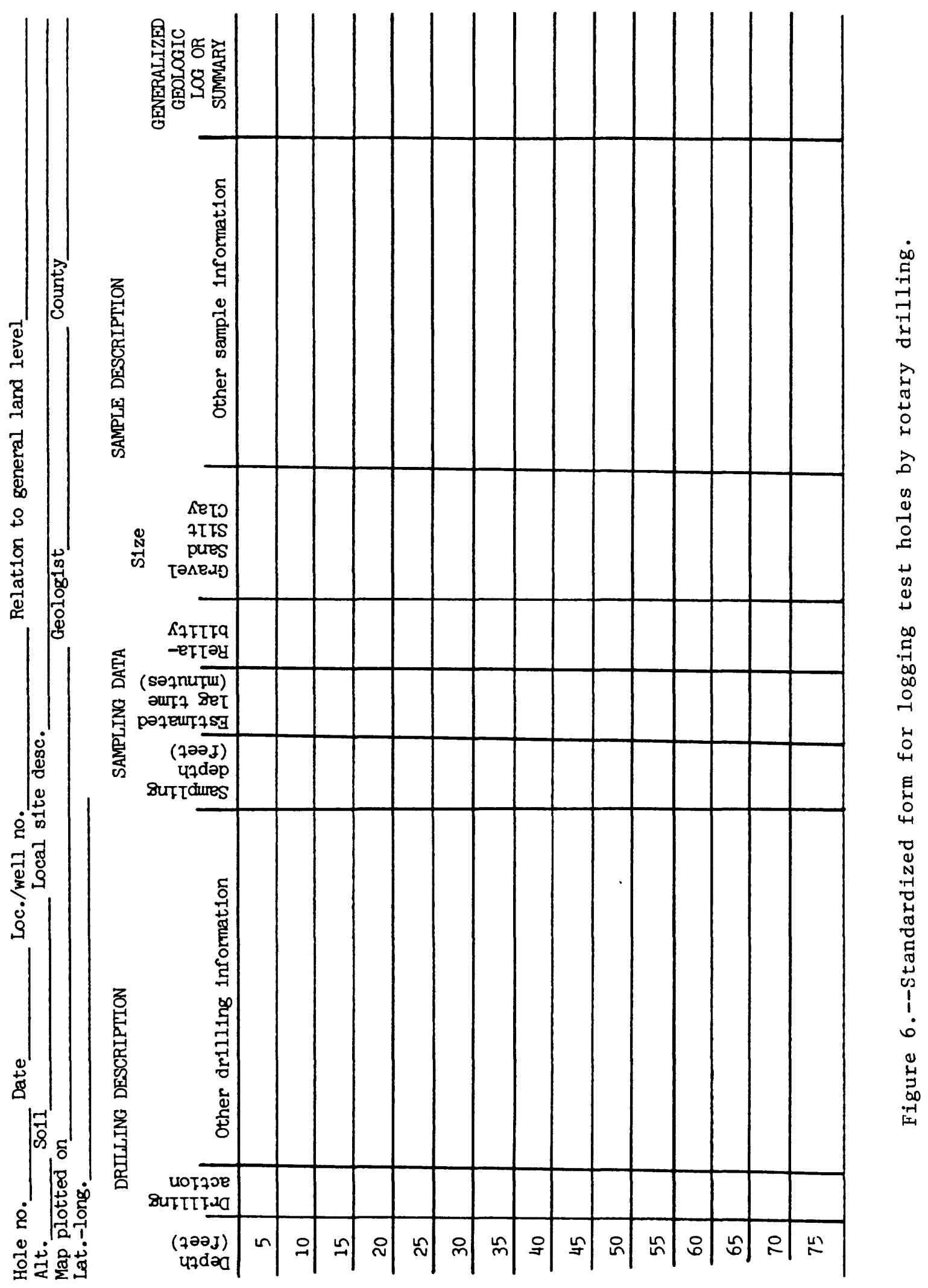




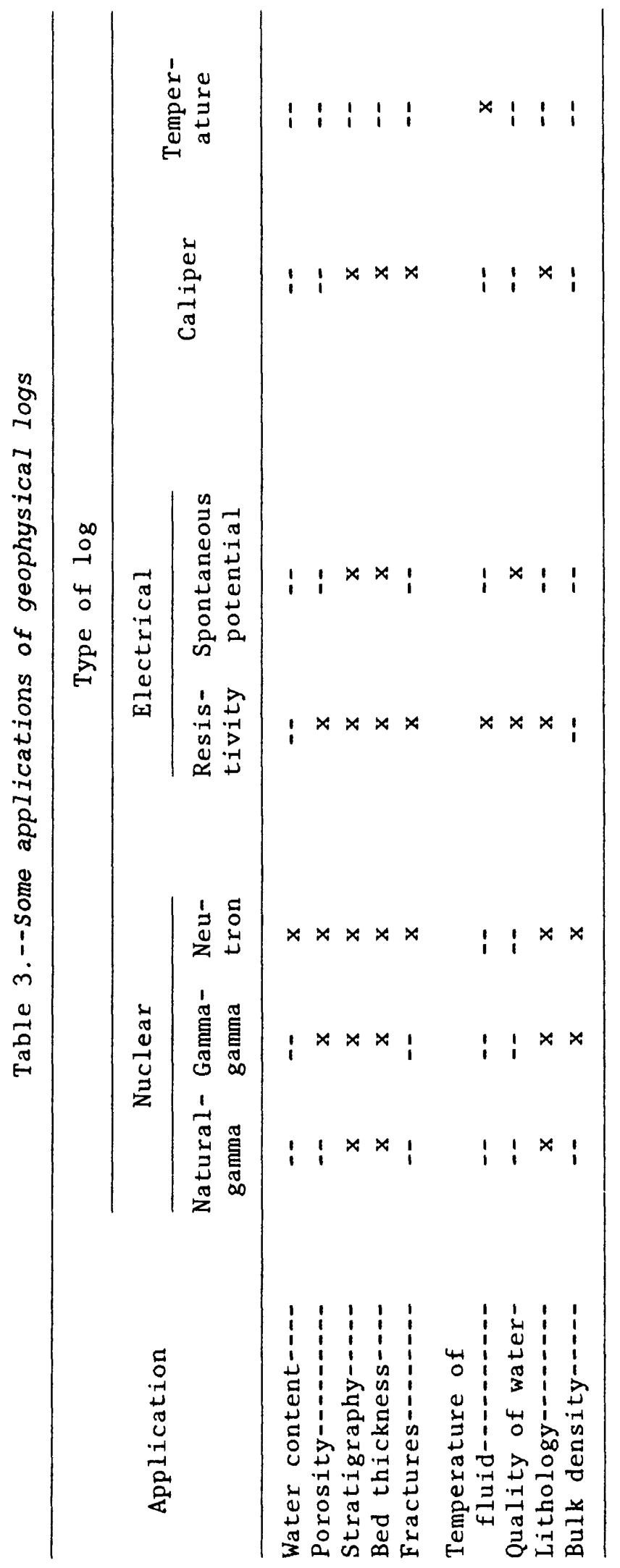


Water Levels in Wells

A steel tape or an electrical contact type of monitor normally is used to measure water levels in wells. The steep tape is chalked and lowered into a well so that the end of the tape is a few feet below the water level. The difference between the point at which the chalked tape is wet and the reading on the tape at the land surface is the depth to water.

The sensor on the electrical contact type of monitor is lowered into the well, and when the sensor touches water, a needle deflects on a gage on the monitor. The depth to water then can be read on the electrical cable at the point of the land surface.

In some cases, it may be desirable to have a continuous record of water levels. Changes in water level often are monitored with either a float or a transducer. Either analog or digital recorders may be used to record water levels. The Water Measurement Manual (U.S. Bureau of Reclamation, 1967) discusses various types of recorders that can be used to monitor changes in ground-water levels.

\section{Aquifer Tests}

Numerous books and articles have been written on methods to evaluate aquifer characteristics. In addition, new methods to improve the assessment of ground-water resources are continually being investigated. Ground Water, Water Resources Research, and Water Resources Bulletin are three of the many periodicals that report the latest investigations in ground-water research. Many texts also give information on ground-water theory and methodology. Following are the names of a few of the many texts available: "Ground-Water Hydrology and Hydraulics," by McWhorter and Sunada (1977); "Groundwater," by Freeze and Cherry (1979); "Groundwater Resource Evaluation," by Walton (1970); and "Hydrogeology," by Davis and DeWiest (1966). Each of these books is slightly different in its approach to the analysis of ground-water systems and, therefore, will give the reader different ideas and viewpoints.

Aquifer tests are a standard means of evaluating hydrogeologic properties of aquifers. Generally one well is used as a pumping well and one or more additional wells are used as observation wells. McWhorter and Sunada (1977) note a number of worthwhile considerations to take into account before beginning aquifer testing.

The tests will give information on the transmissivity $(T)$ of aquifers.

$$
T=K \cdot b,
$$

where: $T=$ transmissivity (length ${ }^{2} /$ time ),

$K=$ hydraulic conductivity (length/time), and

$b=$ saturated thickness $(b=$ length $)$. 
The storage coefficient $(S)$ also can be determined from aquifer tests where:

$S=1 * * *$ : The volume of water an aquifer releases from or

takes into storage per unit surface area of the aquifer

per unit change in head *trk" (Lohman, 1972, p. 8).

Two methods commonly used to evaluate $T$ and $S$ are the Theis method and the Jacob method. Both of these approaches are discussed at length in the previously mentioned texts. Briefly, the Theis method makes use of a type curve $[$ abscissa $=u$, ordinate $=W(u)$ ] where:

$$
\begin{aligned}
u & =\text { Boltzman variable }=\frac{r^{2} S}{4 T t} \text { (Dimensionless), and } \\
W(u) & =\text { well function of } u
\end{aligned}
$$

overlain by a plot of $r^{2} / t(r=$ the distance between the observation well and the pumped well, $t=$ time since start of pumping) versus drawdown ( $s$ ) (abscissa $=r^{2} / t ;$ ordinate $\left.=s\right)$. Both curves are plotted on the same scale log-log paper. The curves are superimposed and any arbitrary match point on the type curve is chosen. Values for $W(u)$ and $u$ then are determined. Standard tables for plotting $u$ versus $W(u)$ are available in many texts.

Transmissivity can be computed once $W(u)$ is found.

$$
T=\frac{Q}{4 \pi s} W(u),
$$

where: $Q=$ well discharge $\left(\frac{L^{3}}{t}\right)$,

$$
\begin{aligned}
s & =\text { drawdown }(L), \text { and } \\
W(u) & =\text { well function of } u .
\end{aligned}
$$

The storage coefficient is calculated from $u$.

$$
s=\frac{4 T t u}{r^{2}}
$$

where: $t=$ time from start of pumping, and

$r=$ distance from observation well to pumping well $(L)$ (radial distance).

Other symbols are as previously defined. 
When the Jacob method is used, the data from each well are plotted on semilog coordinate paper. Values of $t$ are plotted on the log scale and values of $s$ on the arithmetic scale. The plot should approximate a straight line when the value of $t$ becomes large. Transmissivity then is related to the slope of the line,

$$
T=\frac{2.30 Q}{4 \pi \Delta s / \Delta \log t}
$$

where $\Delta s / \Delta \log t=$ drawdown per log cycle of time. The storage coefficient is found by extrapolating the straight line of plotted data to the time $\left(t_{0}\right)$ at which drawdown is zero,

$$
s=\frac{2.246 T t_{0}}{r^{2}} .
$$

All terms are as previously defined.

The Theis method and the Jacob method also can be used if there is no observation well. Drawdown is measured in the well being pumped. However, for this approach only transmissivity can be determined, since $r$ (distance from observation well to pumping well or radius of pumped well) cannot be accurately determined.

If the saturated thickness of the aquifer is minimal or if the aquifer is of low permeability, the Theis or Jacob methods may give erroneous results, since the well may be pumped until it is close to being dry. Thus, discharge $(Q)$ and drawdown ( $s$ ) may be affected, and the calculated transmissivity will be in error.

In lieu of an aquifer test, a slug test may be performed. A slug test is an instantaneous injection or removal of a known volume of water. This is a method for evaluating aquifer properties when only one well is present, when the saturated thickness is minimal, or when the aquifer is of low transmissivity.

The slug method is primarily designed for fully screened wells penetrating confined aquifers of low transmissivity. If the test is used for other aquifer conditions, the results of the test may be questionable. The procedure for finding the transmissivity by the slug method is described by Cooper and others (1967) and also is stated by Lohman (1972). For additional discussions on slug tests, refer to Papadopulos and others (1973). The storage coefficient can be determined by the slug method, but the value found may not be accurate (Cooper and others, 1967). 
Representation of Water-Level Data

Davis and DeWiest (1966) discuss at length the presentation of waterlevel data on maps and graphs. The following discussion highlights some of the points Davis and DeWiest discuss in their book "Hydrogeology."

Water-level data can be presented with water-level contour maps, water-level change maps, depth to water maps, and well hydrographs. If water levels accurately represent the true water table, then contour maps of the water table can be drawn (fig. 7). Lines drawn perpendicular to the watertable contour lines represent the direction of ground-water flow. The watertable contours also can be used to show areas of recharge, such as an upland area (point $A$ in fig. 7); areas of discharge, such as a pumping well (point B in fig. 7); and areas where the aquifer may be recharging a stream (point $C$ in fig. 7).

Water-level change maps can be useful in determining local areas of recharge and discharge and the magnitude of change in these areas. A depthto-water map can be quite useful for determining the depth at which water will be encountered when mining begins in an area.

Well hydrographs can be used to show both long-term and short-term trends in aquifers. The trend information can be used to help project mining impacts on the hydrologic system.

The Site-Selection Criteria for Ground-Water Wells section pointed out the importance of completing wells in one, and only one, aquifer. The maps for presenting water-level data will have little value if the wells are completed in more than one aquifer, or if there is no distinction between water levels of different aquifers (fig. 8).

\section{SEDIMENT}

Before a discussion of sediment data-collection procedures is begun, it is important to define a few terms. It is possible to categorize erosion in numerous classes. For the purposes of this report, only the two categories of geologic erosion and accelerated erosion will be defined. Geologic erosion is the erosion of the Earth's surface under natural or undisturbed conditions. Geologic erosion is highly variable throughout the United States and is primarily dependent on the geology, the climate, and the vegetative conditions of an area. It may be important in the network design to quantify the geologic erosion of the particular area of interest.

Accelerated erosion is the increased rate of erosion over geologic erosion that is brought about by man's activity (Vanoni, 1975, p. 3). Such activity may be from modification of the landscape (either hillslopes or channels), but it also is possible to change erosion rates in subtle ways (for example, by modification of the weather through cloud seeding). Man's impact on erosion rates may appear subtle; sorting out different impacts from man may be extremely difficult. 


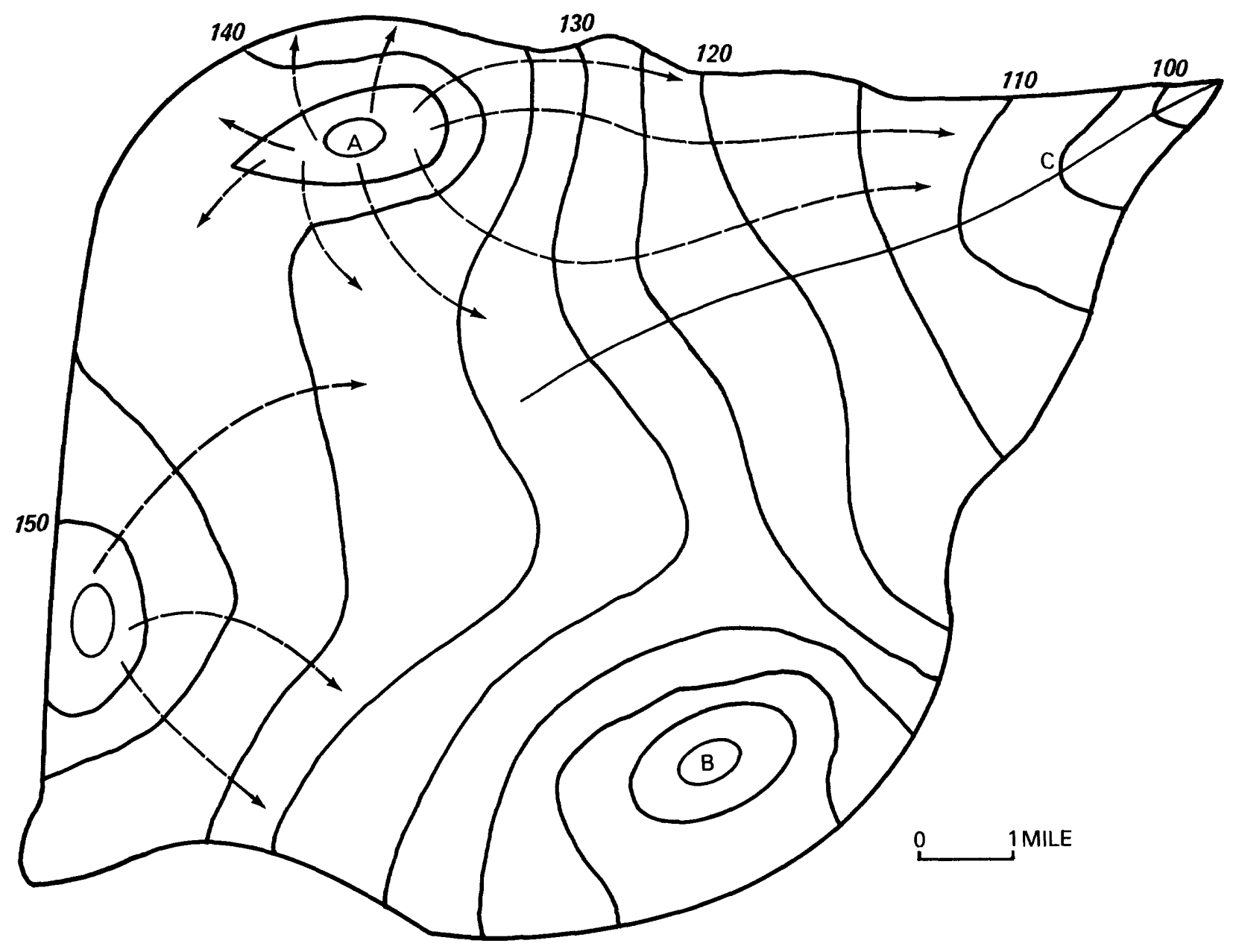

EXPLANATION
A RECHARGE AREA
WATER-TABLE CONTOUR INTERVAL IS 5 FEET
B DISCHARGE AREA
BOUNDARY OF BASIN
C AQUIFER RECHARGING
GROUND-WATER FLOW DIRECTION
THE STREAM

Figure 7.--Contour map and direction of flow for an idealized ground-water basin (modified from Davis and DeWiest, 1966, p. 49). 


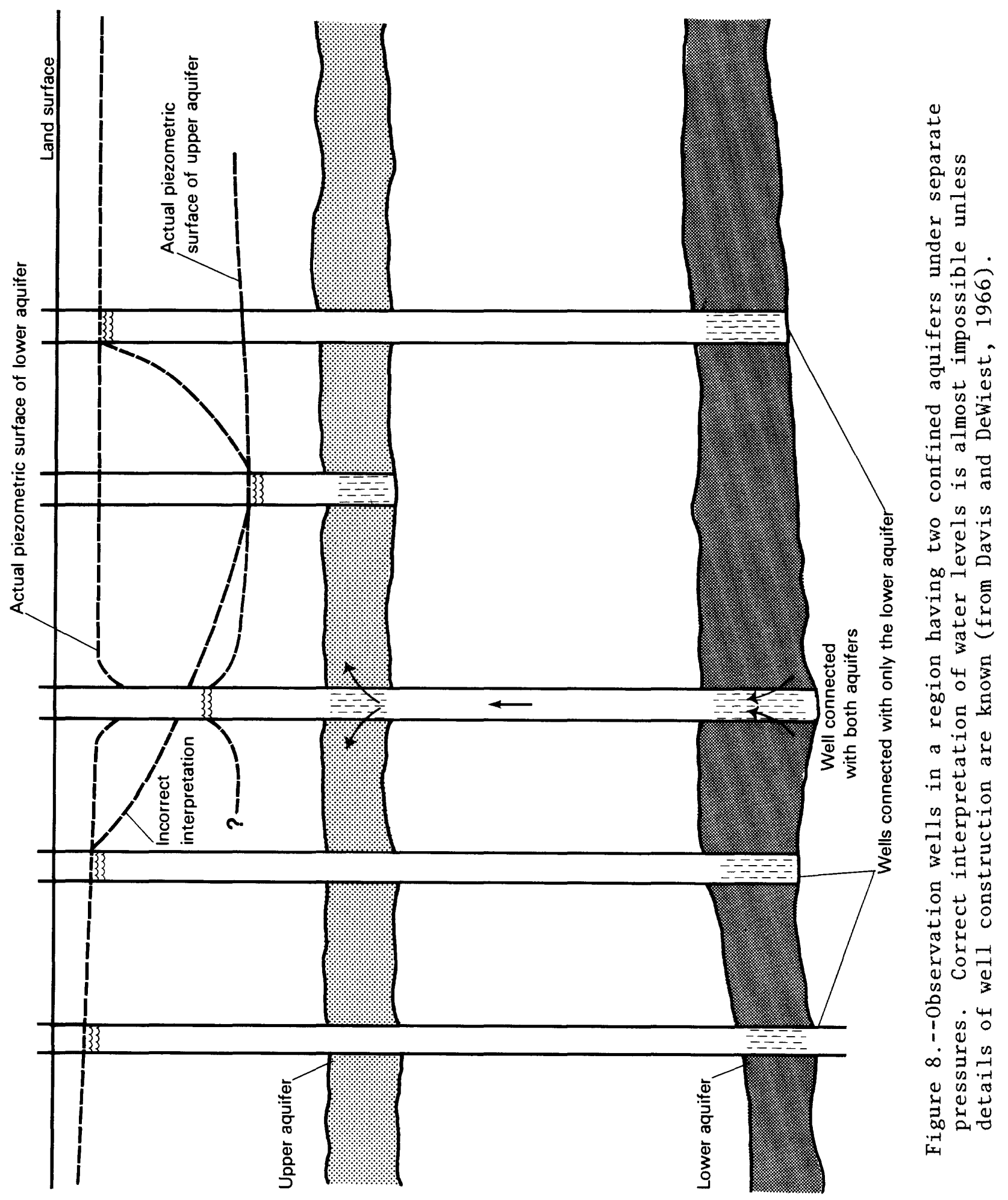


It is important to separate upland erosion and subsequent sediment yield from channel erosion and sediment yield. Erosion, entrainment, transport, and deposition work in both the uplands and in the channel, but the independent variables affecting these processes are quite different.

Sediment production is the amount of onsite eroded material over the whole basin for a given period. Sediment yield is the total sediment outflow from a basin at a specific point over a given time. The sediment-delivery ratio is a measure of the reduction in eroded sediment, by deposition, as it moves from the point of erosion downstream (Vanoni, 1975, p. 438). The delivery ratio can be expressed as a percentage by a ratio of sediment yield to sediment production.

Although sediment production can be estimated, data collection is expensive and very laborious. Sediment production comes from two sources: (1) Upland erosion, and (2) gully migration and modification. Measurements of these two sources are difficult. On the other hand, the calculation of sediment yield in a cross section of the stream is much easier.

In a cross section of a stream, the total load will be defined as consisting of two parts: (1) The bedload is defined as material moving on or near the bed; and (2) the suspended load is defined as material carried in the main body of the flow by upward components of turbulence and left in suspension for considerable distances (Vanoni, 1975, p. 17-18). These two categories are difficult to separate in the actual physical system, but they do provide a basis for discussion of sediment sampling.

It is important to make a distinction between bedload and bed material. Bedload is the material moving on or near the bed. Bed material is simply the material on the streambed and has no connotation of time.

To measure sediment load in a stream, one must be conscious of the fact that the load is highly variable in time. On many streams, only two or three storms in a year may account for greater than 90 percent of the yearly sediment load. Thus, if the load during these several storms is sampled sufficiently, most of the load for the year can be determined. Periodic sampling during the remainder of the year will verify the movement of small sediment loads.

In addition, the position of the suspended-sediment concentration curves can be highly variable relative to a given storm hydrograph. For example, suspended-sediment concentration curves can precede, coincide with, or lag the discharge hydrograph (Porterfield, 1972, p. 21-23). The timing of the concentration curve and the hydrograph may be fairly consistent for a site, at least by season. Initial sampling, however, may have to be more intensive in order to identify the timing characteristics of the site.

Variability in a cross section at a site also is likely to be large for both suspended load and bedload. As an example, Guy (1970, p. 26) showed that the lateral variation of the sampled suspended-sediment concentration at an $85-\mathrm{ft}$ cross section of the Middle Loup River at Dunning, Nebr., ranged between 400 and $2,000 \mathrm{mg} / \mathrm{L}$. Generally, a sampling scheme is used in which 
multiverticals are sampled by methods described in the Sediment-Sample Collection section. Use of a single vertical requires that periodic comparisons be made with multivertical sampling in order to establish a relationship to the entire cross section.

Variability in sediment concentration exists in a vertical at a sampling station. Variability in the vertical is dependent on the hydraulics at the site and the size distribution of the sediment. In general, concentration increases from the water surface to the channel bed.

\section{Network Design}

Surface-water characteristics are important in designing a network for sediment sampling. Streamflow is the driving force for sediment movement in the channel. Because sediment sampling is expensive, it is imperative that site selection provide the necessary information with the least number of sampling sites.

Changes in sediment yield are closely related to the geology and land use of an area. Climate may be regarded as a constant if the area under investigation is not too large. Network design should index the variety of geologic formations and land uses in the area.

Appropriate sites may dictate the network design for sediment sampling more than they do for streamflow. The important time to be sampling is generally during high-water periods. Access to the stream and the ability to sample across the stream during these high-water periods are important. Thus, bridges may be important sampling sites.

\section{Site-Selection Criteria}

If a particular site is chosen to be a sediment-sampling site, water discharge also will have to be obtained. A good site for water discharge is one with a downstream station control. Therefore, the gaging site is generally in a pool with a downstream riffle. Unfortunately, the best site for sediment-data collection is in the riffle where faster velocities and more turbulence maintain the sediment in suspension.

Because access during high-water periods is critical, some compromise in the site selection may have to be made. The sediment-sampling site should be close enough to the discharge-measuring site so that information from the two sites may be combined. If the sediment-sampling site is some distance from the discharge-measuring site, a staff gage or other nonrecording device may be needed at the sediment-sampling site.

Care must be exercised when placing sediment-sampling sites downstream from the junction of two tributaries. Mixing of the sediment from the two tributaries may not occur for long distances downstream. This distance may be quite variable and dependent on stream hydraulics and physical properties (for example, water temperature). 
Sites in areas of active bank erosion should be avoided. Additional information on site selection can be found in Guy and Norman (1970).

There are three types of sites for obtaining sediment records (Guy, 1970, p. 47). The first is a daily station in which the amount of sediment, as measured by suspended-sediment samples, is computed and recorded on a daily basis. Sampling is usually daily, or more frequently, if there is a change in discharge or sediment concentration. Under natural conditions, changes in sediment concentration occur with changes in discharge. However, in areas where man is modifying the landscape, sediment concentrations may increase due to upstream activity and not only to changes in discharge.

The second type of site is a partial-record site. At this type, daily sediment records are obtained only during selected times of the year based on a predictable period of high flow, such as during snowmelt. The timing of samples during the data-collection period is the same as that for the daily stations.

The third site is designated as a periodic sediment-record site. A large variety of sampling techniques and frequencies may be used at this type of site. Perhaps the most common is a sample taken periodically in conjunction with the collection of water-quality constituents and discharge measurements. These kinds of data provide "instantaneous" values of water discharge, sediment concentration, and sediment discharge.

A series of reconnaissance measurements probably should be made prior to establishing any type of site. This should help to eliminate the necessity of making adjustments in the position of sites after the network has been established. Because of the temporal variability in sediment data, it should be remembered that the data collected at a site becomes more useful as the length of record increases.

\section{Sediment-Sample Collection}

Proper sampling is fundamental for obtaining good data in the operation of a sediment program. Suspended-sediment sampling techniques have been the most thoroughly documented. Indeed, there are many references to suspendedsediment onsite methods, such as Guy and Norman (1970).

Suspended-sediment samplers are all basically of the same design--a streamlined body with fins to allow the nozzle to point directly into the flow. This body is of sufficient weight to allow a traverse from the surface to the channel bed without being carried downstream. The hollow body accommodates a standard pint or quart bottle for the sample to allow water to enter the sample body at the same velocity as the surrounding stream velocity. An air-outlet tube is used to exhaust the air as the water-sediment mixture enters the bottle. 
Two general types of suspended-sediment samplers are available. The first is a depth-integrating sampler designed to accumulate the water-sediment mixture from a sampling vertical at the same rate as the surrounding stream velocity, as the sampler is lowered and raised in the vertical at a uniform speed. If the combination of depth and velocity is too great, the bottle will overfill, and the sample will not be accurate. When the combination of depth and velocity is too great, the second type of sampler, or point-integrating sampler, is required. It has a valve that allows water to enter only when it is open. This type of sampler can be used as a depth-integrating sampler by sampling in only one direction. The sampler also can be used to integrate parts of verticals or single points in a vertical.

Depth-integrating samplers are categorized primarily by their weight. A number of samplers are available. Several of the more common ones are discussed below. The smallest lightweight hand sampler, designated "DH-48," weighs $4.5 \mathrm{lb}$ and is used in streams that can be waded. Sampling is done by attaching a rod with a handle.

The "DH-59" was designed to be suspended from a rope and used in streams too deep to wade. It weighs $24 \mathrm{lb}$; because of its light weight, this sampler should not be used in velocities greater than $5 \mathrm{ft} / \mathrm{s}$.

The "D-74" is another depth-integrating sampler designed to be used with a cable-and-reel suspension system. This sampler can use either a pint or quart sample bottle and weighs approximately $62 \mathrm{lb}$.

Several point-integrating samplers are available. The "P-61" has several versions but is basically a 105-1b sampler with an electric solenoid for activating sampling. The "P-63" is a $200-1 b$ point sampler. Because of the size of these samplers, they are designed to be used with a cable-and-reel suspension system. Point-integrating samplers are more complex than depthintegrating samplers; additional information can be obtained from the InterAgency sedimentation reports (Federal Inter-Agency Sedimentation Project, $1952,1963,1966)$.

Both depth-integrating and point samplers can be obtained in a tracemetal sampling version. These samplers are coated with epoxy paint and are outfitted with Teflon nozzles and neoprene head gaskets to prevent metal contamination of the sample.

These samplers and various other sediment-sampling accessories are available from: Federal Inter-Agency Sedimentation Project, St. Anthony Fa1ls Hydraulic Laboratory, Third Avenue S.E. and Hennepin Island, Minneapolis, MN 55414.

Several different sizes of nozzles are available for most sediment samplers. Different sizes help solve the problem of bottle overflow in a vertical transit. Transit rate and nozzle size control bottle filling. In general, it is best to use the largest nozzle possible in order not to exclude the larger suspended particles (Guy and Norman, 1970, p. 10). 
In sampling at a cross section, the number of verticals to use is a critical question. It has been shown that the sediment variability can be very large at a cross section. Therefore, the number of verticals depends, in part, on the accuracy being sought. If the vertical is sampled using the depth-integrated approach, the amount of sample accumulated is directly proportional to the stream velocity. Samples collected by integration with the flow can be used to compute the sediment discharge by:

$$
Q_{s}=Q_{w} C_{s} K
$$

where: $Q_{S}=$ sediment discharge, in short tons per day;

$Q_{w}=$ water discharge, in cubic feet per second;

$c_{S}=$ discharge-weighted mean concentration, in milligrams per liter;

$K=0.0027$ (for concentration, in milligrams per liter).

Because the water discharge $\left(Q_{w}\right)$ and the mean suspended-sediment concentration $\left(C_{s}\right)$ are multiplied directly together to yield a value for load, inaccuracy in the concentration value $\left(c_{S}\right)$ can greatly affect the values of sediment discharge.

Usually the variability in the section is unknown until multiple verticals have been sampled and analyzed. If observers are used, their samples are generally from a single, fixed vertical. Many times the sampler can be housed in a box mounted directly on a bridge. Multiple cross-section samples are taken at various times to compare and rate the single vertical samples.

It is realistic to assume that multiple verticals will have to be made. Sampling may require, particularly at new sites, two to five verticals or more. Two methods are available for establishing multiple verticals at a section. The first is the equal-discharge-increment (EDI) method in which samples are obtained at the centroids of equal discharge increments (Guy and Norman, 1970, p. 31). This method requires some knowledge of the streamflow distribution across the section but, in general, will necessitate fewer verticals than the second method.

The second method is known as the equal-transit rate (ETR) or the equalwidth increment (EWI), which requires a sample volume proportional to the amount of flow at each of several equally spaced verticals. Equal spacing among verticals and equal-transit rates of the sampler, both up and down and in all verticals, yield a sample proportional to the total streamflow. Guy and Norman (1970, p. 33) discuss the methods of calculating transit rates.

The ETR or EWI method has several advantages. First, a water-discharge measurement does not need to be made before a sediment sample is obtained. Second, laboratory analysis can be reduced by compositing sample bottles to yield one concentration for the cross section. 
A pint glass bottle commonly used in sediment collection is shown in figure 9. The side of the bottle has been etched in order to write on it although tags or labels also are used. The necessary information and desired water levels for a sample also are shown in figure 9.

There has been considerable discussion on sampling of suspended sediment. Unfortunately, the suspended sediment is generally only part of the total sediment load at a cross section. Measurement of bedload, however, has proved difficult. It is best to select sites with turbulence in which it can be assumed that all load is in suspension and can be measured by the techniques previously discussed. This is not always possible. In addition, particles in transit as bedload may be too large to enter the suspended-sediment sampler.

If it is necessary to measure bedload, the discussion of equipment and techniques by Hubbell (1964) is useful. In recent years, the U.S. Geological Survey has used the Helley-Smith bedload sampler (Druffel and others, 1976), but arguments persist as to its reliability.

Data on the size distribution of the material making up the streambed are useful for evaluating long-term changes in the channel. Also, these data are used in equations for calculating the unmeasured part of the load to estimate total load.

Three basic types of bed-material samplers are available from the Federal Inter-Agency Sedimentation Project. The "BMH-53" is a piston-type hand sampler. The "BM-60" and "BM-54" are both samplers suspended from a line that has a scoop or bucket that is activated when the sampler rests on the streambed. Descriptions of these samplers and sampling methods are discussed in Guy and Norman (1970).

\section{WATER QUALITY}

\section{Criteria for Selection of Constituents}

In any data-collection effort, many criteria may dictate which constituents should be analyzed. Possible criteria should be considered prior to the design of the data-collection network to minimize delays caused by collection of insufficient data, to maximize cost-effectiveness by consolidating collection and analysis efforts, and to assure that the data will be put to a logical use. Among the criteria that should be considered in the study of the impacts of surface mining are:

(1) Constituents specifically required by the Permanent Regulatory Program (U.S. Office of Surface Mining Reclamation and Enforcement, 1983).

(2) Constituents required at the discretion of the Regulatory Authority.

(3) State and Federal drinking-water standards for activities that may influence actual or potential public and domestic supplies.

(4) Irrigation criteria for activities that may influence supplies that have been allocated for irrigation.

(5) Aquatic life criteria for activities that influence lower organisms, fish, and wildlife in virtually any surface-water system. 


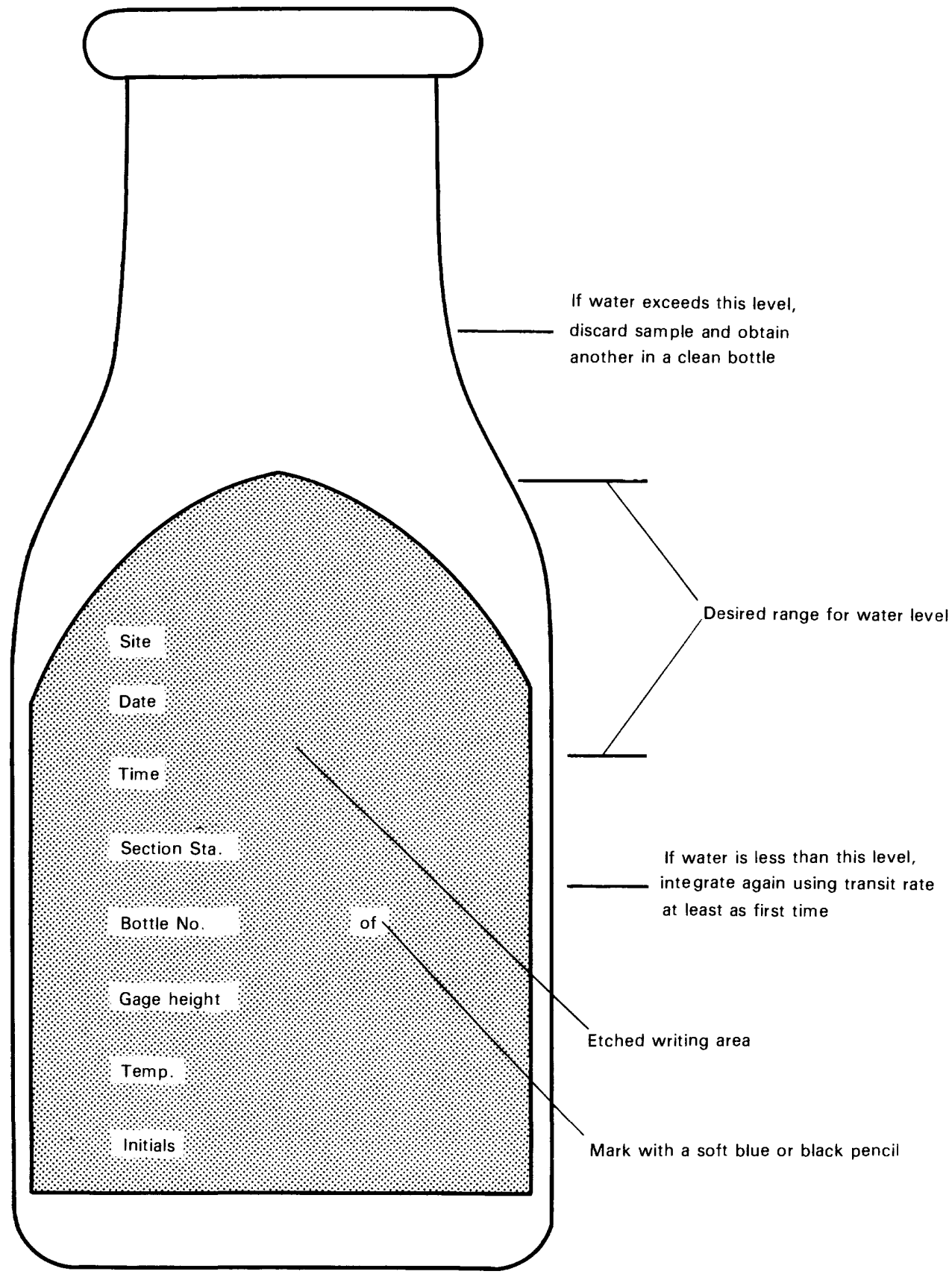

Figure 9.--Sample bottle showing desired water levels and essential recorded information. Sometimes other information concerning type of sampler used, the section location, and stream conditions also should be noted

(Guy and Norman, 1970, p. 29). 
(6) Minimum groups of constituents necessary to perform routine qualitycontrol checks.

(7) Minimum groups of constituents necessary to evaluate possible geochemical controls on the hydrologic system.

The Permanent Regulatory Program (U.S. Office of Surface Mining Reclamation and Enforcement, 1983) and subsequent guidelines (U.S. Office of Surface Mining Reclamation and Enforcement, 1985a, b, c) specifically mention the constituents and their water-quality measurements listed below:

\begin{tabular}{ll}
\hline \multicolumn{1}{c}{ Onsite } & \multicolumn{1}{c}{ Laboratory } \\
\hline Temperature & Total dissolved solids \\
pH, in standard units & Iron \\
Specific conductance, & Manganese \\
in micromhos per centimeter & Arsenic \\
at $25^{\circ}$ Celsius & Mercury \\
& Boron \\
& Lead \\
& Zinc \\
& Silver \\
& Copper \\
& Chromium \\
& Calcium \\
Magnesium \\
Sodium \\
Potassium \\
Chloride \\
Bicarbonate \\
Carbonate \\
Total suspended solids (surface water \\
only) \\
\hline
\end{tabular}

The State Regulatory Authority is given broad latitude in stipulating constituents of regional concern that must be measured in addition to those mentioned in the Permanent Regulatory Program (U.S. Office of Surface Mining Reclamation and Enforcement, 1983). Such constituents might include those enriched in particular coals, overburdens, or water sources relative to levels commonly observed in counterparts elsewhere. For example, boron or selenium may be of particular concern in some western coal operations while lead may be a problem in some eastern coal operations. The Regulatory Authority thus has the mandate to supplement requirements of various Federal and State regulations as dictated by site-specific characteristics rather than to rely only on a fixed list of constituents.

In addition to constituents directly required by the U.S. Office of Surface Mining Reclamation and Enforcement, other Federal and State laws may require analyses of discharges and receiving water. For example, permits issued under the National Pollution Discharge Elimination System may require analysis of constituents that overlap and complement those required by the Permanent Regulatory Program. Such requirements can be based on the nature of the discharge and the use to which the receiving water is put. Guidelines for 
water to be used in irrigation may closely parallel the Permanent Regulatory Program requirements but may add boron, as, for example, in the Wyoming Department of Environmental Quality Guideline no. 4 (Wyoming Department of Environmental Quality, 1980). This guideline requires an extensive analysis of trace metals, arsenic, fluoride, and Ra-226 for water to be used in wildlife and livestock impoundments. It is apparent that implementation of existing Federal and State laws and guidelines can be as site-specific as the discretionary requirements imposed by the State Regulatory Authority.

Quality-assurance tests of chemical data, other than direct testing of each analytical procedure, frequently rely on the premise that "the whole is equal to the sum of the parts." The constituents in the Permanent Regulatory Program list, for example, allow for a test of the dissolved solids being equal to the sum of the major ions measured, thus indicating whether or not some unmeasured constituent is present in large concentrations. A further check on whether an unmeasured constituent is an ion can be made by conducting a test to determine if the total charge of the solution equals zero by summing the milliequivalents of measured positive and negative ions. By doing this, most of the listed constituents can be internally checked to determine whether large problems exist in the analysis of major constituents.

The evaluation of geochemical controls often requires constituents in addition to those required by the Permanent Regulatory Program. If, for example, it is necessary to predict the distribution of nitrate after mining, data probably will be required on other nitrogen species, such as ammonia and organic nitrogen. Such data are necessary because nitrate concentrations can change as a function of dilution processes, by nitrate production, or by removal by transformations from one nitrogen species to another.

In addition, the direct requirements of regulating agencies, the data requirements for quality assurance, and the data needs of predictive models mean that several sets of constituents must be measured at varying frequencies. Many of the sets will overlap. By coordination of all requirements early in the network design, great gains in efficiency can be made. For example, basic monitoring schedules can be combined with one another or even serve as part of the data base for a model that may not be needed until well after the start of monitoring. By coordinating various data needs, not only are direct savings in time and money possible, but also indirect gains in having sufficiently detailed data to allow easier interpretation and prediction of hydrologic characteristics.

\section{Sampling Considerations}

To be representative, a water sample must be collected and processed in different ways depending on the physical state of the sample and characteristics of the system. Heterogeneity in the chemistry of streams, in particular, results from uneven distribution of suspended sediment, both vertically and horizontally, in a cross section. The uneven distribution of algae in lakes can greatly influence the observed concentration of nutrients. Physical properties that control mixing--for example, turbulence in streams, thermal stratification in lakes and ponds, or stratigraphic controls on ground-water flow--can affect both dissolved and suspended components. 


\section{Site Selection}

Streams

The Permanent Regulatory Program and subsequent guidelines (U.S. Office of Surface Mining Reclamation and Enforcement, 1985a, b, c) require streammonitoring sites to identify the characteristics of surface waters in, discharging into, or which will receive flows from surface or ground water from affected areas within the proposed mine plan area. Site selection on streams crossing a mine-plan area boundary, thus, is restricted to the general area of the boundary. Sites on streams wholly within the mine-plan area or additional sites added to simplify quantification of effects from bedrock changes, differences in vegetation, and other effects also may be required or useful in a monitoring plan.

Within the site-specific requirements of the Permanent Regulatory Program or for optional sampling sites, consideration should be given to physical processes and characteristics that affect either the stream chemistry itself or the ease of collection of a representative sample. Variables that should be considered include, but are not limited to, those shown in table 4. To make legitimate comparisons between sites at the upstream and downstream boundaries of the mine-plan area, for example, variables such as those in table 4 should not change between the two watersheds. It would be quite easy for a change in bedrock type from limestone or carbonate-cemented sandstone to a shale containing evaporite minerals to cause a greater change in water quality than that from a well-managed mine. Similar considerations apply, to greater or lesser extent, to other variables affecting water quality. If large changes in these controlling variables occur, additional stations will be required to adequately measure the effects of mining alone.

Initial site selection should be based on the need to eliminate the effects of variables unrelated to mining that can obscure the effects of mining. To simplify the job of sample collection, a single channel with sufficient turbulence to assure mixing is preferred. Such sites often may be found at the downstream end of riffle stretches or straight channels where riffles are not available. Artificial controls established for streamflow gages also may be desirable sampling locations, particularly for shallow, wide streams or those with several natural channels. Further, the site must be accessible during snowmelt or floodflow conditions. Often, even small streams become dangerous or impossible to wade during such conditions, and a bridge or cableway is needed for collection of samples that are not biased by erosion and sediment heterogeneity near the banks. If automatic sampling equipment is to be installed, special consideration will be needed to prevent loss to floods while minimizing the pumping distance and height from stream to sampler. Automatic samplers often are used to sample sites that become inaccessible during floods or that have infrequent, short-duration peak flows.

Lakes

Although sampling details for lakes are not provided by the Permanent Regulatory Program, they are clearly included as part of the responsibility toward surface water and fish and wildlife resources. In addition, other laws 
Table 4.--Some processes and characteristics affecting water-quality site selection along streams

\begin{tabular}{|c|c|}
\hline Variable & Effect \\
\hline Bedrock mineralogy--- & $\begin{array}{l}\text { The presence of minerals of different composition and } \\
\text { solubility can greatly influence dissolved solids, } \\
\text { suspended solids, and the concentration of } \\
\text { individual elements. }\end{array}$ \\
\hline Land use--- & $\begin{array}{l}\text { In changing from various natural states to agricul- } \\
\text { ture, coal mining, oil development, and other uses, } \\
\text { evapotranspiration, soil loss, and the mobility or } \\
\text { supply of individual elements each can be affected. }\end{array}$ \\
\hline Vegetation-- - - & $\begin{array}{l}\text { In addition to being correlated with other important } \\
\text { variables, vegetation can affect the timing, rate } \\
\text { of release, and flow path of precipitation, espec- } \\
\text { ially snow. It also affects soil loss, ground- } \\
\text { water/surface-water interactions, and temperature, } \\
\text { biology, and chemistry. }\end{array}$ \\
\hline Tributary inflow---- & $\begin{array}{l}\text { The more surface- or ground-water inflows upstream } \\
\text { from a sampling site, the greater the potential } \\
\text { variability seen at the site. Proportions of water } \\
\text { and chemistry influenced by different subbasins can } \\
\text { change depending on the distribution of storms, } \\
\text { snowmelt, or other climatic variables. }\end{array}$ \\
\hline
\end{tabular}

and guidelines may require water sampling. For example, Wyoming Department of Environmental Quality Guideline no. 4 (Wyoming Department of Environmental Quality, 1980) provides an extensive list of constituents and maximum concentrations for wildlife and livestock impoundments that may be part of a reclamation plan.

Proper selection of sampling sites on lakes requires an understanding of basic lake processes. Many books are available that provide information of such processes (Reid and Wood, 1976; Hutchinson, 1957). For discussion here, however, a simplified treatment of a few processes is sufficient. The surface shape and bottom contours of a lake, in combination with localized inflows and outflows, cause changes in water quality throughout a lake system. Areas near inflows are obviously influenced primarily by the quality and magnitude of the inflow itself. Bays and wetlands at the lake margin are best considered and sampled as lake systems separate from the main body of water. Within the lake proper, however, some generalization can be made as to water-quality differences.

Perhaps the greatest cause of differences in water quality within the main body of lake water is thermal stratification. The type of distribution that commonly may be found during warmer months for a number of chemical and physical properties in lakes is indicated in figure 10. As lakes warm in the 
TEMPERATURE, IN DEGREES CELSIUS

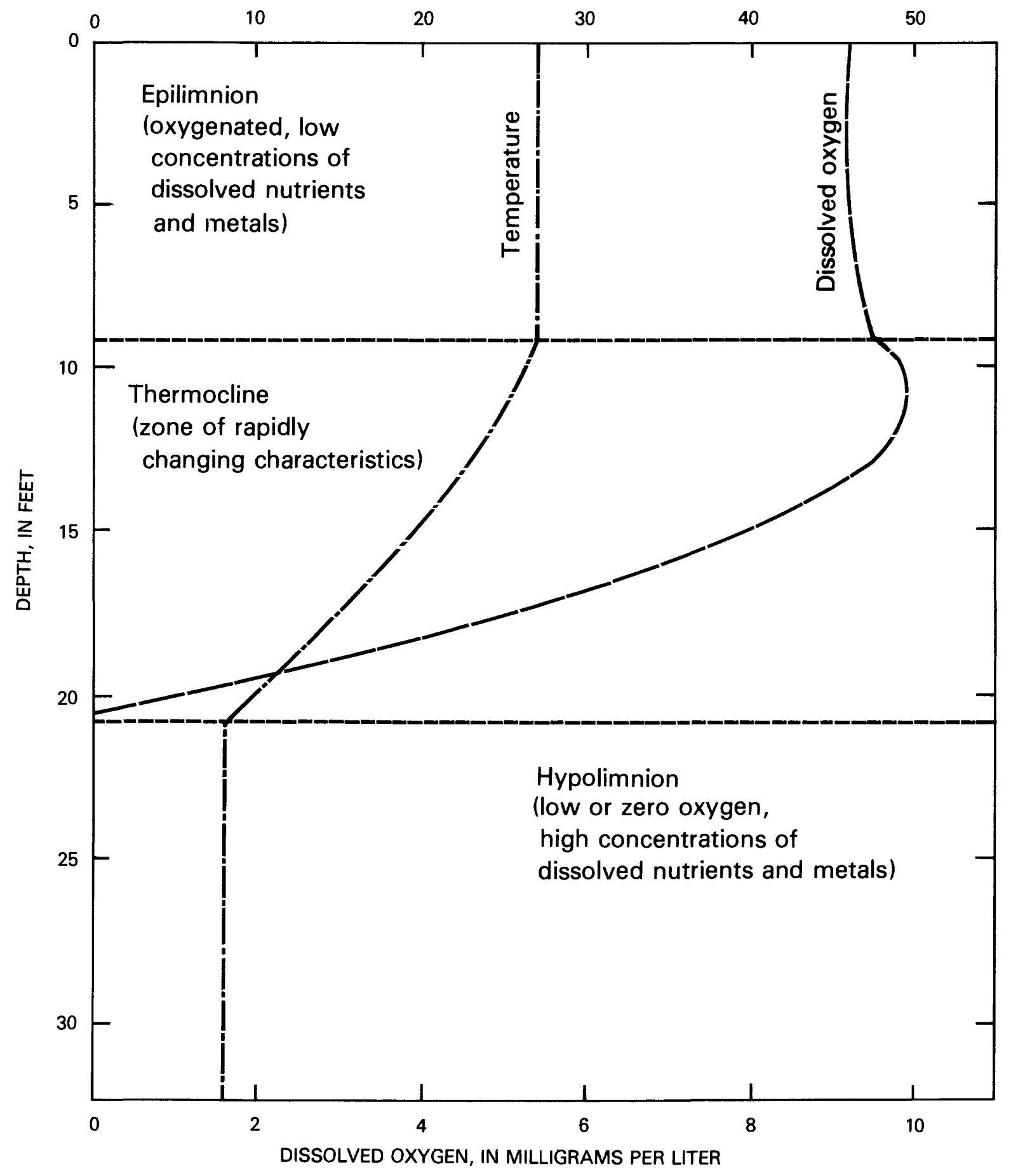

Figure 10.--Thermal stratification effects. 
spring and early summer, the epilimnion, a layer of less-dense, warm water, develops above denser, cool water from the winter, known as the hypolimnion. The transition zone between these two, well-mixed layers is the thermocline. Very small lakes, those exposed to strong winds, and those with rapid replacement times of water may stratify only weakly, or not at all.

The epilimnion is in contact with the atmosphere and also receives oxygen from algal photosynthesis. It characteristically has a substantial oxygen concentration. The presence of oxygen and uptake by algae tend to keep the concentration of dissolved trace metals relatively small. Similarly, use by algae of dissolved nutrients, such as nitrogen and phosphorus, keeps their concentration small in the epilimnion. Sediment and algal detritus sink through the zone of rapidly changing temperature to another well-mixed layer in contact with the lake bottom. In this hypolimnion, decay of algae and other organic matter uses up oxygen and releases dissolved nutrients and, often, trace metals from the algae and the lake sediments. The rapidly changing temperature in the thermocline creates a range of density conditions that can temporarily support and thus concentrate sediments or algae. In fairly clear lakes, much of the algal photosynthesis may take place in such a narrow stratum producing a bulge, or maximum, in the oxygen distribution with depth.

The differences in characteristics caused by thermal stratification indicate that a single sample does not adequately portray lake chemistry. Thus, a sampling point away from local inflows or bays still may not be easily characterized. Sampling must be done vertically to adequately describe the chemistry of the lake. In small lakes, a single site located away from local effects can be sufficient to describe the lake chemistry if samples are taken both above and below the thermocline. In larger lakes, a reconnaissance of the horizontal distribution of characteristics may be necessary before deciding whether the two mixed layers are well mixed horizontally.

The quality of lake water varies not only seasonally, but spatially as well. Thermal stratification is most evident during warm months or during periods of ice cover. Biological processes that influence water quality also are seasonally dependent. Periods of overland runoff or peak flow may cause a complete replacement of the water and its chemistry in short time periods. Thus, an adequate lake-sampling program should incorporate both seasonal and stream hydrograph-determined sampling.

\section{Ground Water}

The primary characteristics that should determine the selection of sites for water-quality sampling from wells are the altitude of the potentiometric surface within the strata, the differences in head between strata, the natural differences in chemical quality within and between strata, and the location of mining activities. Ground-water quality is a result of the direction and rate of movement of water through one or more areas of chemical reaction. The order in which water moves through and the length of time it is in contact with these areas are both important. To logically select sampling sites, it is necessary to first map the stratigraphy and the flow directions of the 
water and examine the area where the mine will be. Some estimate also should be made of the changes in flow direction that may occur as a result of mining. Reconnaissance data on the quality of water from exploration wells and other available sources, such as domestic wells and springs, then can help delineate zones of similar water quality. Such zones in strata affected by the proposed mine then should be selected both upgradient and downgradient from the mine for use as routine sampling sites. If possible, wells should be selected or constructed so that water from different strata are not mixed. Such an approach will greatly simplify later data interpretation.

\section{Network Evaluation}

Although initial site selection should be based on a combination of regulatory requirements, watershed characteristics, and fiscal restraints, networks often can be refined after such data have been collected. The intent of such refinement in the network is to assure that the various causes of water-quality variability are properly identified and monitored while simultaneously reducing unnecessary duplication among the stations in the network. The same techniques can be applied to virtually all parameters of interest and include approaches such as graphical comparisons, comparison of mean values, and comparison of regression relationships among the individual stations.

Perhaps the most common graphical comparison technique is to plot all the values for the constituents being determined as a function of station location. Because the water quality may vary as a function of time, all the data should be collected during a short sampling period. The sampling period that must be used for this instantaneous, or synoptic, picture of the hydrologic system varies depending on the constituent. Dissolved oxygen, for example, can vary widely between day and night because of net production by plants during the day and net uptake by plants and animals during the night. Dissolved-solids concentrations, however, may be relatively constant in some systems for periods shorter than seasons of the year. Graphical comparisons also can use methods to portray the relative chemical composition of samples. For example, Stiff and Piper diagrams (Freeze and Cherry, 1979) can be plotted for samples as a function of time or location.

For stream systems, the data often are plotted as a function of distance along the stream channel from some arbitrary point, such as the stream mouth or the most downstream station. Changes in major characteristics, such as the presence of a discharge point, change in land use, or bedrock change can be noted on the graph. For many systems there will be stretches having little change in water quality and other stretches having more rapid changes in water quality. The greatest definition of the hydrologic system for the least investment in station operation often is obtained by having a greater density of stations in the areas of rapid change than in the more stable areas. Also, the effects of any single watershed characteristic are best evaluated by bracketing that area representing the characteristic with upstream and downstream stations. 
Lake- and ground-water systems are treated the same as stream systems except that two or three dimensions must be considered instead of the one dimension of a well-mixed stream. For example, a grid network of sites can be represented as a series of parallel plots similar to those described for the stream system. To simplify visual recognition of patterns, these plots can be segregated by strata of different chemistry--for example, the upper and lower layers of a lake can be presented separately, as can overburden, coal, and underlying aquifers.

Although simple graphical comparison of sites can be performed after a single sample has been collected at each site, more rigorous tests for duplication among sites rely on having several samples at each site. Statistical tests, such as an analysis of variance to detect differences in the mean concentration of a constituent among many sites, can be used after initial network evaluation by graphical methods. Analyses of variance techniques are described in detail by standard statistics texts--for example, Ostle (1963). Additionally, there are many standard statistical texts available "off the shelf" to be used on computers. Tests of differences among mean concentrations require several samples at each site, the number depending on the variability at each site, the variability among sites, and the precision with which the test is to be performed. A common test is to evaluate whether there is greater than a 5-percent chance that the data from the sites that are to be compared are different from site to site. In this test, sites that were shown not to differ from one another at this level of precision could be consolidated, and a single site could be used as a substitute for all the identical sites. For sites that differ from one another, the hydrologic system could be better defined by maintaining the individual sites. If large differences were observed among the sites, it might be advisable to increase the number of sites. This type of test of the mean is most frequently used to define differences among sites for concentrations, but it also is frequently used to compare loads of material at various stream sites.

A related test involves a comparison of linear, or more complex, regression lines among sites. In much the same way that the test of differences among means indicates whether the individual concentrations are different at several sites, the evaluation of differences among regressions for several sites helps to indicate whether relationships among parameters are similar at the sites. For example, there frequently is a very good relationship between the concentrations of individual major ions and specific conductance at a site. The actual concentrations of the ions may change as a result of many factors--climate and land use among them. To decide whether increases in the mean concentration of an ion are due to evaporation of the water or to a source such as mining activity, tests of regression relationships can be useful.

For example, sulfate may be added to the hydrologic system as a result of oxidation of pyrite normally associated with coal. Sulfate also results from other natural contributions of the watershed, along with the other major ions. To determine whether sulfate is added more rapidly than other ions and, therefore, from a source with chemistry different from that of the bulk of the watershed, regressions of sulfate on specific conductance for sites upstream 
and downstream from the mine site can be used. If the regression for the downstream site shows a significantly greater amount of sulfate for any given specific conductance than does the upstream site, then sulfate is being added at a disproportionately large rate relative to other natural weathering products. This information then can be used to decide on additional sites or investigations to identify the source of the added sulfate.

\section{Onsite Measurements}

In addition to measurements of discharge, which are covered in a separate section, some water-quality determinations are made at the sampling site. The Permanent Regulatory Program and subsequent guidelines (U.S. Office of Surface Mining Reclamation and Enforcement, 1985a, b, c) list seven kinds of measurements that can, or should, be performed at the site: temperature, $\mathrm{pH}$, specific conductance, acidity, alkalinity, dissolved oxygen, and physical appearance. Of these, acidity and alkalinity may be measured in the laboratory within 24 hours of collection (American Public Health Association and others, 1981).

Detailed information on approved methods of determining the onsite measurements considered here is provided in several references (American Public Health Association and others, 1981; U.S. Environmental Protection Agency, 1974; Skougstad and others, 1978). Because of the documentation provided by these references, only information needed to aid implementation at the site will be presented.

The seven kinds of measurements considered can be placed in three basic groups: subjective judgment (physical appearance); titration using either $\mathrm{pH}$ meters or colorimetric indicators to detect the endpoint (acidity, alkalinity, and dissolved oxygen); and measurements that can be made conveniently using probes (temperature, $\mathrm{pH}$, specific conductance, and dissolved oxygen). The subjective judgment of appearance can best be standardized by the use of forms listing particular aspects of appearance, along with grading scales, and by internal standardization of these scales among all personnel making the measurements. Aspects such as color, cloudiness, and presence of foam or oil could be ranked differently by different personnel unless all used the same standards for judgment.

The necessity of measuring $\mathrm{pH}$ itself eliminates any real cost savings from performing acidity and alkalinity titrations by colorimetric means. The use of the $\mathrm{pH}$ meter has the added advantage of providing information on how rapidly one is approaching the endpoint as well as elimination of interference from color or cloudiness in the water. Whether acidity and alkalinity are determined in the laboratory or onsite, precautions are necessary to prevent changes before or during measurement. At the alkaline $\mathrm{pH}$ created in approaching the acidity endpoint, atmospheric carbon dioxide can continuously enter a beaker open to the atmosphere, thereby increasing the measured acidity of the sample. Care should be taken to use a container having seals around the electrode and buret that allow only enough airspace for titrant additions. 
In alkalinity determinations, care must be taken to titrate only dissolved material. For many samples, this requires no special handling because the suspended material does not always react with the titrant acid. In some alkaline-soil areas, however, there may be significant amounts of suspended carbonate minerals that can react with the acid, thus yielding greater alkalinity and more variable alkalinity than is actually the case. This often can be detected by comparing the charge balance of anions and cations--excessive alkalinity caused by solids will cause bicarbonate and the total anions charge to be in excess of the cations charge. Where evidence of this is found, it may be necessary to filter alkalinity samples prior to titration, unless statutes require the use of unfiltered samples.

The use of probes to determine temperature, $\mathrm{pH}$, specific conductance, and dissolved oxygen (which also can be determined by titration) generally is accepted. The choice is between the use of individual instruments for each measurement or more compact instruments that combine probes for all four measurements. In large streams and in lakes, it often is timesaving to use the combined systems, which generally are available with long cables allowing detailed onsite measurements throughout a profile without collecting many individual samples. Detailed directions on the calibration of the instruments normally is provided by the manufacturer and will not be discussed here. Additional general information on calibration can be found in the references cited earlier in this section.

Onsite measurements are not only required by many of the regulations and guidelines pertaining to surface mining; they also are very useful in selecting the proper approach to sample collection. For example, after calibration of the appropriate meter(s), the cross-section distribution of temperature and specific conductance can be determined and used to indicate whether complete mixing has occurred upstream from the sampling site. If marked differences occur in the stream cross section, sample composites may be necessary to obtain a representative sample. Depending on the nature of tributary and discharge inflows, $\mathrm{pH}$ and dissolved oxygen also may be used to determine the extent of mixing. The multiparameter, onsite instruments are best suited for such work, although single-parameter onsite instruments also can be effective. Instruments not designed for onsite work are very time consuming to use for cross-section measurements; however, rapid analysis of point samples taken with sampling bottles or sediment samplers can be useful in the absence of better instrumentation.

When a sample of water is taken from a well for quality of water analysis at a site, special methods of collection and measurement may be necessary to avoid seriously affecting the quality of the water sampled. The introduction of oxygen, loss of carbon dioxide, and other changes that can readily occur can completely alter the analytical results for a wide variety of constituents. An excellent reference is available describing special sampling procedures and equipment for such work (Wood, 1976). The casing, screen, and grout used in well construction can seriously alter the chemistry of a sample. Because steel and brass are readily soluble in many water types, water from wells having plastic casing and screening is preferable for the determination of inorganic constituents. Grout can cause an increase in $\mathrm{pH}$ and in the concentration of several major ions if the system is not thoroughly purged by continuous or frequent pumping. 


\section{Collection and Onsite Processing}

In addition to the onsite measurements required by regulations and guidelines, there are requirements for the collection and analys is of samples to determine a wide variety of chemical constituents. Just as the values from onsite measurement of temperature, dissolved oxygen, and $\mathrm{pH}$ can change markedly if samples are not analyzed immediately, values determined later in a laboratory can be affected by improper or delayed processing of the samples after collection. In general, guidelines cannot be given that specify the tolerable delay of procedures, such as filtration and preservation other than to require immediate, onsite processing. While some constituents from some hydrologic systems may be stable for long periods of time, others change within minutes after collection.

To effectively collect and process samples for later analysis, it is useful to have a working understanding of the reasons behind the procedures used. Generally, onsite procedures for sample processing can be broken into a few groups: filtration, addition of chemicals to prevent chemical reactions, and suppression of biological processes.

\section{Collection}

After site selection is complete and onsite data have been examined to determine the thoroughness of water mixing at a site, decisions must be made as to the proper means of obtaining a representative sample. As mentioned in the previous section, there are many processes in streams, lakes, and ground water that produce differences in chemical character within these bodies. In no case is it advantageous to sample from a single point of a heterogeneous system to attempt to represent the average character of the cross section or vertical column. This is a false economy in that it produces inaccurate data and is at odds with the intent of guidelines to collect representative samples .

In heterogeneous cross sections or vertical columns, it is necessary either to composite samples based on the fraction of water having various characteristics or to collect discrete samples of the various water types present. The composite samples save analytical costs and onsite manpower, while the discrete samples offer data that may be much easier to interpret. In streams, composites should represent the discharge-weighted average. Such samples are commonly collected using depth-integrating samplers originally designed for suspended-sediment collection. Methods, such as the equal-transit rate or equal-discharge-increment method (see Sediment-Sample Collection section), provide representative water samples. Information on samplers and methods of discharge-weighted sampling is available (Brakensiek and others, 1979). Samplers designed for the collection of suspended sediment must be modified slightly for collection of samples to be analyzed for constituents such as trace metals. Brass nozzles and some gaskets that are acceptable for suspended-sediment collection must be replaced with noncontaminating substitutes--for example, Teflon nozzles, silicone-rubber gaskets, and noncontaminating paint, such as epoxy. 
In lakes, composites may be taken to represent the horizontal and vertical distribution of chemical quality. Such samples should be averaged on the basis of the fraction of the lake volume represented by the various samples. For example, a grid pattern can be used to evenly distribute sampling sites areally. At each point the ratio of epilimnion and hypolimnion water can be determined by the thickness of the two layers. Because of the marked character differences that commonly can be found in lakes, however, serious consideration should be given to separate collecting and processing of major water types--for example, epilimnion and hypolimnion samples. Lake samples are most commonly collected with messenger-activated sampling bottles, such as the Kemmerer and Van Dorn designs. The bottle is lowered to the predetermined depth and a messenger allowed to slip down the line to trigger collection of the sample. Some use also is made of inert tubing/pump combinations that pump water from the level of the intakes to a discharge at the boat.

In ground water, composites may be determined by the screening interval or by the sampling of separate wells screened in discrete intervals representing differing water quality. By far the most desirable approach is the sampling of wells screened only in intervals of similar rock type and water quality. Mixing within the well or between strata in the vicinity of the well tends to seriously bias data from wells screened haphazardly in several

strata. Such samples do not normally represent the average water quality that will discharge from an excavation that is freely draining because head differences cause interference between strata if water accumulates in the well. Sample collection from wells is discussed, as are appropriate samplers, in an excellent reference (Wood, 1976).

\section{Onsite Processing}

\section{Filtration}

In the broadest sense, filtration is the division of samples into dissolved and suspended materials. Most regulations and guidelines require that an analysis be made of filtered samples, only the material collected on the filter, or an unfiltered mixture of water and sediment. Reasons for collecting the different types of samples are:

Filtered samples.--

(1) Major ions, such as calcium, magnesium, sulfate, bicarbonate, and chloride are readily soluble in water and are primarily transported in the dissolved state. Filtration takes out the minor variations in quality that may be. caused by changes in the amount of sediment and permits determination of only the dissolved solids that potentially can affect suitability of the water for irrigation, domestic, and other uses. Filters with a pore size of $0.45 \mathrm{micron}$ are generally used to separate dissolved and suspended materials. However, some very fine suspended materials, colloids for example, can pass through even this size filter. 
(2) Nutrients, such as nitrogen and phosphorus, are most available to algae when in the dissolved state and are readily transported through the cell wall to sites of photosynthesis. Measurement of unfiltered samples might allow the large amounts of unavailable nutrients to obscure the changes of dissolved nutrients that cause algal blooms.

(3) Metals are most available as trace nutrients or toxins in the dissolved state. Unfiltered samples might allow suspended metals to obscure the small dissolved concentrations.

(4) The normal physical state of materials transported in ground water is the dissolved state. Only in very coarse deposits with relatively rapid flow rates will suspended material be stable. Suspended material in samples from most wells represents contamination of the ambient ground water by debris from well installation or by chemical precipitates deposited within the well. Variations in the amount of such suspended material in a sample not only influence the chemistry of the sample, but do so inconsistently. The causes of variation in the amount of suspended material in a ground-water sample generally have little or nothing to do with actual changes in ground-water chemistry and, thus, only complicate interpretation of data. For these reasons, it is generally advisable to filter samples of ground water. If regulations or guidelines specify unfiltered ground-water samples, it is advisable to collect both filtered and unfiltered samples. Also, proper well development and pumping prior to sampling can minimize the influence of suspended materials on ambient groundwater quality.

Suspended sediment samples.--

(1) The primary use is to relate the concentration of some rather insoluble constituent to suspended-sediment concentration, for which a more continuous record may be available.

(2) It is sometimes difficult to extract suspended constituents from a water-sediment mixture. Therefore, a strong "digestion" is used directly on the suspended material collected by a filter. This is commonly done for organic materials.

Unfiltered samples.--

(1) Many standards for discharges from industry or wastewater-treatment plants and for intakes for public water supplies apply to the total recoverable concentration rather than dissolved concentration. Therefore, it is necessary to collect unfiltered samples . 
(2) If essentially all of a constituent is in either the dissolved or suspended state, an unfiltered sample can be used to measure actual concentrations. This is not always a good assumption and data should be available to support it for the sampling conditions. This approximation can be particularly useful in sampling for insoluble constituents during floods. Many trace metals and phosphorus, for example, will be found almost entirely in the suspended phase when the suspended-sediment concentration is high. At such times, collecting unfiltered samples for these constituents can save valuable time--but again, only with the proper data to back up the assumption.

(3) In measuring the total transport of materials within stream systems, various processes, such as chemical precipitation or dissolution, can move constituents from one physical state to another. These state transitions complicate data interpretation if only a single state, the dissolved state, for example, is sampled. This change in state is especially noticeable when acidic or oxygen-poor ground water enters oxygenated streams of neutral $\mathrm{pH}$, and metals such as iron and manganese are precipitated.

\section{Addition of chemicals to prevent chemical reactions}

When removing a water sample from its natural environment and placing it in a bottle for later analysis, changes may be made in processes controlling the sample chemistry. The greatest potential for major changes exists with samples from environments most different from the surface environment. For example, samples from wells, seeps, springs, or the bottoms of some lakes may have no oxygen but may have much carbon dioxide and hydrogen sulfide. The introduction of oxygen and removal of the other dissolved gases naturally present can change the $\mathrm{pH}$ and cause the precipitation of heavy metals as well as calcium and bicarbonate. Most analytical procedures work best if all of a particular constituent is in a "free, dissolved" state, not bound as association of ions, known as ion-pairs, or particulates. Sample collection and processing, thus, should be designed to separate the water-suspendedsediment mixture into dissolved and suspended parts (without altering the distribution) and ensure that these parts are in a form most suitable for analys is.

Iron is an example of a constituent that is affected when oxygen enters a water sample that originally contained no oxygen. Like many other elements, iron can have several different amounts of electrical charge per atom. Common metallic iron has a charge of 0 ; iron in many ground-water or bog systems has a charge of +2 and is known as ferrous iron, while iron in rust or in oxidized surface water is often +3 , or ferric iron. Only ferrous and ferric iron will be considered here. Each different unit of charge that an ion may have, called its valence state, brings with it a chemistry completely different from that of other valence states. The chemistry of different valence states of the same element differs as much as the chemistry among elements. 
The solubility of ferrous and ferric iron hydroxides is determined by the solution $\mathrm{pH}$, which controls the hydroxide concentration. For example, at a $\mathrm{pH}$ of 7 , the solubility of the ferrous ion is about $5.6 \mathrm{~g} / \mathrm{L}$, or $5,600,000 \mu \mathrm{g} / \mathrm{L}$. The solubility of ferric iron at the same $\mathrm{pH}$ is below the detection limit of available analytical methods. Thus, the valence of iron and similar metals directiy controls their solubility. In sample collection and processing, this is extremely important, particularly in the collection of samples from oxygenpoor (anaerobic) systems such as ground water or the lower, cold-water layer in some lakes. If a sample from an anaerobic system is exposed to air, the oxygen that dissolves in the water rapidly reacts with dissolved ferrous iron and other metals to oxidize them to their higher valence states. As they oxidize, precipitation begins almost immediately to form colloids or larger particles, not all of which will pass through a 0.45 -micron filter. Chemical analysis of the filtered sample will indicate a dissolved-iron concentration much lower than that in the water that was actually sampled.

The addition of acid to lower the $\mathrm{pH}$ is the most common onsite treatment for a group known as the transition metals (also frequently referred to as trace metals), of which iron is a typical example. Although the solubility of iron at a $\mathrm{pH}$ of 7 in a bottle into which oxygen has leaked is well below the detection limit of available analytical methods, the solubility of a sample acidified to a $\mathrm{pH}$ of 2 is much greater--about one-half a gram per liter, or $560,000 \mu \mathrm{g} / \mathrm{L}$. The important thing is that any iron dissolved in an anaerobic sample will stay dissolved if the sample is immediately filtered and then acidified. An acidified unfiltered sample puts most suspended iron into solution, making it readily available for analysis at the laboratory.

Changes in carbon-dioxide concentration during sampling also can affect analytical results. The changes in carbon-dioxide solubility as a function of temperature and the partial pressure of carbon dioxide are illustrated in figure 11. The partial pressure of a gas is merely the fraction of the air molecules that are a particular gas, such as carbon dioxide, times the overall atmospheric pressure. For example, carbon dioxide makes up about

0.033 percent of the atmosphere, while in many ground-water or spring samples, the soil atmosphere that the sample has contacted may be easily 10 times higher in carbon dioxide.

The solubility of carbon dioxide varies dramatically over the range of temperature and partial pressure of carbon dioxide likely to be encountered in normal sample collections (fig. 11). At $25^{\circ} \mathrm{C}$, a sample from a lake during algal-bloom conditions (when the algae are rapidly extracting carbon dioxide for photosynthesis) would contain much less carbon dioxide--perhaps as little as $0.01 \mathrm{mg} / \mathrm{L}--$ than a sample equilibrated with the atmosphere would contain. Atmospheric carbon dioxide will move through the walls of a sample bottle standing in a dark ice chest and will dissolve in the sample until the carbon dioxide attains a much greater concentration--perhaps more than $1 \mathrm{mg} / \mathrm{L}$. Similarly, a sample collected from a cold spring or well may contain 5 to $10 \mathrm{mg} / \mathrm{L}$ of carbon dioxide. The solubility will decrease to perhaps $0.4^{\circ} \mathrm{mg} / \mathrm{L}$, and carbon dioxide will bubble from the sample when it warms and equilibrates with the atmosphere. 

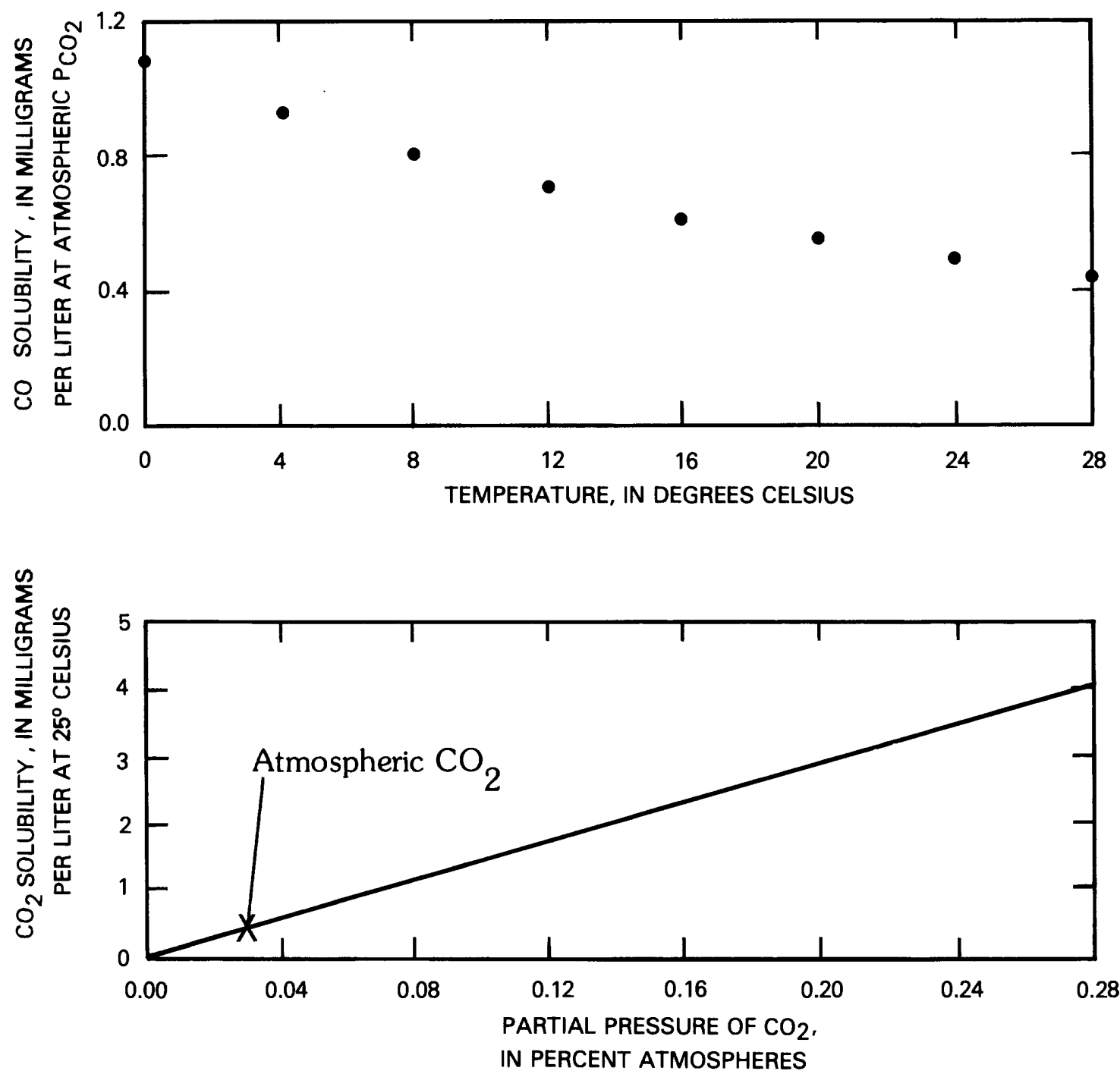

Figure 11.--Effects of temperature and partial pressure on the solubility of carbon dioxide. 
These changes in dissolved carbon-dioxide concentration cause corresponding changes in the solubility of other constituents in the sample. For example, the effects on calcite (limestone) solubility of common ranges in temperature and carbon-dioxide partial pressure are indicated in table 5 .

By using the effects of both temperature and carbon-dioxide partial pressure shown in table 5 , it can be shown that a very cold, calcite-saturated ground-water sample with high $\mathrm{P}_{\mathrm{CO}_{2}}$ would lose about 75 percent of the dissolved calcite when allowed to warm in contact with air. If the sample is not processed before this has occurred to a significant extent, the chemistry of the ground water will be misjudged badly. For example, if the sample for calcium is not filtered immediately and then acidified, the resultant calcium concentration will be about 25 percent of the original because the precipitated calcite would be filtered out. Similar results could be expected for other metals with sparingly soluble carbonates, including lead, iron, and manganese. The effect is to change the distribution between the bicarbonate and carbonate ions, which is a function of the $\mathrm{pH}$. If a sample had a typical value for bicarbonate of $61 \mathrm{mg} / \mathrm{L}$ and was at $\mathrm{pH}$ of 7 , the maximum calcium concentration in equilibrium with calcite would be about $400 \mathrm{mg} / \mathrm{L}$. In a sample acidified to $\mathrm{pH}$ of 2 , the maximum calcium concentration before the sample changes by calcite precipitation would be about $40,000 \mathrm{~g} / \mathrm{L}$. Thus, immediate filtration followed by acidification can prevent loss of calcium from samples.

\section{Suppression of biological processes}

Many constituents are subject to biological activity and can be taken up or liberated by organisms present in the sample. This is especially true of elements that serve as major nutrients to phytoplankton and bacteria, such as nitrogen and phosphorus. Many methods have been tried to minimize the biological reactions after sample collection; however, very few are widely used. Chilling and storage in the dark is a common procedure for samples that will be analyzed within very short periods of time. Such an approach is recommended for some forms of nitrogen and phosphorus if the analysis is made within 24 hours (U.S. Environmental Protection Agency, 1974). For other forms, the addition of sulfuric acid in addition to chilling is recommended to prevent volatilization, to promote hydrolysis, or to further retard biological reactions. For longer storage times, biocides are commonly used; the best documented probably is mercuric chloride. Used in sufficiently strong doses, mercuric chloride effectively sterilizes the sample and inactivates enzymes that may promote changes in nutrient speciation.

\section{SITE-SPECIFIC EXAMPLES}

The following are hypothetical examples of drainage basins in three major geomorphic provinces in the central-western United States in which coal mining is presently carried out or is anticipated. The provinces are characterized by ridge-valley, prairie, and mesa topography typical of arid and semiarid climates. The stratigraphy and hydrology of the basins are characteristic of 
Table 5.--Effect of carbon-dioxide partial pressure and temperature on calcite solubility

[ $\mathrm{P}_{\mathrm{CO}_{2}}$, carbon-dioxide partial pressure]

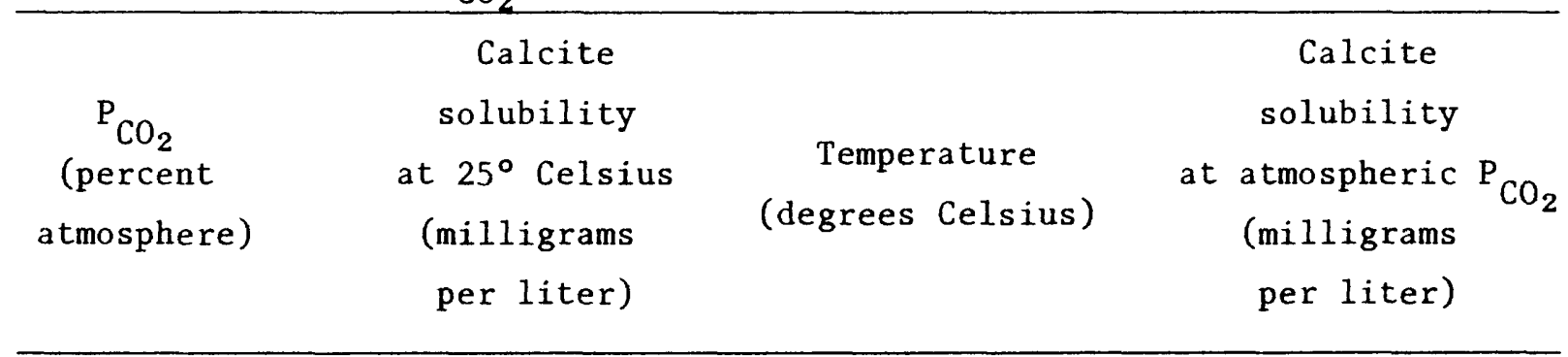

$\begin{array}{rrrr}0.02 & 35 & 0 & 96 \\ .03 & 52 & 3 & 90 \\ .05 & 61 & 6 & 84 \\ .07 & 69 & 9 & 77 \\ .09 & 75 & 12 & 71 \\ .15 & 15 & 67 \\ .20 & 89 & 18 & 62 \\ .25 & 99 & 21 & 57 \\ .30 & 106 & 24 & 54 \\ & 113 & 27 & 51\end{array}$

the provinces in which the basins lie. Although specific monitoring plans have been proposed for each of the example basins, these plans are meant to represent only one of several possible acceptable approaches. In particular, inspection of initial data from the proposed plans would be expected to influence later decisions on either reducing or expanding the proposed monitoring.

\section{Drainage Basin in Semiarid Region of Ridge-Valley Topography}

The hypothetical basin used in this example (fig. 12) is typical of northwestern Colorado; the basin area is about $5 \mathrm{mi}^{2}$ and elevations range from about 8,000 down to about 7,200 ft. Precipitation is approximately $15 \mathrm{in} / \mathrm{yr}$, most of which occurs in the winter as snow and runs off as snowmelt during April to June. The stratigraphy is characterized by alternating sandstones and shales. Faulting is very common and creates steep side walls, which in many places form the divides between drainage basins. The basin upstream from the anticipated mining area is primarily underlain by sandstone bedrock and is covered with mixed aspen-oak brush vegetation. The basin in the vicinity of the mine-plan area is characterized by outcrops of shale that overlie coal that overlies sandstone. The vegetation in this area is characterized by a mixture of sage and scrub brush. 


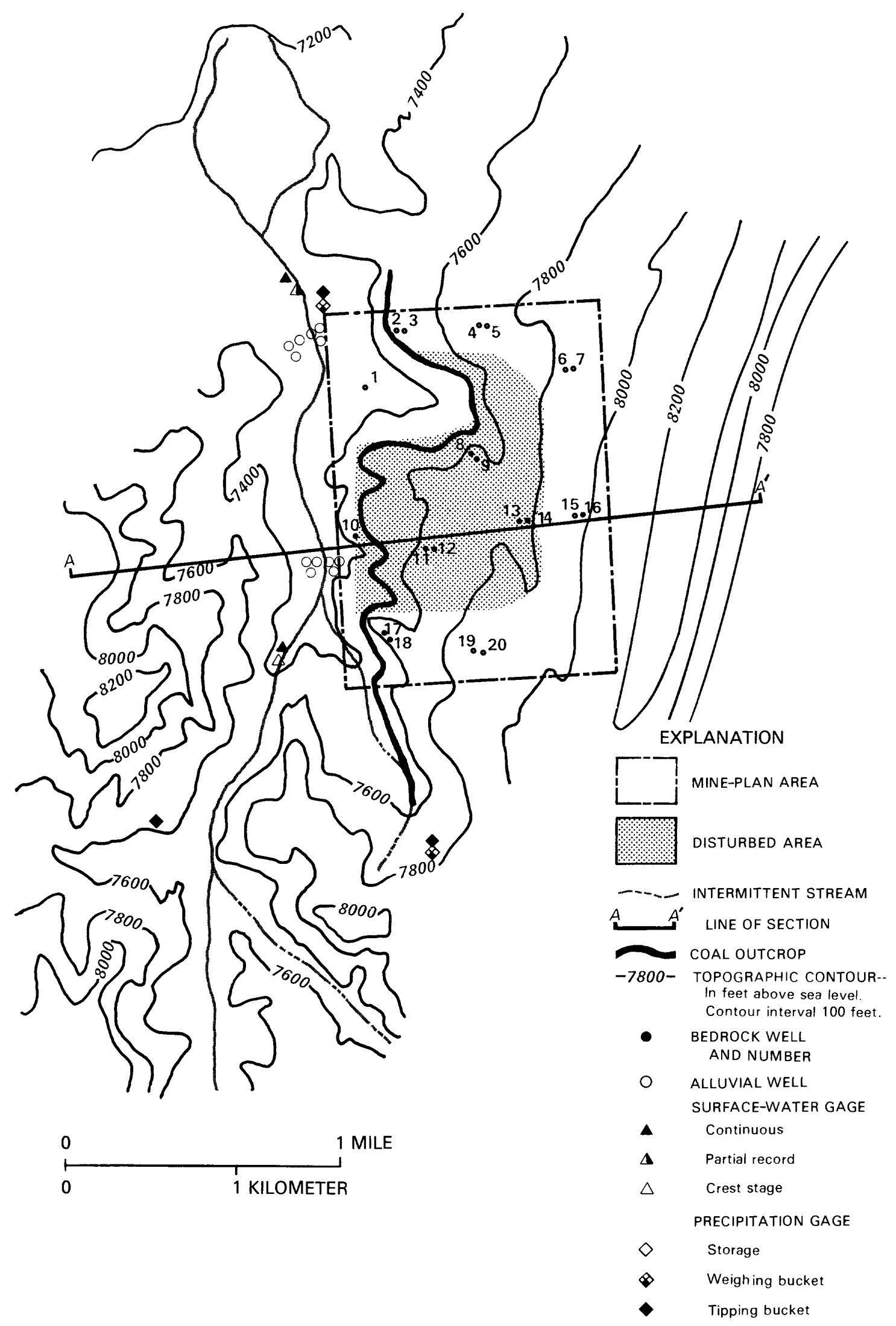

Figure 12.--Location map of hypothetical semiarid, ridge-valley basin. 


\section{Precipitation}

The design of the precipitation network must take into account the dominance of snowfall and snowmelt in the hydrologic regime. The range of elevation is between 7,200 and $8,200 \mathrm{ft}$. In order to get an estimate of the change in precipitation with increasing elevation, gages should be established at both low and high elevations. A precipitation gage should be established at the lower streamflow-gaging site for ease of winter operation. The highelevation site needs to be accessible both before and during mining and to be in the range of 7,600 to $7,800 \mathrm{ft}$. The gage also should be located outside of the mine area so that it does not have to be moved once mining is started. Moving a precipitation gage makes it difficult to estimate long-term changes in precipitation.

The equipment to be used at each site is a weighing-bucket precipitation gage with a windshield and a 30-day clock to minimize the frequency of service. This is the best gage for measuring snowfall and will provide daily information on the number of inches of water that have fallen on the watershed. The data are not sufficiently refined, however, to provide information on summer rainfall intensities.

To determine the warm-weather rainfall-runoff hydrologic regime, several intensity gages using tipping-bucket gages should be established. Because of the cold nature of the area and the lack of convective storms in the winter months, these intensity gages should be operated only in warm-weather months-May through October. Because convective storms have smaller cells than frontal storms, gages should be established at three sites. Two of the gages should be located at the weighing-bucket sites.

A tipping-bucket gage should be established at a third site in the watershed to provide adequate areal coverage. Notice that these gages have been located in such a way as to divide the measurement of rainfall in the watershed into three approximately equal segments (fig. 12).

Snow courses could be established in the area that, in turn, would help define a simple relation between the amount of snow and the volume of runoff each year. In addition, these data would supply some estimate of the recharge for ground water. If snow courses were established, it would be important to place one snow-course site at each of the weighing-bucket sites. The snow courses would be traversed at the first of each month to match the snow-survey data being collected in surrounding areas by the U.S. Soil Conservation Service. Placing the courses at the gages also would help in estimating missing records and in evaluating the catch efficiency of the gage.

\section{Surface Water}

The stream through this area is perennial and has a peak discharge of approximately $30 \mathrm{ft}^{3} / \mathrm{s}$, primarily resulting from snowmelt in the spring. Approximately 9 months of the year, the discharge will be from ground-water sources and will be less than $1 \mathrm{ft}^{3} / \mathrm{s}$. The regimen of streams in the area is principally the result of snowmelt runoff. Peak flows generally occur in April or May, although sharp rises in the streams may be caused by thunderstorms in later summer or early fall. 
Two continuous-record streamflow gages should be installed, one upstream and one downstream from the mine site. It is desirable to monitor these upstream and downstream sites for several years before mining starts because the hydrologic-response units in the lower area, which will be affected by the mining, will be different from those in the upper area. The lower area is primarily sage and scrub-type vegetation, whereas the upper area is primarily oak and aspen. Examining the record from these two streamflow gages will help to determine the differences in the natural hydrologic responses of these two areas.

At the downstream streamflow-gaging site, the control should be a supercritical flume of poured concrete because it passes sediment well, and increases in sediment may be expected with the onset of mining.

Unfortunately, with the supercritical flume, the accuracy of the discharge record at low flows will not be very good (see the Surface Water section). Therefore, when taking water-quality samples during the summer months, it is important to make a discharge measurement to more accurately determine the discharge. Fortunately, the summer month low-discharge regimen is commonly very steady; several measurements made during this period can be useful in evaluating the accuracy of the surface-water record.

The upstream site has grassy banks and no barren slopes to indicate any accelerated erosion, and there is little evidence of any major amounts of sediment moving through the channel. This upstream site contains about two-thirds of the drainage area of the downstream streamflow-gaging site. Therefore, a V-notched weir, which will provide suitable accuracy and capacity for low-to-moderate flows, should be installed at the upstream site. For a control during peak flows, a prefabricated Parshall flume should be installed downstream from the $V$-notched weir. It can be expected that the flows will be very small throughout most of the year, and the V-notched weir will help to determine these low flows accurately.

A manometer with a strip-chart recorder should be installed at the downstream streamflow-gaging site. A manometer should be installed because there is a 15- to 20-ft-high vertical bank along the channel, and the manometer is easier to install than a stilling well. The strip-chart recorder will provide a readily interpreted hydrograph to determine the need for sampling both sediment and water-quality constituents.

The upstream site has a low bank. A stilling well installed in the weir pond, a suitable distance upstream from the V-notched weir, should work fairly well because of the lack of sediment movement in the channel.

Crest-stage gages should be installed at both the upstream and downstream sites. These gages will be used to help estimate peak flows in the event of equipment failure or if the flood wave is fairly large. The crest-stage gages also can be used to mount staff gages to be used as an outside reference. Three crest-stage gages should be installed parallel to the stream both upstream and downstream from the control at each site. 
Several miscellaneous sites should be established on the larger tributaries in the mine area. A crest-stage gage should be installed at each of these sites in order to identify peak discharges in these tributaries. Data from the crest-stage gage can be used to compute discharge by indirect methods, as referenced in the Surface Water section. A staff gage also should be installed on the crest-stage gage. In this way, a discharge measurement can be made and the appropriate stage read from the staff gage each time sampling for water quality or sediment is done at the site. Over a period of time, the measurement of stage and discharge will form a general rating for the section. Each of these sites will use a natural control.

\section{Ground Water}

Existing exploratory drilling data and geologic maps were used to select sites for the network of wells. The sites were selected based on expected geologic structure, stratigraphy, hydrology, and proposed mine boundaries. Previously collected information from the exploratory drilling shows that the proposed mine site is in an area of recharge for downgradient aquifers. The upper reaches of the mine site are bounded by a cliff that drops $500 \mathrm{ft}$ to an adjacent valley floor (fig. 13), which effectively eliminates any interbasin recharge to aquifers within $400 \mathrm{ft}$ of the mine surface. The stratigraphic units dip toward the stream channel. The area of proposed mining and the map locations for both bedrock and alluvial wells are shown in figure 12 .

Groups of bedrock wells should be placed in and around the proposed area of mining; obviously, some of these wells will be destroyed during mining. Data from the wells will be used to describe and to define the premining hydrogeology and will aid in showing changes in the quality of ground water and fluctuations in water levels as mining progresses.

Because the shale overburden is a confining layer, wells need only be completed in the coal and sandstone aquifers. The sandstone aquifer is underlain by a shale confining layer. The wells to be completed in the sandstone aquifer and the wells to be completed in the coal aquifer are listed in table 6 , which also lists the wells that will be destroyed by mining. All the wells should be used to monitor water levels and water chemistry. Additionally, each well should be completed so that, if necessary, hydrogeologic properties can be tested at a number of wells.

The alluvial valley wells need to be drilled in a location that will allow monitoring of interactions between the bedrock aquifers, the alluvial aquifer, and surface-water flow. Ideally, three alluvial wells should be drilled on each side of the stream in a triangular configuration to define the water-table gradient. This configuration and this number of wells are not always possible, due to the topography of the alluvial valley. The alluvial wells also can be placed in line with the bedrock wells to facilitate interpreting the relationship between bedrock and alluvial aquifers. 


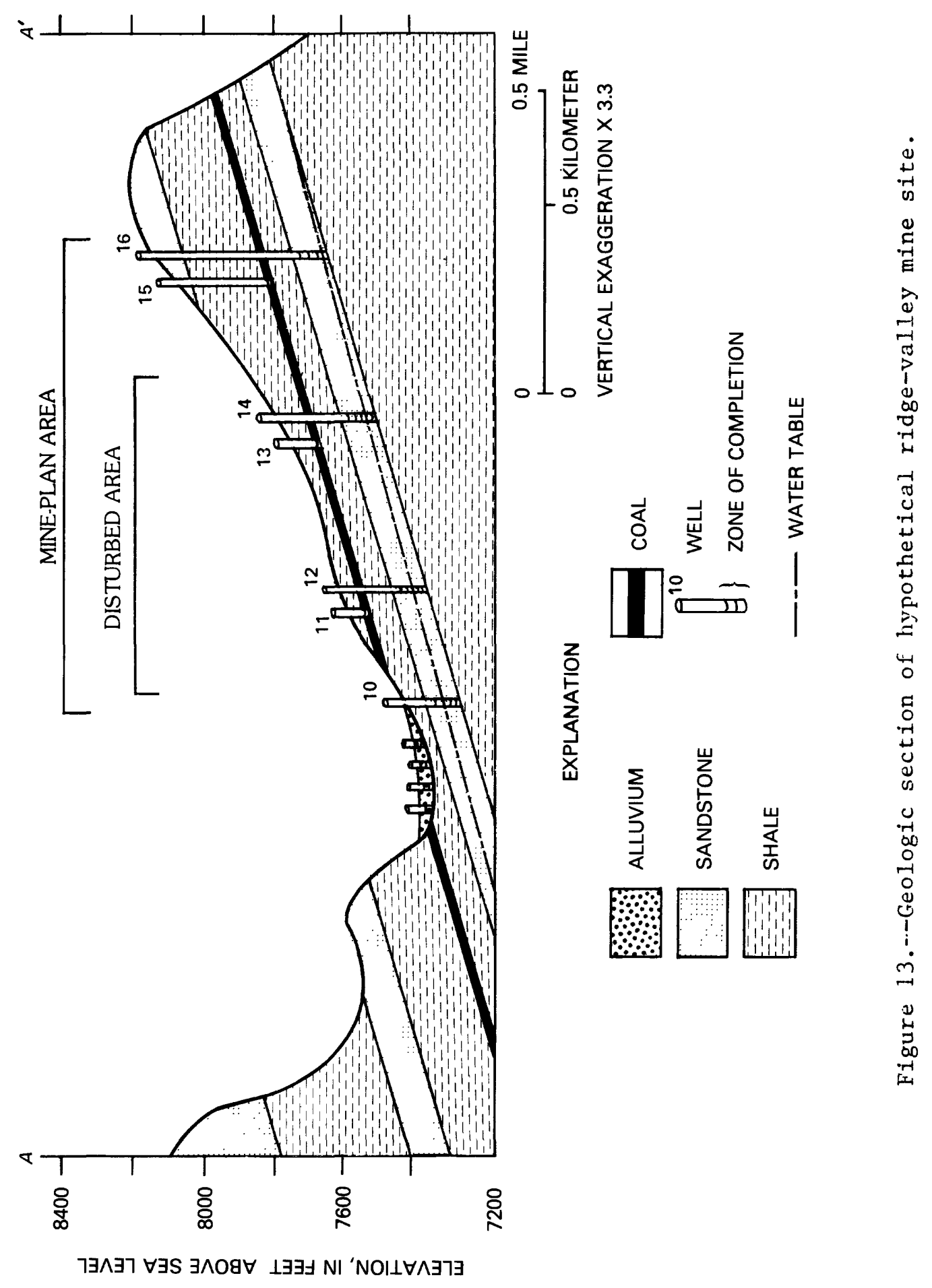


Table 6.--Well-completion information for hypothetical ridge-valley mine site

\begin{tabular}{llcc}
$\begin{array}{c}\text { Bedrock } \\
\text { wells } \\
\text { site }\end{array}$ & Zone of completion & $\begin{array}{c}\text { Wells to be } \\
\text { destroyed } \\
\text { by } \\
\text { mining }\end{array}$ \\
\cline { 2 - 4 } 1 & Coal & Sandstone & - \\
2 & - & $X$ & - \\
3 & $\mathrm{X}$ & - & $\mathrm{X}$ \\
4 & - & $\mathrm{X}$ & - \\
5 & $\mathrm{X}$ & - & - \\
6 & - & $\mathrm{X}$ & $\mathrm{X}$ \\
7 & $\mathrm{X}$ & - & - \\
8 & - & $\mathrm{X}$ & $\mathrm{X}$ \\
9 & $\mathrm{X}$ & - & - \\
10 & - & $\mathrm{X}$ & $\mathrm{X}$ \\
11 & - & $\mathrm{X}$ & $\mathrm{X}$ \\
12 & $\mathrm{X}$ & - & $\mathrm{X}$ \\
13 & - & $\mathrm{X}$ & $\mathrm{X}$ \\
14 & $\mathrm{X}$ & - & - \\
15 & - & $\mathrm{X}$ & - \\
16 & $\mathrm{X}$ & $\mathrm{X}$ & - \\
17 & - & $\mathrm{X}$ & - \\
18 & $\mathrm{X}$ & - & - \\
19 & - & $\mathrm{X}$ & - \\
20 & $\mathrm{X}$ & - & $\mathrm{X}$ \\
\hline
\end{tabular}

In the alluvial valley, the wells should be drilled to the bottom of the alluvium. At least one well at each alluvial site needs to be completed with well screen so that aquifer tests can be run. Also, water samples can be taken for chemical analysis from this well. The other wells at the site should serve as observation wells for monitoring water levels. Near the streamflow gage, a continuous recorder should be placed on a well to monitor changes in the alluvial water level and, therefore, to help determine stream-aquifer interactions.

\section{Water Quality}

Near the permit area, the major stream network does not cross changes in bedrock composition or major changes in vegetation, and there are no major tributaries entering the stream. Therefore, in monitoring the effects of the mining activity, the two continuous streamflow-gaging stations would be adequate, and no additional stations would be necessary for monitoring water quality. Because of the small area to be covered, it would not be necessary to install automatic sampling equipment; these stations can be serviced by observers or onsite personnel. The shallow depths and small velocities of the stream will require only hand-held sediment sampling and water-quality sampling equipment. An improvement could be made in the accuracy of calculating the loads of dissolved solids and other chemical constituents by the 
installation of continuous specific-conductance and temperature monitors at the two continuous streamflow gages. For example, the use of a regression of dissolved solids on specific conductance could determine dissolved solids on a continuous basis. These dissolved-solids concentrations multiplied by the continuous record of discharge would give a continuous record of dissolvedsolids load.

Miscellaneous sites where small ephemeral streams enter or leave the permit area also could be sampled by observers or onsite personnel in addition to the sampling at the continuous sites. Sediment samples could be collected with single-stage samplers, and water-quality samples could be collected by observers with hand-held sampling equipment.

In addition to sampling of the stream system, the reservoir also should be sampled. This reservoir has an area of approximately $0.25 \mathrm{mi}^{2}$, a surfaceoverflow control, no major tributaries other than the stream being gaged, no isolated embayments, and an average depth of approximately $15 \mathrm{ft}$. The reservoir was established approximately 20 years ago for downstream irrigation of meadowlands. There is some evidence of sediment deposition near the inflow to the reservoir.

Sampling of this reservoir is recommended at one site in the deepest part. The lake probably will stratify thermally in the summer, and a sample should be taken at the sampling site from both the upper and lower layers. When the reservoir is not stratified, one sample could be taken at mid-depth. Aids in sampling the reservoir would include an onsite temperature and dissolved-oxygen instrument. This would provide a profile of temperature and dissolved oxygen to determine thermal stratification or dissolved-oxygen loss in the lower stratified layer. Water samples could be taken from a boat or a raft by the use of a Van Dorn or Kenmerer sampling bottle.

A useful addition to sediment sampling would be the establishment of several cross sections at the reservoir to determine sediment-accumulation rates. These cross sections could be surveyed and rerun at intervals of 5 or 10 years to determine the amount of sediment accumulated during the intervening time period.

Three ground-water systems in the area--the coal, sandstone, and alluvial systems--have water that differs naturally in quality. Each of these systems should be monitored because the quality of water may change as a result of mining. Preferably, wells should be placed in each system upgradient from, downgradient from, and within the mined area. The monitoring wells outside the mined area should operate before, during, and after mining. Monitoring wells used to obtain premining data will be destroyed during mining. Other wells installed after mining will be used to obtain postmining data. Sampling frequency and network density, if not specified by the Regulatory Authority, could be determined by standard statistical tests on the initial data. For example, samples could be collected from all wells on a seasonal basis, and an analysis of variance could be performed on the data to determine whether seasonal or areal differences were significant. This could reduce the number of samples necessary during at least part of the monitoring. Interpretation would be aided, however, by frequent and dense sampling before and after mining. 


\section{Drainage Basins in Semiarid Region of Prairie Topography}

The hypothetical basins used in this example (fig. 14) are typical of basins in northeastern Wyoming and have a combined area of about $6 \mathrm{mi}^{2}$; elevations range from about 4,300 down to about 4,100 ft. Precipitation is approximately $12 \mathrm{in} / \mathrm{yr}$, most of which occurs as convective storms in summer. At times, snowfall from individual storms may contribute temporarily to runoff; however, a continuous winter accumulation of snowpack followed by a single runoff event does not occur. The stratigraphy is characterized by sandstone-mudstone-shale strata both above and below coal seams; the beds dip to the west about $60 \mathrm{ft} / \mathrm{mi}$. Much of the recharge and discharge of the groundwater system is local because of the relatively flat-lying stratigraphy and because the more permeable beds are exposed at the surface; however, some strata may continue for tens of miles and also become confined aquifer systems. Mining often is begun in the vicinity of clinker deposits that form at the site of coal outcrops. In this hypothetical example, the clinker deposit is from a coal seam other than the one to be mined. Often clinker deposits are on the seam to be mined; however, the principles employed here are applicable in either situation. The vegetation is characterized by fairly uniform sage and short-grass prairie communities.

\section{Precipitation}

This area has some snowfall and the streams respond somewhat to snowmelt, but the predominant hydrologic regimen is one of rainfall and runoff in the summer months. This rainfall is primarily from summer convective-type storms; therefore, a fairly dense network of intensity-type precipitation gages is needed. Changes in elevation have little effect on precipitation. It would be helpful to establish one weighing-bucket gage at one of the streamflowgaging stations in order to determine the number of inches of water that fall monthly in the watershed. This type of gage is easy to operate and readily provides daily totals.

The most important aspect of the climate is the intensity of rainfall; therefore, the primary network should have tipping-bucket rain gages that could operate during the warm 6 months. Four tipping-bucket gages should be installed in a grid network about 1 to $2 \mathrm{mi}$ apart (fig. 14). Note that all these gages are outside the mine area so they will not have to be moved. In addition, four storage gages should be established. These storage gages, which can be serviced at intervals ranging from 2 to 4 weeks, will help determine the size of the storms that are being recorded on the tipping-bucket gages and will effectively reduce the precipitation network spacing to approximately $1 \mathrm{mi}$. Note that two storage gages are to be located in each watershed (fig. 14). These storage gages are located in the mined area and will have to be removed at some later time.

\section{Surface Water}

This mine area is drained by two watersheds; however, within the two watersheds, there are two distinctive types of geology that will yield extremely different hydrologic responses. The upper part of each watershed 

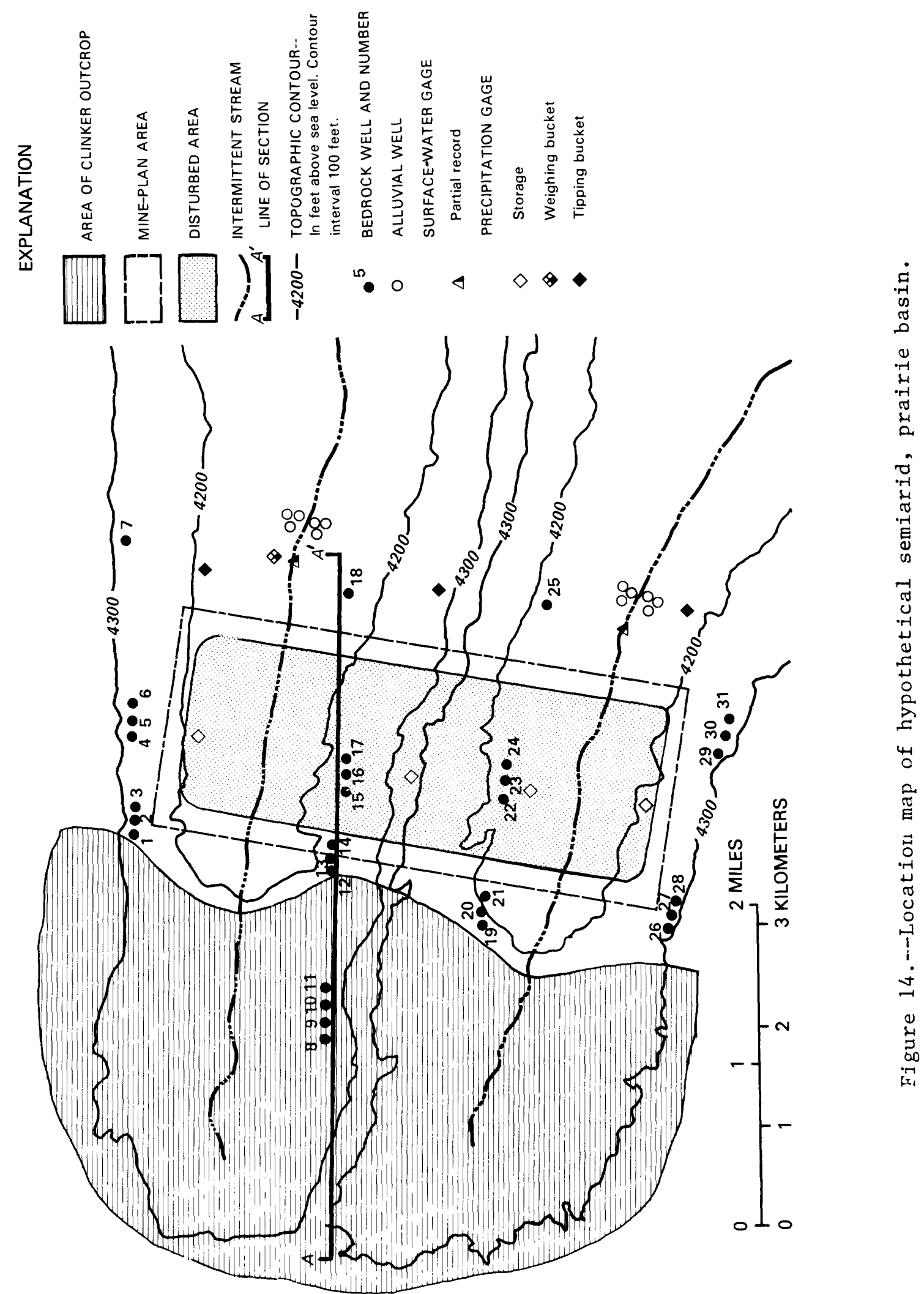
consists of surficial clinker material and has very high infiltration rates. The lower part of each watershed is predominantly mudstone, shale, and sandstone; has developed a very clayey soil; and has a very low infiltration rate.

Four gages should be established in order to evaluate the hydrologic response of the two distinctive types of surficial geology. In each of the two watersheds, two gages are installed. The upper gage is at the contact of the clinker and the shale, and the area drained is from the clinker with higher infiltration rates. The lower gage is established in the mudstone, shale, and sandstone, and the area drained includes both areas of high and low infiltration rates. Comparison of data among the four gages will allow an evaluation of the two different hydrologic responses. Because runoff in this area is predominantly from rainfall and storms are fairly infrequent, the gages could be either continuous or partial-record stations designed to provide data only for flood hydrographs.

The equipment at each of these stations, if they were continuous-record stations, would be a supercritical flume because of potential high sediment loads--both in the natural situation and after the onset of mining.

\section{Ground Water}

Existing exploratory drilling data and geologic maps were used to select sites for the network of wells. Selection of the sites was based on expected geologic structure, stratigraphy, hydrology, and proposed mine boundaries. The geologic units in the area dip to the west whereas the surficial topography slopes to the east (fig. 15). The area of proposed mining and the map locations for both bedrock and alluvial wells are shown in figure 14 .

Groups of bedrock wells should be placed in and around the proposed area of mining; obviously some of these wells will be destroyed during mining. Data from the wells wild be used to describe the premining hydrogeology and will aid in showing the effect of mining on ground water as mining progresses.

We1ls should be completed where aquifers are present in the clinker, the overburden, the coal, and the underburden. Discontinuous sandstone beds or lenses are present in both the overburden and the underburden; these units may be confined or unconfined. Shales, siltstones, and mudstones also are interbedded with the sandstones. The zones of completion in each bedrock well are listed in table 7. These wells should be used to monitor water levels and water chemistry. In addition, each well should be completed for the purpose of testing the hydrogeologic properties of the aquifer. It also may be desirable to install a continuous recorder on a well completed in the aquifer that is most likely to be affected by mining, probably the coal aquifer in this example.

The alluvial valley wells are drilled in a location that will allow monitoring of interactions between the bedrock aquifers, the alluvial aquifers, and surface-water flow. Ideally, three alluvial wells should be drilled on either side of the stream in a triangular configuration to define the water-table gradient. This configuration and this number of wells are not always possible due to the topography of the alluvial valley. The alluvial 


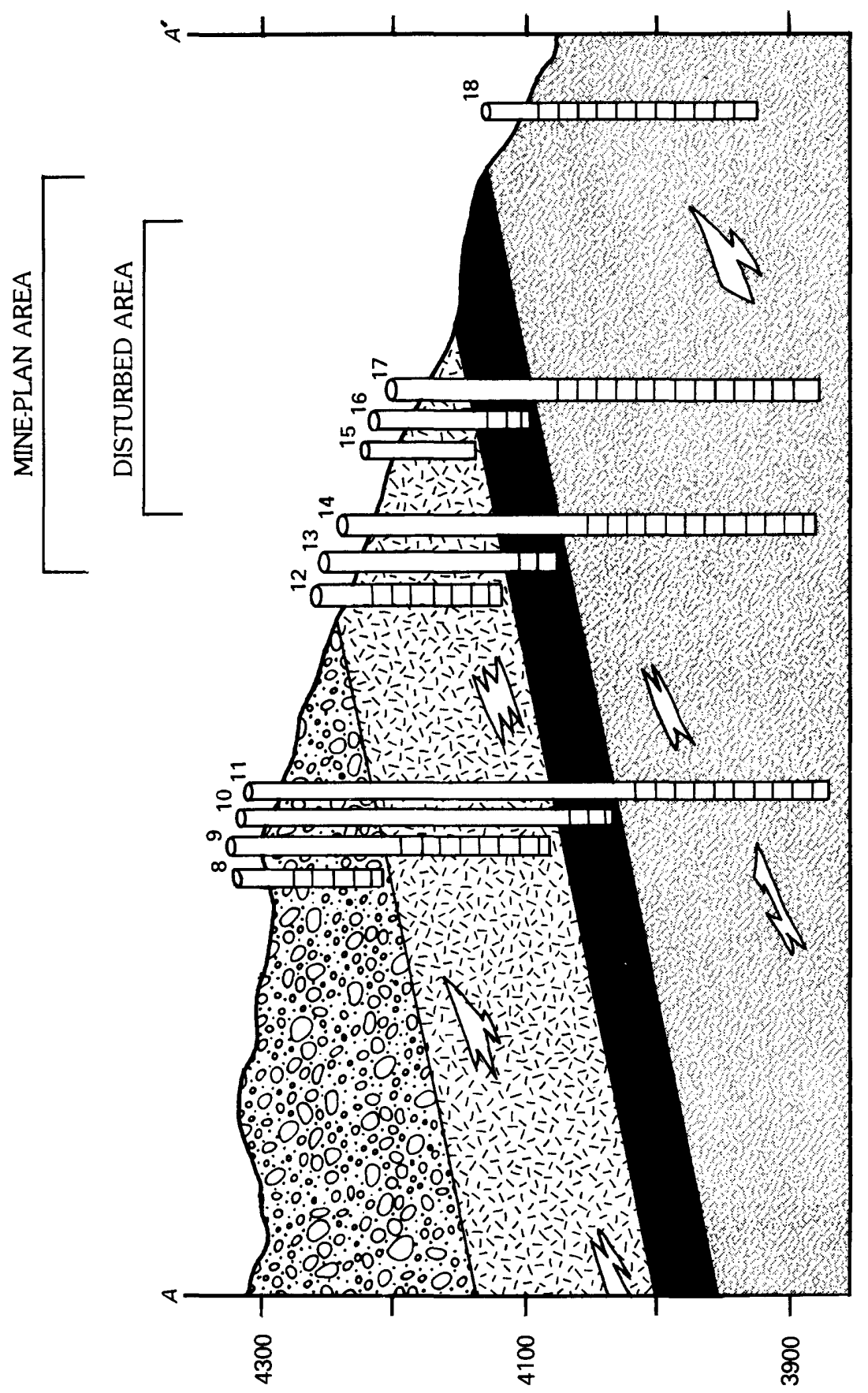

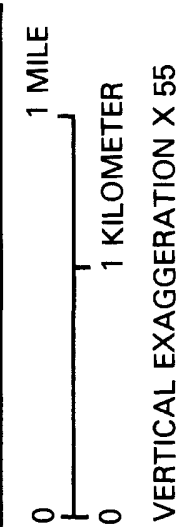

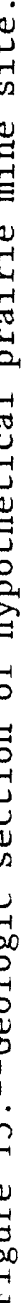

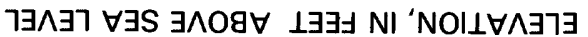


Table 7.--Well-completion information for hypothetical prairie mine site

\begin{tabular}{|c|c|c|c|c|c|}
\hline \multirow{2}{*}{$\begin{array}{l}\text { Bedrock } \\
\text { well }\end{array}$} & \multicolumn{4}{|c|}{ Zone of completion } & \multirow{2}{*}{$\begin{array}{c}\text { Wells to be } \\
\text { destroyed } \\
\text { by } \\
\text { mining }\end{array}$} \\
\hline & Clinker & Overburden & Coal & Underburden & \\
\hline 1 & - & $\mathrm{x}$ & - & - & - \\
\hline 2 & - & - & $\mathrm{X}$ & - & - \\
\hline 3 & - & - & - & $\mathrm{X}$ & - \\
\hline 4 & - & $\mathrm{X}$ & $\mathrm{X}$ & - & - \\
\hline 5 & - & - & $\mathrm{X}$ & - & - \\
\hline 6 & - & - & - & $\mathrm{x}$ & - \\
\hline 7 & - & - & - & $\mathrm{X}$ & - \\
\hline 8 & $\mathrm{x}$ & - & - & - & - \\
\hline 9 & - & $\mathrm{X}$ & - & - & - \\
\hline 10 & - & - & $\mathrm{X}$ & - & - \\
\hline 11 & - & - & - & $\mathrm{x}$ & - \\
\hline 12 & - & $\mathrm{X}$ & $\mathrm{X}$ & - & - \\
\hline 13 & - & - & $\mathrm{X}$ & $X$ & - \\
\hline 14 & - & - & $\mathrm{X}$ & $X$ & - \\
\hline 15 & - & $x$ & - & $X$ & $X$ \\
\hline 16 & - & - & $X$ & - & $X$ \\
\hline 17 & - & - & - & $\mathrm{X}$ & $X$ \\
\hline 18 & - & - & $X$ & $X$ & - \\
\hline 19 & - & $X$ & - & $X$ & - \\
\hline 20 & - & - & $X$ & $X$ & - \\
\hline 21 & - & - & - & $\mathrm{X}$ & - \\
\hline 22 & - & $X$ & - & $X$ & $X$ \\
\hline 23 & - & - & $\mathrm{X}$ & $X$ & $X$ \\
\hline 24 & - & - & - & $X$ & $\mathrm{X}$ \\
\hline 25 & - & - & - & $X$ & - \\
\hline 26 & - & $x$ & - & - & - \\
\hline 27 & - & - & $X$ & - & - \\
\hline 28 & - & - & - & $X$ & - \\
\hline 29 & - & $X$ & - & - & - \\
\hline 30 & - & - & $\mathrm{X}$ & - & - \\
\hline 31 & - & - & - & $X$ & - \\
\hline
\end{tabular}

wells also should be placed in line with the bedrock wells to facilitate interpreting the relationship between bedrock and alluvial aquifers.

In the alluvial valley, the wells should be drilled to the bottom of the alluvium. At least one well at each alluvial site needs to be completed with well screen so that aquifer tests can be run. Also, water samples can be taken for chemical analysis from this well. The other wells at the site should serve as observation wells for monitoring water levels. Near the streamflow gage, a continuous recorder should be placed on a well to monitor changes in the alluvial water level and, therefore, to help determine stream-aquifer interactions. 
Near the mine-plan area, there are no major changes in vegetation, only two major streams and two major soil types. The lack of streamflow, except during thunderstorms and periods of snowmelt runoff, makes it difficult to operate continuous specific-conductance monitors because the probes dry out. In addition, the ephemeral nature of the discharge makes it difficult to obtain sufficient samples from the sites. Therefore, in addition to samples collected by observers or onsite personnel, automatic water-sediment samplers would be invaluable in obtaining enough samples for interpretation. These samplers should be located at the streamflow-gaging sites. The differences in runoff characteristics and soil types that may be transported probably will create major natural differences in the water quality. Because of this, one basin cannot be used as an index of natural conditions and the other as an index of mining or postmining conditions. The choice must be made either to collect sufficient data before, during, and after mining in each basin to allow statistical tests to be made of temporal differences or to select nearby index basins having water quality not significantly different from the mined watersheds. The former approach is preferable to eliminate the possibility of spurious correlation.

Each of the four ground-water systems in the area--the overburden, coal, underburden, and alluvium--has a different natural quality of water. In addition, the quality of water in these individual systems may change as a result of mining. The water within a stratum (for example, the discontinuous sandstone lenses of the overburden and underburden) then may be chemically heterogeneous. Wells in each of the different systems should be monitored upgradient from, downgradient from, and within the mined area. The same type of statistical tests mentioned in the example on semiarid, ridge-valley basins should be applied to the wells initially monitored in this basin.

\section{Drainage Basin in Arid Region of Mesa Topography}

The hypothetical basin used in this example (fig. 16) is typical of basins in northwestern New Mexico. The basin area is about $3 \mathrm{mi}^{2}$, and elevations range from about 6,300 down to about 6,200 ft. Precipitation is about $8 \mathrm{in} / \mathrm{yr}$, most of which occurs from warm-weather convective storms. The stratigraphy is characterized by about $10 \mathrm{ft}$ of eolian sand that overlies siltstone-sandstone assemblages interbedded with the coal seams. The underburden is a massive sandstone stratum, which is the only saturated bedrock unit penetrated by mining activity. The vegetation in this area is characterized by sage, shadscale, rabbitbrush, and alkali sacaton.

\section{Precipitation}

This area has essentially no hydrologic response to snowfall; the infrequent runoff is caused by intense local convective storms. Therefore, the primary network should consist of intensity-type precipitation gages. There is no significant difference in elevation throughout the watershed; only the 


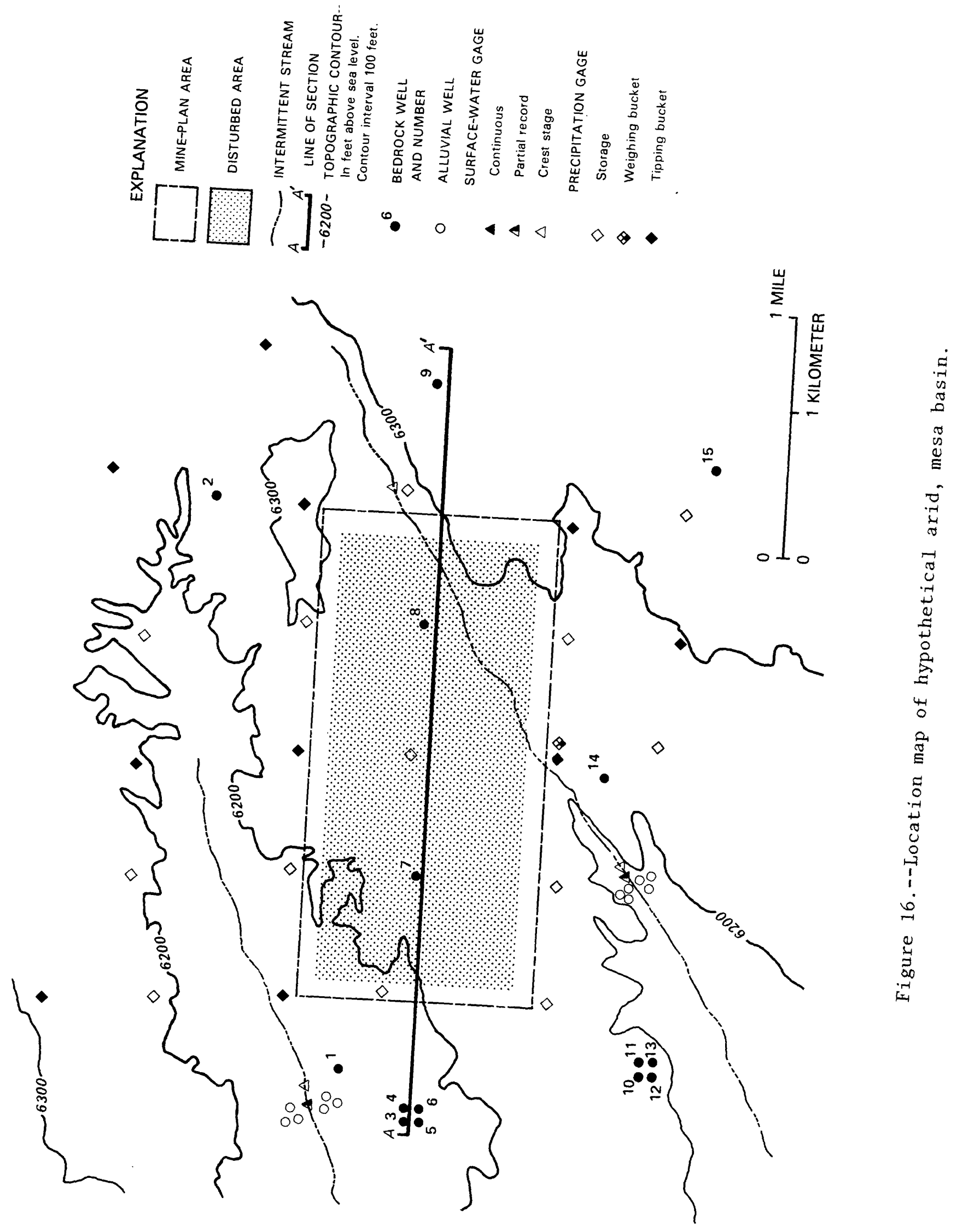


areal extent of the convective storms must be considered. A single weighingbucket gage at the principal streamflow-gaging station would be useful as an index and to provide summary statistics, such as monthly precipitation totals. The network is established with a spacing of approximately $0.50 \mathrm{mi}$ between stations to allow definition of the size and intensity of the storms.

To reduce costs and also be able to maintain this density, the tippingbucket gages should be alternated with storage gages. Storage gages are used for all the temporary sites within the permit area. In some basins of this type, the contributing drainage may extend far beyond the permit area, with precipitation in distant parts of the basin causing runoff to traverse the permit area. In such a case, much of the precipitation network would need to be located away from the permit area. The network of precipitation gages can become very large, and the operation of the network can be expensive in this climatic regime. Careful consideration of previous data collection and analysis is needed in order to limit this network. Costs in this environment can be dramatically reduced if data on precipitation are not needed.

\section{Surface Water}

Because of the ephemeral nature of the stream systems in the area, nothing more than partial-record stations would be needed to define the flood hydrographs. A partial-record station could be established where the larger of the two streams crossing the permit area is constricted soon after leaving the area. Another partial-record station is established on the smaller stream to the north. The point where the larger stream enters the mine boundary needs only be monitored by a series of crest-stage gages because the contributing drainage is small. This series of crest-stage gages helps to identify the water-surface profile at the peak of a runoff event. Such data, along with channel cross sections, allow computation of a crest-stage discharge through indirect methods (Benson and Dalrymple, 1967; Dalrymple and Benson, 1967; Bodhaine, 1968; Matthai, 1967; Hulsing, 1967). Crest-stage gages in the vicinity of the partial-record stations are helpful in establishing peak discharge even with equipment malfunction.

\section{Ground Water}

Existing exploratory drilling data and geologic maps were used to select sites for the network of wells. Selection of the site was based on expected geologic structure, stratigraphy, hydrology, and proposed mine boundaries. The geologic units and the topography in the area dip to the west (fig. 17). The area of proposed mining and the map locations for both bedrock and alluvial wells are shown in figure 16 .

Groups of bedrock wells should be placed in and around the proposed area of mining; obviously, some of these wells will be destroyed during mining. Data from the wells will be used to describe the premining hydrogeology and will aid in showing the effect of mining on the ground water as mining progresses. 


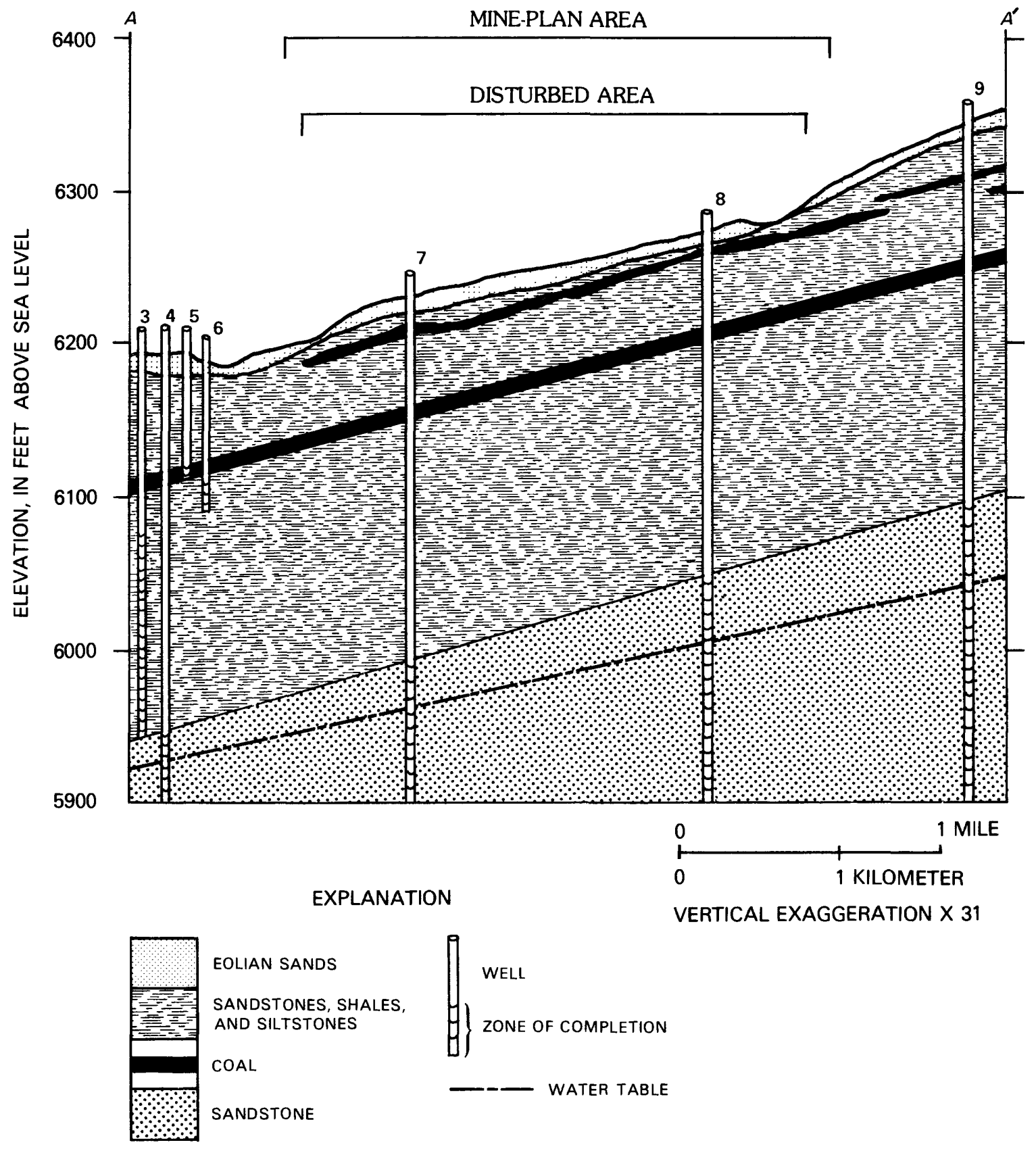

Figure 17.--Geologic section of hypothetical mesa mine site. 
The only premining saturated bedrock unit found in the area of the mine is in the massive sandstone underlying the coal. For this reason, most of the bedrock wells in the area should be completed in this aquifer. Downgradient from the mine, two sites need to have wells completed in the coal; in the sandstone directly under the coal; and in the interbedded sandstone, shale, and siltstone unit that overlies the massive sandstone.

After reclamation, the spoil pile may be more permeable than the surrounding undisturbed area. If the spoil pile is more permeable, then water can percolate to the bottom of the spoil pile where a spoil-pile aquifer may develop. The spoil pile will interface with the unmined units near the base of the spoil pile. In many areas, these units are capable of readily transmitting water. Therefore, the poor quality leachate from the spoil pile can move into the units and flow downgradient. If this happens, wel1s 3,5 , $6,10,11$, and 12 will allow early detection of the spoil-pile aquifer development ( $\mathrm{fig}, 16$ ).

The zones of completion in each bedrock well are listed in table 8 . These wells should be used to monitor water levels and water chemistry.

Table 8.--Well-completion information for hypothetical mesa mine site

\begin{tabular}{|c|c|c|c|c|c|}
\hline \multirow[b]{2}{*}{$\begin{array}{l}\text { Bedrock } \\
\text { well }\end{array}$} & \multicolumn{4}{|c|}{ Zone of completion } & \multirow{2}{*}{$\begin{array}{c}\text { Wells to be } \\
\text { destroyed } \\
\text { by } \\
\text { mining }\end{array}$} \\
\hline & Coal & Sandstones & $\begin{array}{l}\text { Sandstone, } \\
\text { shale, and } \\
\text { siltstone }\end{array}$ & $\begin{array}{c}\text { Massive } \\
\text { sandstone }\end{array}$ & \\
\hline 1 & - & - & - & $\mathrm{X}$ & - \\
\hline 2 & - & - & - & $\mathrm{X}$ & - \\
\hline 3 & - & - & $\mathrm{X}$ & - & - \\
\hline 4 & - & - & - & $\mathrm{X}$ & - \\
\hline 5 & $\mathrm{X}$ & - & - & $\mathrm{X}$ & - \\
\hline 6 & - & $\mathrm{X}$ & - & - & - \\
\hline 7 & - & - & - & $\mathrm{X}$ & $\mathrm{X}$ \\
\hline 8 & - & - & - & $\mathrm{X}$ & $\mathrm{X}$ \\
\hline 9 & - & - & - & $\mathrm{X}$ & - \\
\hline 10 & - & - & $\mathrm{X}$ & - & - \\
\hline 11 & $\mathrm{X}$ & - & - & - & - \\
\hline 12 & - & $\mathrm{X}$ & - & - & - \\
\hline 13 & - & - & - & $\mathrm{X}$ & - \\
\hline 14 & - & - & - & $X$ & - \\
\hline 15 & - & - & - & $X$ & - \\
\hline
\end{tabular}

Additionally, each well should be completed for the purpose of testing the hydrogeologic properties of the aquifer. It also may be desirable to install a continuous recorder on a well completed downgradient from the mine in the sandstone aquifer. 
The alluvial valley wells need to be drilled in a location that will allow monitoring of interactions between the bedrock aquifers, the alluvial aquifer, and surface-water flow. If, after drilling the first alluvial well at a site, no water is found, then it is not necessary to drill additional wells. If water is found, three alluvial wells should be drilled on either side of the stream in a triangular configuration to define the water-table gradient. This configuration and this number of wells are not always possible due to the topography of the alluvial valley. The alluvial wells also should be placed in line with the bedrock wells to facilitate interpretation of the relationship between bedrock and alluvial aquifers.

In the alluvial valley, the wells should be drilled to the bottom of the alluvium. At least one well at each alluvial site needs to be equipped with a well screen and used to test the hydrogeologic properties of the aquifer.

Near the streamflow gage, a continuous recorder should be placed in a well to monitor changes in the alluvial water level and, therefore, to help determine alluvial and surface-water interactions. This well also can be used to obtain water samples for chemical analysis. The other alluvial wells should be used to monitor water levels.

\section{Water Quality}

Because of the ephemeral nature of the stream systems, sampling would most likely require the use of an automatic water-sediment sampler at the streamflow gage to supplement samples taken by observers or onsite personnel. Particularly in areas with larger drainage basins--but in this case also--large convective storms could cause severe problems of safety and access to the entire cross section. In such cases, a cableway or small footbridge would be necessary for effective sediment and water-quality sampling. There would be little use for continuous monitors of specific conductance or temperature for this system because of the infrequent, short-duration hydrograph.

In addition, single-stage sediment samplers (U.S. Inter-Agency Committee on Water Resources, 1961) would be useful at the point where the main stream enters the permit area and on the smaller stream to the north at the partialrecord station. For occasional large storms, automatic samplers also may prove useful at these sites; however, given the small drainages, the data may be too sparse to be truly useful. The probable lack of data to allow beforeand-after mining comparisons could be supplemented with data collected from nearby similar basins. The validity of these surrogate data would have to be established by analysis of variance tests comparing the surrogate data with data in the watershed of interest.

Each of the two ground-water systems in the area--the underburden and the alluvium--has a different natural quality of water. In addition, the quality of water in these individual systems may change as a result of mining. Wells in each of the different systems should be monitored upgradient from, downgradient from, and within the mined area. The statistical tests mentioned in the previous examples would be useful in selecting monitoring wells from those initially sampled. 


\section{SUMMARY}

Hydrologic monitoring of the impacts of surface mining must be guided not only by legislation but also by technically defensible principles that allow adaptation to site-specific basin characteristics and controlling mechanisms. These characteristics and controls determine acceptable approaches to site selection, equipment, recording requirements, and sampling methodology. This report details the influences of basin characteristics common to the centralwestern United States on the design of hydrologic monitoring networks. Basins common to the central-western United States are semiarid, ridge-valley basins; semiarid, prairie basins; and arid mesa basins. Site-specific examples of these hydrologic regimens are provided to demonstrate the application of basic hydrologic principles to monitoring network design.

\section{SELECTED REFERENCES}

American Geological Institute, 1976, Dictionary of geological terms (rev. ed.): Garden City, N.Y., Anchor Press, 472 p.

American Public Health Association, American Water Works Association, and the Water Pollution Control Federation, 1981, Standard methods for the examination of water and wastewater (15th ed.): Washington, D.C., $1200 \mathrm{p}$.

Anderson, G., 1975, Coring and core analysis handbook: Tulsa, Okla., Petroleum Publishing Co., 200 p.

Benson, M.A., and Dalrymple, Tate, 1967, General field and office procedures for indirect discharge measurements: U.S. Geological Survey Techniques of Water-Resources Investigations, Book 3, Chapter A1, $30 \mathrm{p}$.

Bodhaine, G.L., 1968, Measurement of peak discharge at culverts by indirect methods: U.S. Geological Survey Techniques of Water-Resources Investigations, Book 3, Chapter A3, $60 \mathrm{p}$.

Bos, M.G., ed., 1976, Discharge measurement structures: Wageningen, The Netherlands, International Institute for Land Reclamation and Improvement/ILRI, Publication 20, $464 \mathrm{p}$.

Brakensiek, D.L., Osborn, H.B., and Rawls, W.J., 1979, Field manual for research in agricultural hydrology: U.S. Department of Agriculture, Agriculture Handbook 224, 550 p.

Buchanan, T.J., and Somers, W.P., 1968, Stage measurement at gaging stations: U.S. Geological Survey Techniques of Water-Resources Investigations, Book 3, Chapter A7, 28 p. 1969, Discharge measurements at gaging stations: U.S. Geological Survey Techniques of Water-Resources Investigations, Book 3, Chapter A8, 65 p.

Carter, R.W., and Davidian, Jacob, 1968, General procedure for gaging streams: U.S. Geological Survey Techniques of Water-Resources Investigations, Book 3, Chapter A6, 13 p.

Chamberlain, A.R., 1957, Preliminary model tests of a flume for measuring discharge of steep ephemeral streams: Fort Collins, Colorado State University, Civil Engineering Department Report CER-57-ARC-12.

Compton, R.R., 1962, Manual of field geology: New York, John Wiley, 378 p.

Cooper, H.H., Jr., Bredehoeft, J.D., and Papadopulos, S.S., 1967, Response of a finite diameter well to an instantaneous charge of water: Water Resources Research, v. 3, no. 1, p. 263-269. 
Craig, J.D., 1983, Installation and service manual for U.S. Geological Survey manometers: U.S. Geological Survey Techniques of Water-Resources Investigations, Book 8 , Chapter $\mathrm{A} 2,57 \mathrm{p}$.

Dalrymple, Tate, and Benson, M.A., 1967, Measurement of peak discharge by the slope-area method: U.S. Geological Survey Techniques of Water-Resources Investigations, Book 3, Chapter A2, $12 \mathrm{p}$.

Davis, S.N., and DeWiest, R.J.M., 1966, Hydrogeology: New York, John Wiley, $463 \mathrm{p}$.

Druffel, Leroy, Emmett, W.W., Schneider, V.R., and Skinner, J.V., 1976, Laboratory hydraulic calibration of the Helley-Smith bedload sediment sampler: U.S. Geological Survey Open-File Report 76-752, 67 p.

Federal Inter-Agency Sedimentation Project of the Inter-Agency Committee on Water Resources, 1952, The design of improved types of suspendedsediment samplers: Minneapolis, Minn., St. Anthony Falls Hydraulics Laboratory, Report 6, 103 p.

1963, A summary of the work of the Federal Inter-Agency Sedimentation project: Minneapolis, Minn., St. Anthony Falls Hydraulics Laboratory, Report 5, 29 p.

1966, Instruments and reports for fluvial sediments investigations: Minneapolis, Minn., St. Anthony Falls Hydraulics Laboratory, Report Catalog, $67 \mathrm{p}$.

Fetter, C.W., Jr., 1980, Applied hydrogeology: Columbus, Ohio, Merrill, $504 \mathrm{p}$.

Freeze, R.A., and Cherry, J.A., 1979, Groundwater: Englewood Cliffs, N.J., Prentice-Hall, 604 p.

Freeze, R.A., and Witherspoon, P.A., 1967, Theoretical analysis of regional groundwater flow, Pt. 2--Effect of water-table configuration and subsurface permeability variation: Water Resources Research, v. 3, no. 3, p. $623-634$.

Guy, H.P., 1970, Fluvial sediment concepts: U.S. Geological Survey Techniques of Water-Resources Investigations, Book 3, Chapter C1, $55 \mathrm{p}$.

Guy, H.P., and Norman, V.W., 1970, Field methods for measurement of fluvial sediment: U.S. Geological Survey Techniques of Water-Resources Investigations, Book 3, Chapter C3, 66 p.

Gwinn, W.R., 1970, Calibration of Walnut Gulch supercritical flumes: American Society of Civil Engineers, Journal of the Hydraulics Division Proceedings, v. 96, no. HY8, p. 1681-1689.

Hubbe11, D.W., 1964, Apparatus and techniques for measuring bedload: U.S. Geological Survey Water-Supply Paper 1748, 74 p.

Huff, F.A., 1955, Comparison between standard and small orifice rain gages: American Geophysical Union Transactions, v. 36, no. 4, p. 689-694.

Hulsing, Harry, 1967, Measurement of peak discharge at dams by indirect methods: U.S. Geological Survey Techniques of Water-Resources Investigations, Book 3, Chapter A5, 29 p.

Hutchinson, G.E., 1957, A treatise on limnology: New York, John Wiley, $1015 \mathrm{p}$.

Kennedy, E.J., 1983, Computation of continuous records of streamflow: U.S. Geological Survey Techniques of Water-Resources Investigations, Book 3, Chapter A13, 53 p.

Keys, W.S., and MacCary, L.M., 1976, Application of borehole geophysics to water-resources investigations (2nd ed.): U.S. Geological Survey Techniques of Water-Resources Investigations, Book 2, Chapter E1, 126 p. 
Kilpatrick, F.A., and Schneider, V.R., 1983, Use of flumes in measuring discharge: U.S. Geological Survey Techniques of Water-Resources Investigations, Book 3, Chapter A14, $46 \mathrm{p}$.

Kulin, G., and Compton, P.R., 1975, A guide to methods and standards for the measurement of water flow: U.S. National Bureau of Standards, Special Publication $421,89 \mathrm{p}$.

Leroy, L.W., and Leroy, D.0., 1977, Subsurface geology: Golden, Colorado School of Mines Press, 941 p.

Linsley, R.K., Jr., Kohler, M., and Paulhus, J.L.H., 1975, Hydrology for engineers (2nd ed.): New York, McGraw-Hi11, 482 p.

Lohman, S.W., 1972, Ground-water hydraulics: U.S. Geological Survey Professional Paper 708, 70 p.

Matthai, H.F., 1967, Measurement of peak discharge at width contractions by indirect methods: U.S. Geological Survey Techniques of Water-Resources Investigations, Book 3, Chapter A4, 44 p.

McWhorter, D.B., and Sunada, D.K., 1977, Ground-water hydrology and hydraulics: Fort Collins, Colo., Water Resources Publications, 280 p.

Meyboom, P., 1966, Groundwater studies in the Assiniboine River Drainage Basin, Pt. 1--The evaluation of a flow system in south-central Saskatchewan: U.S. Geological Survey Canadian Bulletin no. 139, 65 p.

Ostle, Bernard, 1963, Statistics in research: Ames, Iowa State University Press, 585 p.

Papadopulos, S.S., Bredehoeft, J.D., and Cooper, H.H., Jr., 1973, On the analysis of "slug-test" data: Water Resources Research, v. 9, no. 4, p. 1087-1089.

Porterfield, George, 1972, Computation of fluvial-sediment discharge: U.S. Geological Survey Techniques of Water-Resources Investigations, Book 3, Chapter C3, $66 \mathrm{p}$.

Rantz, S.E., and others, 1982a, Measurement and computation of streamflow, v. 1--Computation of discharge: U.S. Geological Survey Water-Supply Paper 2175, p. 1-284. $1982 \mathrm{~b}$, Measurement and computation of streamflow, v. 2--Computation of discharge: U.S. Geological Survey Water-Supply Paper 2175, p. 285-631.

Reid, G.K., and Wood, R.D., 1976, Ecology of inland waters and estuaries: New York, D. Van Nostrand Co., 485 p.

Replogle, J.A., 1971, Critical-depth flumes for determining flow in canals and natural channels: American Society of Agricultural Engineers Transactions, v. 14, no. 3, p. 428-433.

Robinson, A.R., 1961, Study of the Beaver Creek measuring flumes: Fort Collins, Colorado State University, Civil Engineering Report CER-61ARR-10, $14 \mathrm{p}$.

Siegel, D.I., 1980, Method of logging holes drilled by the rotary method: U.S. Geological Survey, Water Resources Bulletin, July-December 1979-January-March 1980 , p. 47-49.

Skougstad, M.W., Fishman, M.J., Friedman, L.C., Erdmann, D.E., and Duncan, S.S., eds., 1979, Methods for determination of inorganic substances in water and fluvial sediments: U.S. Geological Survey Techniques of Water-Resources Investigations, Book 5, Chapter A1, $1159 \mathrm{p}$.

Smith, R.E., Chery, D.L., Jr., Renard, K.G., and Gwinn, W.R., 1982, Supercritical flumes for measurement of sediment laden flow: Fort Collins, Colo., Science and Education Administration Technical Bulletin no. $1655,70 \mathrm{p}$. 
Smoot, G.F., and Novak, C.E., 1968, Calibration and maintenance of vertical-axis type current meters: U.S. Geological Survey Techniques of Water-Resources Investigations, Book 8, Chapter B2, 15 p.

Tóth, 1963, A theoretical analysis of groundwater flow in small drainage basins: Journal of Geophysical Research, v. 68, no. 16, p. 4795-4812. 1966. Mapping and interpretation of field phenomena for groundwater reconnaissance in a prairie environment, Alberta, Canada: Bulletin of International Association of Scientific Hydrology, v. 11, no. 2, p. 1-49.

U.S. Bureau of Reclamation, 1967, Water measurement manual: Denver, 327 p. 1977, Ground water manual: Denver, $480 \mathrm{p}$.

U.S. Environmental Protection Agency, 1974, Manual of methods for chemical analysis of water and wastes: Washington, D.C., 298 p. 1976, Quality criteria for water: Washington, D.C., 256 p.

U.S. Inter-Agency Committee on Water Resources, Subcommittee on Sedimentation, 1961, The single-stage sampler for suspended sediment, Report 13 of A study of methods used in measurement and analysis of sediment loads in streams: Washington, D.C., 105 p.

U.S. Office of the Federal Register, 1985, Code of federal regulations--Mineral resources: Washington, D.C., National Archives and Records Administration, 30 CFR 700.1, p. 204-205.

U.S. Office of Surface Mining Reclamation and Enforcement, 1983, Surface coal mining and reclamation operations--Permanent regulatory program: Federal Register, v. 48, no. 187, p. 43956-44052.

1985a, Guidelines for preparation of a cumulative hydrologic impact assessment (CHIA) (draft): 1 volume. 1985b, Guidelines for preparation of a probable hydrologic consequences determination (PHC) (draft): 1 volume. 1985c, Appendices to PHC and CHIA guideline documents: 1 volume.

Universal Oil Products, Inc., Johnson Division, 1975, Ground water and wells-A reference book for the water-well industry ( 4 th printing): St. Paul, Minn., 440 p.

Vanoni, V.A., ed., 1975, Sedimentation engineering: New York, American Society of Civil Engineers, 745 p.

Walton, W.C., 1970, Groundwater resource evaluation: New York, McGraw-Hill, $664 \mathrm{p}$.

Wood, W.W., 1976, Guidelines for collection and field analysis of groundwater samples for selected unstable constituents: U.S. Geological Survey Techniques of Water-Resources Investigations, Book 1, Chapter D2, 24 p.

World Meteorological Organization, 1965, Guide to hydrometeorological practices: Geneva, Switzerland, WMO no. 168, TP 82.

Wyoming Department of Environmental Quality, 1980, Guideline no. 4 (revised): 5 p.

Zohdy, A.A.R., Eaton, G.P., and Mabey, D.R., 1974, Application of surface geophysics to ground-water investigations: U.S. Geological Survey Techniques of Water-Resources Investigations, Book 2, Chapter D1, $116 \mathrm{p}$. 